\title{
SEISMIC DESIGN AND PERFORMANCE EVALUATION OF DUAL-FUSED H-FRAME SYSTEM \\ by
}

\author{
Hamidreza Etebarian \\ B.Sc., Sharif University of Technology, 2016 \\ A THESIS SUBMITTED IN PARTIAL FULFILLMENT OF \\ THE REQUIREMENTS FOR THE DEGREE OF \\ MASTER OF APPLIED SCIENCE \\ in \\ THE FACULTY OF GRADUATE AND POSTDOCTORAL STUDIES \\ (Civil Engineering) \\ THE UNIVERSITY OF BRITISH COLUMBIA \\ (Vancouver)
}

August 2018

(C) Hamidreza Etebarian, 2018 
The following individuals certify that they have read, and recommend to the Faculty of Graduate and Postdoctoral Studies for acceptance, a thesis/dissertation entitled:

Seismic design and performance evaluation of dual-fused h-frame system

Submitted by Hamidreza Etebarian in partial fulfillment of the requirements the degree of Master of Applied Science

in Civil Engineering

\section{Examining Committee:}

Tony Yang, Civil Engineering, University of British Columbia

Supervisor

Wei Guo, Civil Engineering, Central South University

Additional Examiner 


\section{Abstract}

A Dual-Fused H-Frame (DFHF) is an efficient structural system that combines Damped H-Frame (DHF) modules with Welded Wide Flange Fuses (WWFFs) to create a structural solution which is efficient in construction and more seismic resilient. Each DHF module consists of two columns pin connected to a beam with two buckling restrained knee braces (BRKBs). Each DHF module can be prefabricated in the factory, shipped to the site and connected vertically using simple bolt connections. The connections between the DHF modules have relatively small moment demand which makes the design, fabrication and construction of the DHF modules very efficient. Once the DHF modules have been assembled vertically, the bays of the DHF can be connected using WWFFs. WWFFs are simple shear connectors which can dissipate stable earthquake energy. In this paper, two prototype DFHF buildings of varying heights (3- and 9- story) are designed using the Equivalent Energy Design Procedure (EEDP). EEDP is a novel design method which is developed to design innovative systems, where the structural system can achieve different performance objectives under different earthquake shaking intensities. To verify the performance of the DFHF, advanced finite element models are developed using OpenSees and subjected to an extensive array of time history analyses. The results show that the proposed EEDP designed DFHF can achieve the targeted performance objectives under different seismic shaking intensities. In addition, DFHF has sufficient margin of safety against collapse. Hence the proposed DFHF can be used as an efficient structural system in high seismic zone 


\section{Lay Summary}

Recent earthquakes have caused significant damages into structures. These damages lead to loss of functionality and result in prolonged downtime. To address this issue, an innovative seismic force resisting system (SFRS) called Dual-Fused H-Frame (DFHF) is proposed in this thesis. DFHF employs two types of specially designed structural fuses to sacrifice during a seismic event while protecting the main structural members. These structural fuses can be quickly inspected, repaired, or replaced if needed after a strong earthquake shaking. Two prototype DFHF buildings of varying heights (3- and 9-story) are designed and analyzed numerically using past earthquake records. The results show that the proposed DFHF has acceptable seismic performance and has sufficient margin of seismic safety against collapse. Hence, it can be used as an effective SFRS in high seismic regions. 


\section{Preface}

This thesis is the original, independent work of Hamidreza Etebarian. The author was responsible for the literature review, model development, computational analysis, data processing, and results presentation. The author has drafted this thesis and revised it based on the comments by Prof. Tony Yang. It should be noted that this thesis is summarized into a peer-reviewed journal paper which is currently under review. 


\section{Table of Contents}

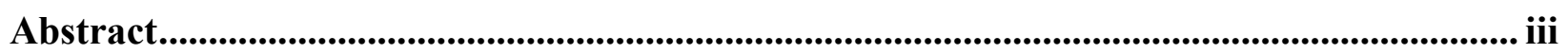

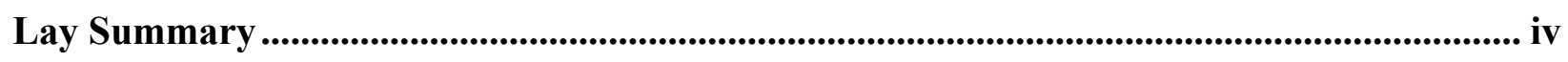

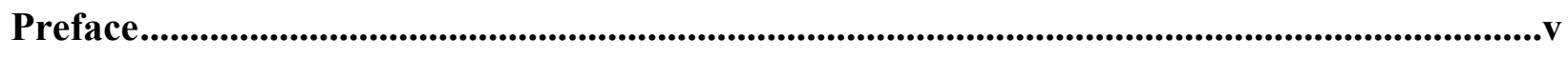

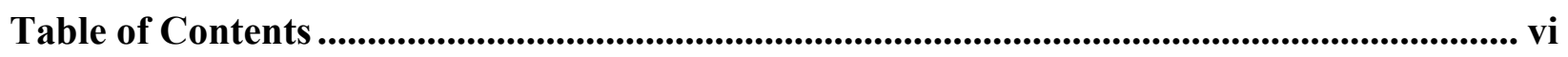

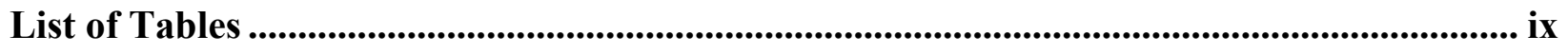

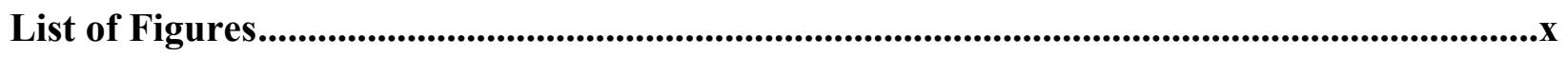

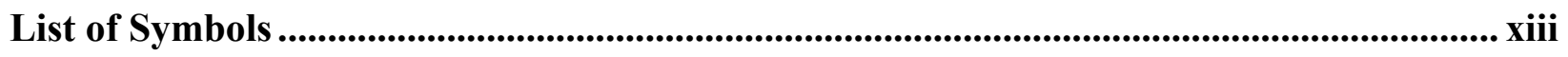

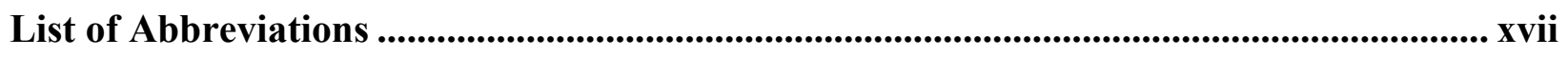

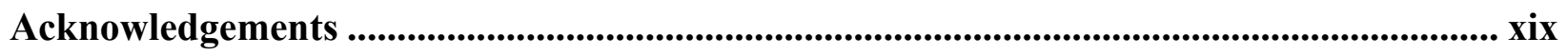

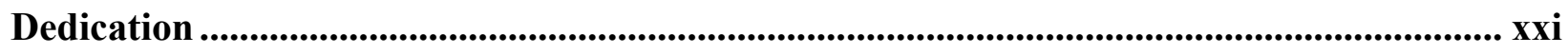

Chapter 1: Introduction ...........................................................................................................................1

1.1 Overview of Conventional Seismic Force Resisting Systems ................................. 1

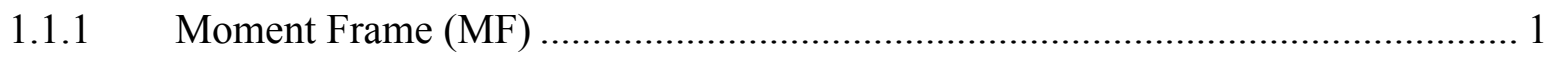

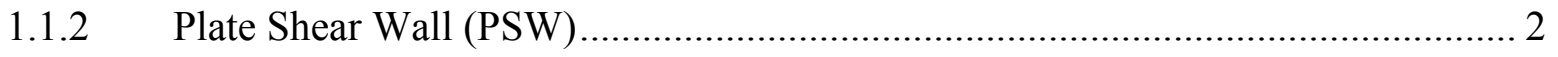

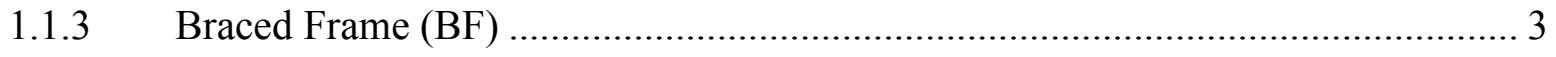

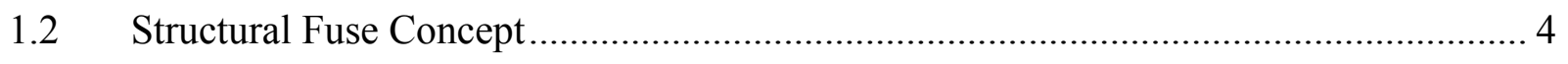

1.3 Review of Fused Seismic Force Resisting Systems .......................................... 4

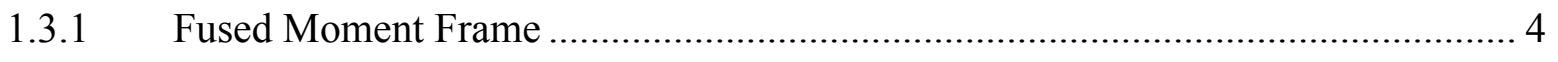

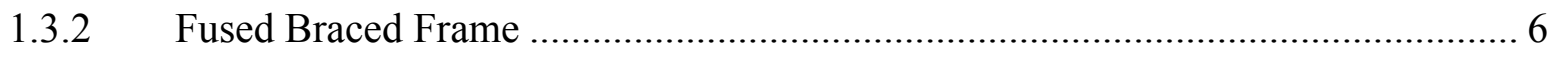

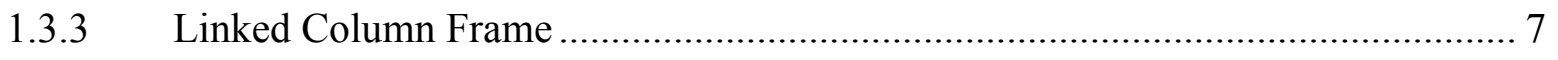

1.3.4 Buckling Restrained Knee Braced Truss Moment Frame ................................. 8 
1.3.5 Buckling Restrained Knee Braced Frame ............................................................. 9

$1.4 \quad$ Dual Fused H-Frame System Description ........................................................... 10

1.5 Energy Dissipation Mechanism of DFHF System.................................................... 13

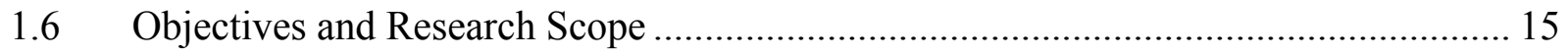

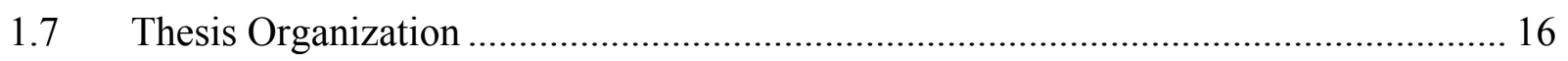

Chapter 2: Design Methodology for DFHF System...........................................................................17

$2.1 \quad$ Conventional Design Approach........................................................................... 17

2.2 Equivalent Energy Design Procedure …………….............................................. 17

Chapter 3: Prototype Buildings .............................................................................................................27

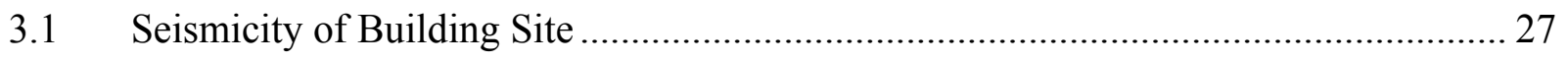

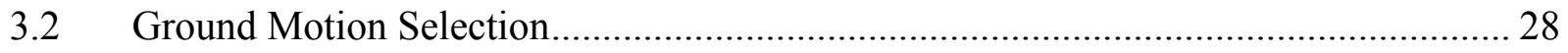

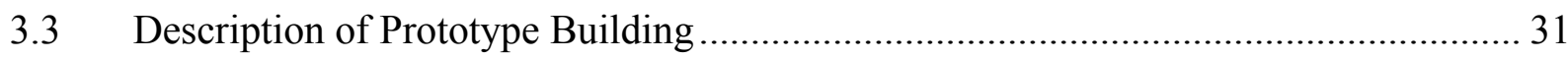

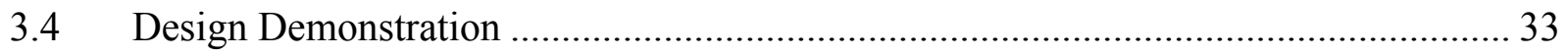

Chapter 4: Analytical Modeling .............................................................................................................36

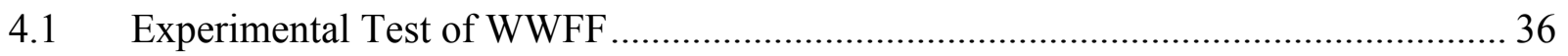

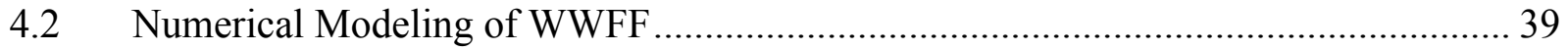

4.3 Validation of WWFF Numerical Model ................................................................. 46

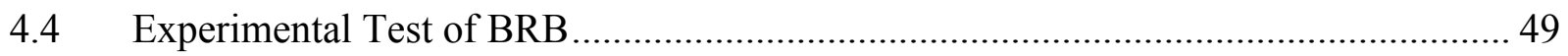

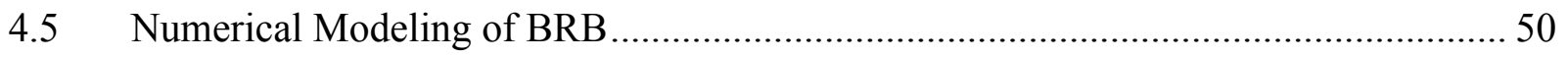

4.6 Element Removal Modeling Technique ……………................................................. 51

4.7 Modeling of Prototype buildings .............................................................................. 52

Chapter 5: Results of Nonlinear Time History Analysis................................................................54

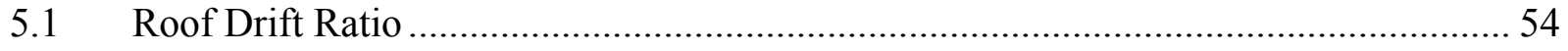




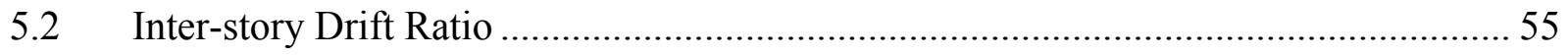

5.3 Demand-Capacity Ratio of Structural Fuses........................................................ 56

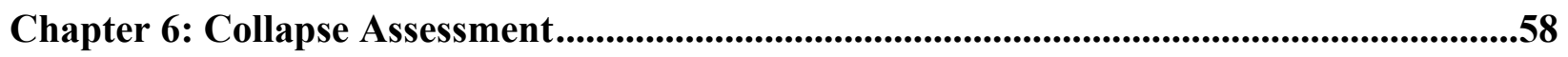

Chapter 7: Parametric Study of WWFF Geometric Parameter .............................................62

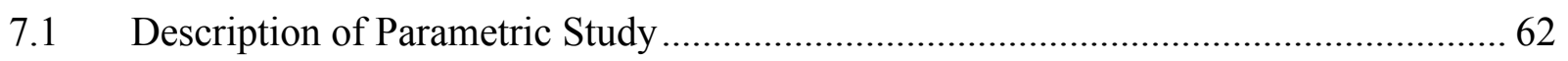

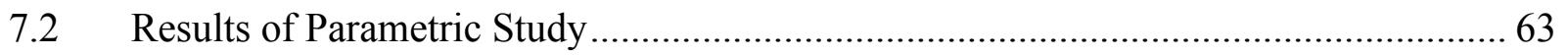

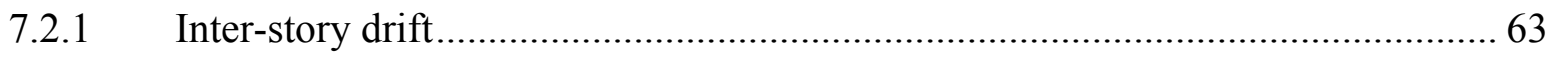

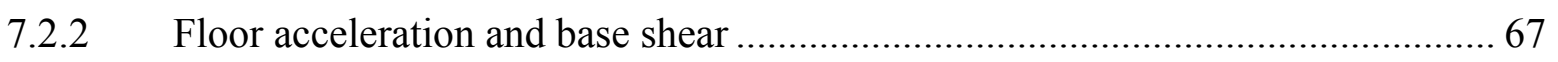

Chapter 8: Summary, Conclusion and Recommendation .....................................................68

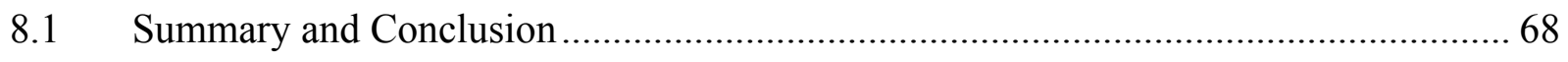

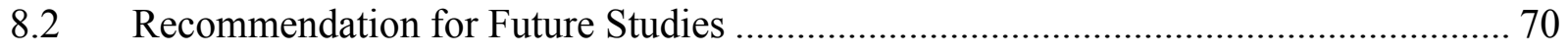

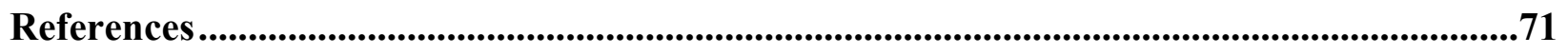

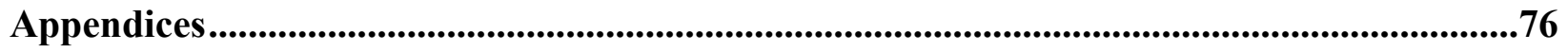

A.1 3-story Building Ground Motions Scale Factor ................................................. 76

A.2 9-story Building Ground Motions Scale Factor ................................................... 77 


\section{List of Tables}

Table 3.1 Record set information summary......................................... 30

Table 3.2 Summary of EEDP design parameters........................................ 34

Table 3.3 Summary of structural fuses................................................

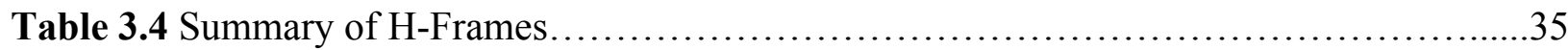

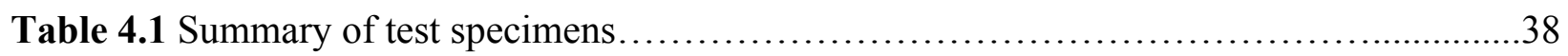

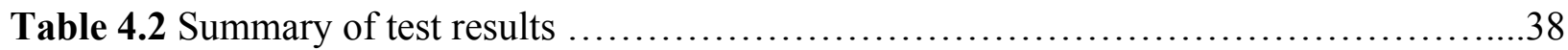

Table 4.3 Calibrated WWFF pinching parameters ......................................44

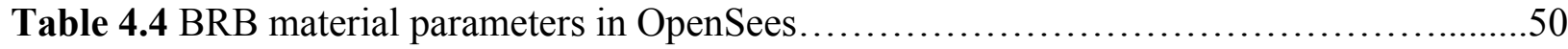

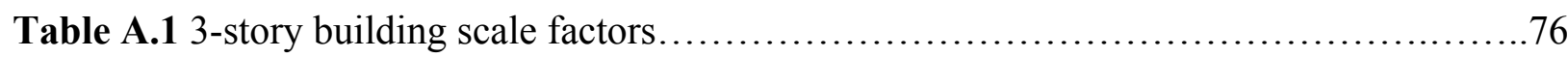

Table A.2 9 -story building scale factors........................................ 77 


\section{List of Figures}

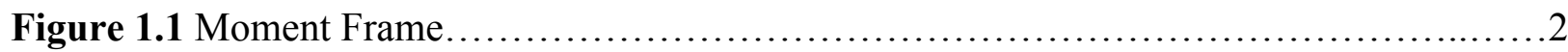

Figure 1.2 Schematic Plate Shear Wall......................................................

Figure 1.3 Schematic (a) concentrically and (b) eccentrically braced frames.....................3

Figure 1.4 Fused Moment Frames.......................................................

Figure 1.5 Fused Brace Frames........................................................... 6

Figure 1.6 LCF system (Malakoutian et al. 2013) ...........................................

Figure 1.7 Buckling Restrained Knee Braced Truss Moment Frame (Yang et al. 2014)...........8

Figure 1.8 Buckling Restrained Knee Braced Frame (Junda et al. 2018).......................9

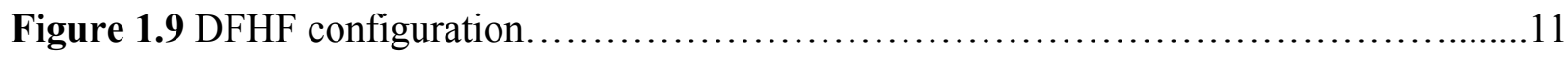

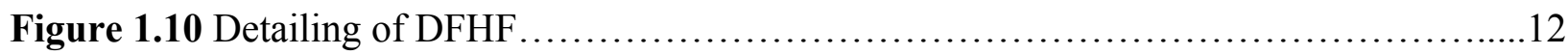

Figure 1.11 Performance objectives and force-deformation relationship of DFHF...............14

Figure 2.1 EEDP energy balanced concept............................................ 18

Figure 2.2 Primary system yielding mechanism......................................... 20

Figure 2.3 Distribution of design base shear to primary and secondary system...............22

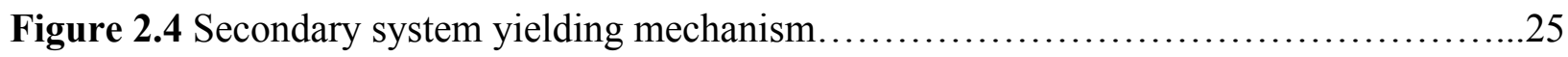

Figure 2.5 (a) undeformed and (b) deformed geometry of BRKBs........................25

Figure 3.1. Design spectra for a) San Francisco, CA and b) Seattle, WA.......................28 
Figure 3.2 Response spectra of scaled ground motion records for 3-story (a-b-c) and 9-story (d-

e-f) prototype buildings

Figure 3.3 Elevation and plan of prototype buildings. 33

Figure 4.1 (a) Experimental setup, (b) loading protocol, and (c) notation for WWFF. .37

Figure 4.2 (a) WWFF macro model and (b) Pinching4 material model....

Figure 4.3 Second point (a) displacement and (b) force; third point (c) displacement and (d)

force; fourth point (e) displacement and(f) force.

Figure 4.4 Comparison of WWFF force-deformation in OpenSees simulations and experiment

results for $\mathrm{A} 1.5 \mathrm{~S} 32$. .44

Figure 4.5 Comparison of the WWFF force-deformation relationship from the experimental

results and OpenSees numerical simulations for 7 test specimens. 45

Figure 4.6 Comparison of the WWFF force-deformation relationship from the ABAQUS and

OpenSees numerical simulations .48

Figure 4.7 Force-deformation relationship comparison for BRB between experimental result and OpenSees numerical simulation. .50

Figure 4.8 Element removal procedure (Yang et al. 2015)............................51

Figure 4.9 Two-dimensional finite element models in OpenSees platform....................53

Figure 5.1 Roof drift ratio probability of exceedance................................55 
Figure 5.2 Inter-story Drift Ratio.

Figure 5.3 Demand-capacity ratio of $(a, b)$ WWFFs and $(c, d)$ BRKBs.......................57

Figure 6.1 Incremental dynamic analysis curves...................................... 59

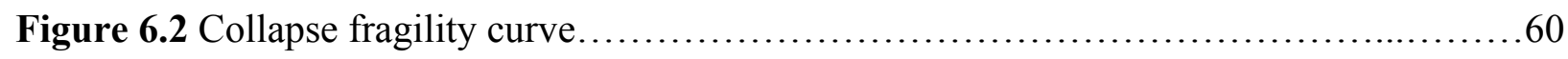

Figure 7.1 Incremental dynamic analyses result for (a) $S=20$, (b) $S=25$, (c) $S=30$, (d) $S=35$, (e)

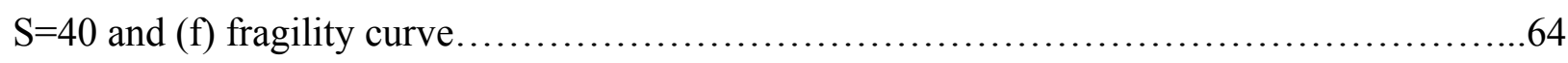

Figure 7.2 Acceptable collapse margin ratios for different categories: (a) poor, (b) fair, (c) good

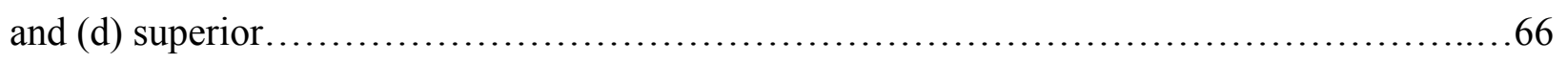

Figure 7.3 Median peak floor (a) acceleration and (b) base shear.........................67 


\section{List of Symbols}

$\delta_{\mathrm{y}, \mathrm{WWFF}}$ : Yielding ratio of WWFFs

$\mathrm{V}_{\mathrm{i}}$ : Story shear at the level $\mathrm{i}$

$L$ : Distance between column centerlines

F : Base shear

$F_{i}$ : Design lateral forces at level i

$F_{y}$ : Yielding base shears of the ENLSDOF system

$F_{p}$ : Plastic base shears of the ENLSDOF system

$E_{a}$ : Elastic Energy

$\mathrm{E}_{\mathrm{h}}$ : Hysteresis Energy

$E_{s}$ : Elastic Strain Energy

$m$ : Mass

$\Delta$ : Roof Drift Ratio

$\Delta_{\mathrm{y}}$ : Roof drift ratio of the ENLSDOF system which corresponds to the base shear of $\mathrm{F}_{\mathrm{y}}$ $\Delta_{\mathrm{p}}$ : Roof drift ratio of the ENLSDOF system which corresponds to the base shear of $\mathrm{F}_{\mathrm{p}}$ $\Delta_{\mathrm{u}}$ : Ultimate roof drift ratio $\mathrm{C}_{0}$ : Coefficient to modify the displacement, $S_{d}$, of an ELSDOF system to the roof displacement of a multiple DOF system

H: Height of the structure

$S_{a}$ : Pseudo Acceleration

$\mathrm{w}_{\mathrm{j}}$ : Seismic weight at the level $\mathrm{j}$

$h_{j}$ : Heights from the ground to level $j$ 
$\lambda_{\mathrm{i}}$ : The ratio of the equivalent lateral force at level i with respect to the design base shear

$\beta_{\mathrm{i}}$ : Vertical distribution factor of the design lateral forces

$\alpha:$ BRKB vertical inclination angle

$\mathrm{F}_{\mathrm{SLE}}$ : Elastic base shear corresponds to the SLE hazard intensity

$\mathrm{F}_{\mathrm{DBE}}$ : Elastic base shear corresponds to the DBE hazard itensity

$\mathrm{F}_{\mathrm{MCE}}$ : Elastic base shear corresponds to the MCE hazard intensity

$\mathrm{D}_{\mathrm{x}}$ : Horizontal length of BRKB

$\mathrm{D}_{\mathrm{y}}$ : Vertical length of BRKB

$l_{b}$ : Length of BRKB

$\varepsilon_{y}$ : BRKB yielding strain

$\delta_{\mathrm{y}, \mathrm{BRKB}}$ : Yielding axial deformation of BRKB

$N_{B R K B, i}:$ Total yielding strength shared by multiple bays of BRKBs at each floor.

$\Delta \mathrm{E}_{\mathrm{E} 1}$ : Incremental input energy from an earthquake when the shaking intensity increases from

SLE to DBE

$\Delta \mathrm{E}_{\mathrm{E} 2}$ : Incremental input energy from an earthquake when the shaking intensity increases from

DBE to MCE

$\gamma_{a}$ : Incremental energy modification factor from SLE to DBE

$\gamma_{b}$ : Incremental energy modification factor from DBE to MCE

T: Structural period of the building

$\mu$ : Ratio of $\Delta_{\mathrm{p}}$ over $\Delta_{\mathrm{y}}$

$\lambda$ : Ratio of $F_{p}$ over $F_{y}$

$\mathrm{F}_{\mathrm{se}}$ : Yielding strength of the secondary system 
$\mathrm{F}_{\mathrm{pr}}$ : Yielding strength of the primary system

$W_{\text {ext,pr }}:$ Work external of primary system

$\mathrm{W}_{\mathrm{int}, \mathrm{pr}}$ : Work internal of primary system

$\mathrm{W}_{\text {int,se }}$ : Work internal of secondary system

$W_{\text {ext,se }}:$ Work external of secondary system

$\mathrm{h}_{\mathrm{c}}$ : Column height

$\mathrm{b}_{\mathrm{c}}$ : Column width

$\mathrm{t}_{\mathrm{fc}}$ : Column flange thickness

$\mathrm{t}_{\mathrm{wc}}$ Column web thickness

D': WWFF net length

D: WWFF length

$t_{\mathrm{w}}$ WWFF web thickness

$\mathrm{t}_{\mathrm{f}}: \mathrm{WWFF}$ flange thickness

$a$ : WWFF web height

$\left(\Delta_{y}, V_{y}\right)$ : WWFF yield point coordinate

$\left(\Delta_{t}, V_{t}\right):$ WWFF transition point coordinate

$\left(\Delta_{\mathrm{u}}, \mathrm{V}_{\mathrm{u}}\right)$ : WWFF ultimate point coordinate

$\left(\Delta_{\mathrm{f}}, \mathrm{V}_{\mathrm{f}}\right):$ WWFF fracture point coordinate

G: Shear modulus or modulus of rigidity

$\tau_{\mathrm{xy}}:$ Shear stress

$\gamma_{\mathrm{xy}}:$ Shear strain

$\sigma_{\mathrm{y}}:$ Yield stress 
$S$ : WWFF slenderness ratio

$A$ : WWFF aspect ratio

$\mathrm{V}_{\mathrm{p}}$ : Pure shear force

$S_{\mathrm{MT}}$ : Spectral acceleration of the design base level at the fundamental period of the structure

$S_{\mathrm{CT}}$ : Spectral acceleration at $50 \%$ collapse probability

$S_{\mathrm{aT} 1}:$ Spectral acceleration at the fundamental period of the structure

$\beta_{\text {TOT }}:$ System total composite uncertainty

$\beta_{R T R}$ : Collapse uncertainty due to record-to-record variability in ground motions

$\beta_{D R}$ : Collapse uncertainty due to quality ratings of design requirement

$\beta_{T D}$ : Collapse uncertainty due to test data

$\beta_{M D L}$ : Collapse uncertainty due to numerical modeling 


\section{List of Abbreviations}

ACMR: Adjusted Collapse Margin Ratio

ASCE: American Society of Civil Engineers

BF: Braced Frame

BRB: Buckling Restrained Brace

BRKB: Buckling Restrained Knee Brace

CA: California

CBF: Concentrically Braced Frame

CMR: Collapse Margin Ratio

CP: Collapse Prevention

DBE: Design-based Earthquake

DCR: Demand-Capacity Ratio

DFHF: Dual-Fused H-Frame

EBF: Eccentrically Braced Frame

EEDP: Equivalent Energy Design Procedure

ELSDOF: Equivalent linear single degree-of-freedom

ENLSDOF: Equivalent nonlinear single degree-of-freedom

IDA: Incremental Dynamic Analyses

IO: Immediate Occupancy

ISD: Inter-Story Drift

MCE: Maximum Credible Earthquake

MF: Moment Frame 
NBCC: National Building Code of Canada

NTHA: Nonlinear Time History Analyses

PBEE: Performance-Based Earthquake Engineering

PEER: Pacific Earthquake Engineering Research Center

PSW: Plate Shear Wall

RDR: Roof Drift Ratio

RR: Rapid Return

SFRS: Seismic Force Resisting System

SLE: Service Level Earthquake

SSF: Spectra Shape Factor

WA: Washington

WWFF: Welded Wide Flange Fuse 


\section{Acknowledgements}

First and foremost, I thank God without whom nothing is possible. Truly, He was always with me at every single moment. He guided me to this field of study, which I truly love, faithfully planned to meet right mentors, right colleagues, and right friends to accomplish His work.

I would like to express my sincere gratitude to my research supervisor, Prof. Tony Yang, for his constant support, generosity with his time and his vast knowledge, and insightful advises throughout my research. I consider myself very fortunate for being able to work with a very considerate and encouraging professor like him. I also would like to express my appreciation to Dr. Dorian Tung for his tremendous support, incisive comments and discussions. Without his guidance, this research would never have taken shape.

I gratefully acknowledge two of my research colleagues, Fabrício Bagatini-Cachuço and Lisa Tober for their valuable guidance and insightful comments which greatly assisted me during my research. Thanks for the brainstorming sessions, I will be forever indebted.

I would like to gratefully recognize my close friends, Amin Sadeghi, Amir Esmalian, Amirsalar Heydari, Pouya Aein and James Adinata, for their great friendship and all-time support. I am also thankful to my friends and fellow students at the Department of Civil Engineering for their helpful discussions and joyful company. Special thanks to Francesca Palmieri, Mohamed Rashad, Tianyi Li, Hongzhou Zhang, Winda Banjuradja, Andrés Barrero, Andrés Reyes and Yuxin Pan. I would also like to extend my gratitude to my best friends back in Iran, Khashayar Ghorab, xix 
Khashayar Yavari, Soroush Sadeghi and Mehrdad Mashayekhi, who always believed in me and encouraged me during my studies.

Finally, my heart is filled with deep respect and gratitude to my family. My mother and father have given me their unequivocal support throughout, as always, for which my mere expression of thanks likewise does not suffice. Being thankful for their caring, sacrifices and guidance, my hope is to become the person they have raised me to be. I am grateful to my lovely sister for her love, encouragement, and concern for me and for always being there as a close friend even with miles apart. I am also thankful to my uncle Sadegh, for his unconditional sharing expertise and experiences which never diminished by the long distance between us. 


\section{Dedication}

This thesis is dedicated to the memory of my beloved grandma Forough, a strong woman whom I still miss every day. This is for her.

"Ma mozorg" 


\section{Chapter 1: Introduction}

\subsection{Overview of Conventional Seismic Force Resisting Systems}

Over the last decades, several seismic force resisting systems (SFRSs) have seen adopted by the codes in the United States (AISC 2010) and Canada (NBCC 2015). The following paragraphs summarize these conventional SFRSs namely, moment frames (MFs), plate shear walls (PSWs) and braced frames (BFs).

\subsubsection{Moment Frame (MF)}

Moment Frame (MF), as shown in Figure 1.1, is one of the most regularly used SFRSs. It employs the flexural behavior of beams to dissipate the earthquake energy. It has many noteworthy advantages, including large openings and architectural planning friendly. A well-designed MF should follow "Strong Column - Weak Beam" mechanism. This can be achieved by ensuring the beam can deform inelastically through ductile hinging, while columns are capacity designed to be stronger than the beam end moments. Prior to the 1994 Northridge earthquake, MFs were assumed to be superior for earthquake application. However, as reported in FEMA-355C (2000) the beamcolumn connections exhibited brittle fractures at very low level of plastic demands. This led to brittle behavior of the system. Another essential drawback of MFs is its low structural stiffness, where the structural design of MF is typically governed by the deflection limit instead of strength. Thus, the use of structural material is usually not optimized. More importantly, the design philosophy did not take the postearthquake repair into account, making the repair of this system difficult after the earthquake. 


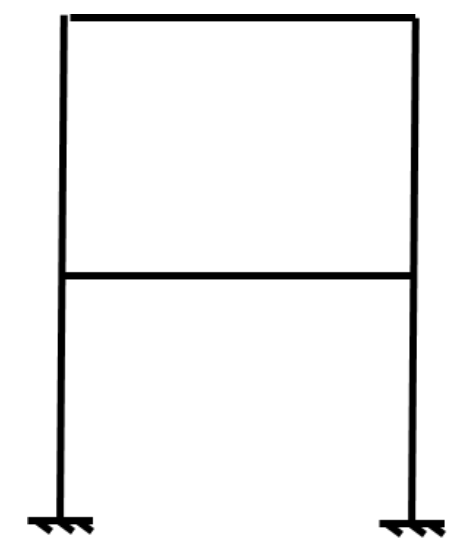

Figure 1.1 Schematic Moment Frame

\subsubsection{Plate Shear Wall (PSW)}

Plate shear wall (PSW), as shown in Figure 1.2, is another efficient SFRS that has been applied extensively in high seismic regions. PSWs were used in the United States since the 1970's and initially used for seismic retrofit of low and median-rise existing hospitals. Nowadays, PSWs are adopted by tall buildings to resist seismic forces. The advantage of PSW is that it has high stiffness and could resist larger seismic forces with high stiffness. However, the PSW may be hard to repair after a seismic event because of the welded boundary elements and shear plates.

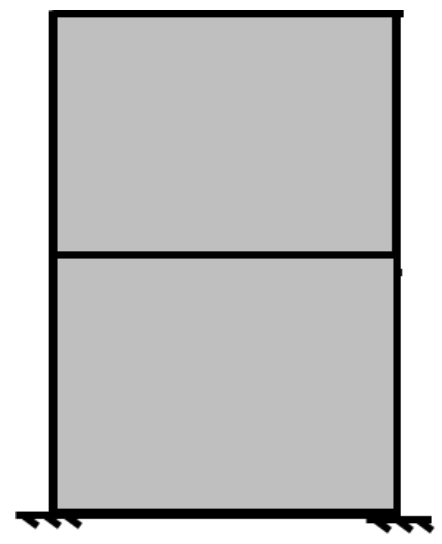

Figure 1.2 Schematic Plate Shear Wall 


\subsubsection{Braced Frame (BF)}

Braced frames (BFs), as shown in Figure 1.3, including concentrically braced frames (CBFs) and eccentrically braced frames (EBF) have been widely studied in the past. CBF uses braces to increase the lateral structural stiffness, and dissipate the earthquake energy. CBFs can be arranged in various configurations, among all types, balanced diagonal $\mathrm{BF}$ is the most common selection. The seismic behaviors of CBF were analyzed in past, and it is found that large unbalance vertical forces are created because of the existence of brace buckling. To address this issue, conventional braces are replaced by buckling restrained braces (BRBs). EBF is a relatively new SFRS, proposed by Popov and Engelhardt (1988). EBF combines the features of MF and CBF, while minimizing the disadvantages of both systems. According to the link length, EBFs can be classified as shear-controlled or flexural controlled. The shear-controlled links are favorable with its excellent behavior, while the flexuralcontrolled links are preferred for their large openings.

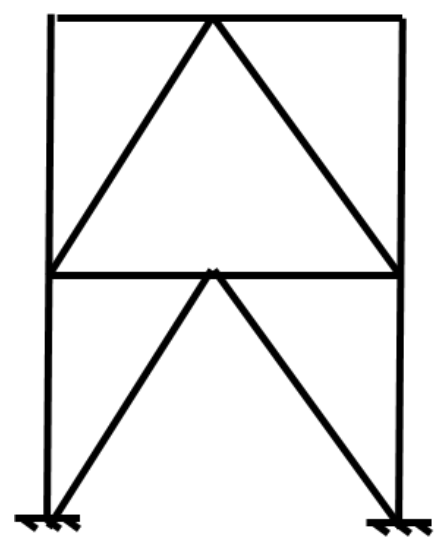

(a)

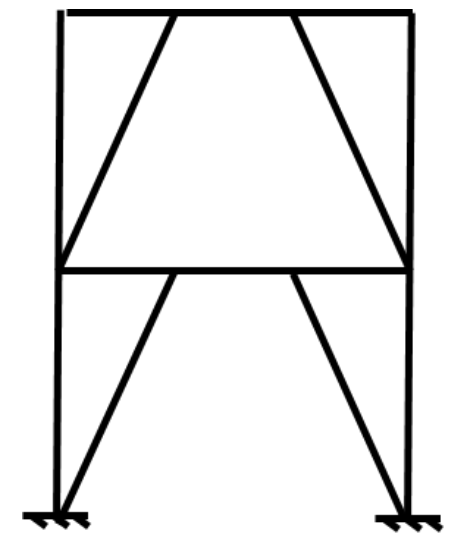

(b)

Figure 1.3 Schematic (a) concentrically and (b) eccentrically braced frames 


\subsection{Structural Fuse Concept}

The current seismic design philosophy focuses on achieving collapse prevention performance objective after a structure is subjected to the maximum considered earthquake shaking. Most conventional SFRSs such as MFs, PSWs or BFs can demonstrate acceptable margin of safety against collapse. However, the past earthquakes have shown that extensive inelastic deformation and residual drift result in significant structural and non-structural damages. These damages lead to loss of functionality and result in prolonged downtime. Thus, there is a need for resilient SFRSs to not only protect the lives of occupants during an earthquake, but also concentrate the damages where they can be easily and quickly repaired following an earthquake.

An effective strategy to improve the reparability of structural members is to concentrate inelastic deformation in carefully designed and replaceable elements, typically known as structural fuses. Structural fuses are detailed to dissipate earthquake energy while protecting the remaining structural members. After an earthquake, these fuses are replaced if needed without affecting the functionality of the structure.

\subsection{Review of Fused Seismic Force Resisting Systems}

\subsubsection{Fused Moment Frame}

The concept of fused SFRS was first proposed by Balut and Gioncu (2003) where they proposed the dismountable dog-bone connection in MFs. The proposed connection, as shown in Figure 1.4 (a), gives the feasibility to repair structural damages without replacing the entire steel beam in a MF. Similarly, Shen et al. (2011) proposed a replaceable flexural link, as shown in Figure 1.4 (b), in steel MFs at a short distance away from the column face, forcing the plastic hinge 
to form away from the critical welded section. In addition, Nikoukalam and Dolatshahi (2015) and Nikoukalam et al. (2015) proposed a replaceable shear structural fuse for MFs as shown in Figure 1.4 (c). With weakened shear strength at the middle of a beam, seismic energy is dissipated by stable shear hysteretic behavior.

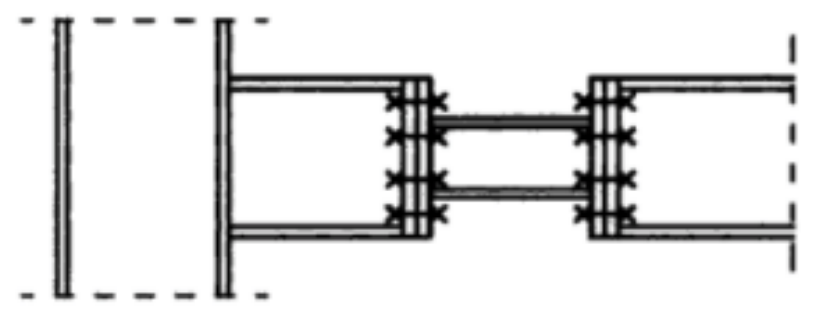

(a) (Balut and Gioncu 2003)

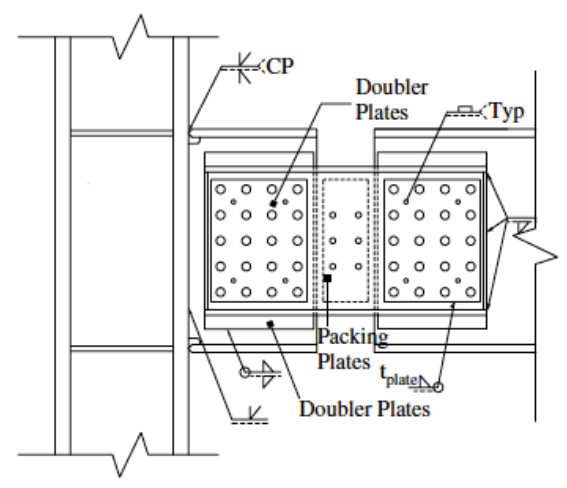

(b) (Shen et al. 2011)

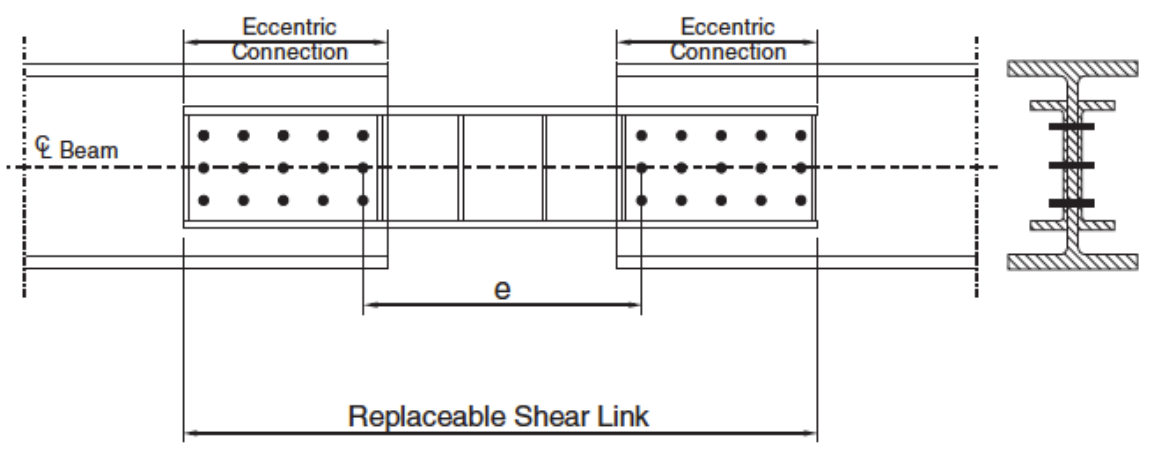

(c) (Nikoukalam and Dolatshahi 2015)

Figure 1.4 Fused Moment Frames 


\subsubsection{Fused Braced Frame}

Vayas and Thanopoulos (2005) proposed an innovative connection, as shown in Figure 1.5 (a), to be used in CBFs. The specially designed connection forces inelasticity within the connection to protect the braces. Gray et al. (2013) developed a novel cast steel yielding brace, as shown in Figure 1.5 (b), to enhance the seismic performance of CBFs. Similarly, Mansour et al. (2011) introduced replaceable shear links, as shown in Figure 1.5 (c), into EBFs to decouple yielding elements from main beams. This optimizes the design of links and EBFs.

(a)

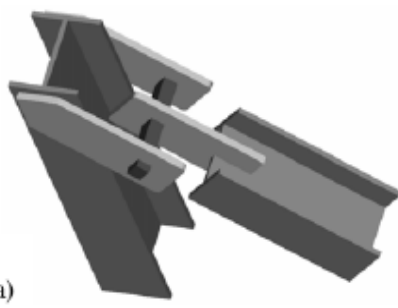

(b)

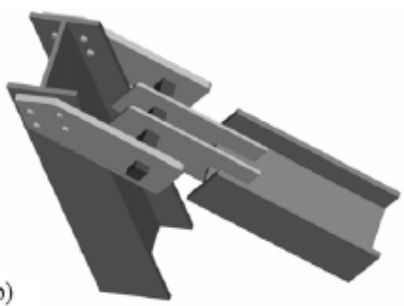

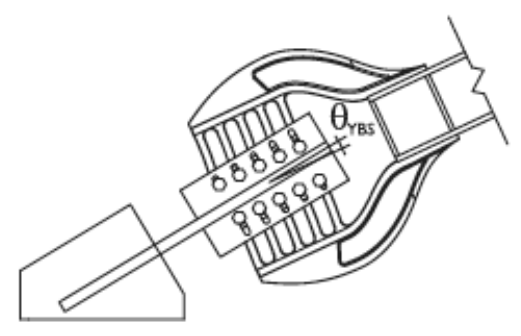

(b) (Gray et al. 2013)

(a) (Vayas and Thanopoulos 2005)

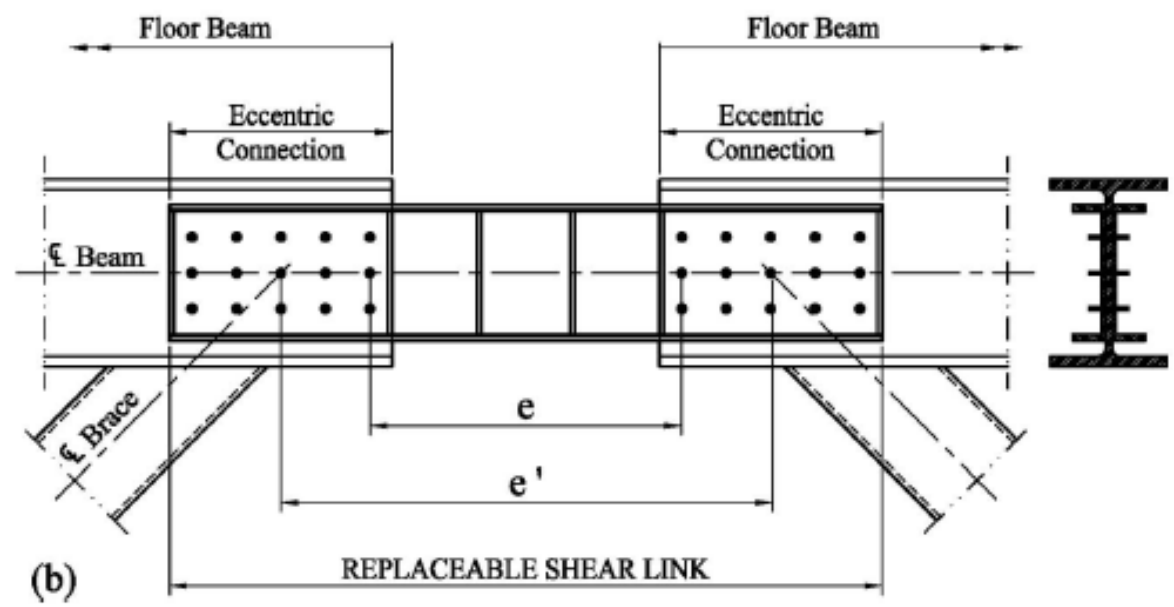

(c) (Mansour et al. 2011)

Figure 1.5 Fused Brace Frames 


\subsubsection{Linked Column Frame}

Dusicka and Iwai (2007) and Malakoutian et al. (2013) proposed a new SFRS called linked column frame (LCF) that uses conventional components to limit seismic damage to relatively easily replaced elements. The LCF, as shown in Figure 1.6, features a primary lateral system, denoted the linked column, which is made up of dual columns connected with replaceable links, and a secondary flexible MF system with beams having fully restrained connections at one end and simple pin connections at the other. The linked columns are designed to limit seismic forces and provide energy dissipation via link yielding, while preventing damage to the MF under certain earthquake hazard levels.

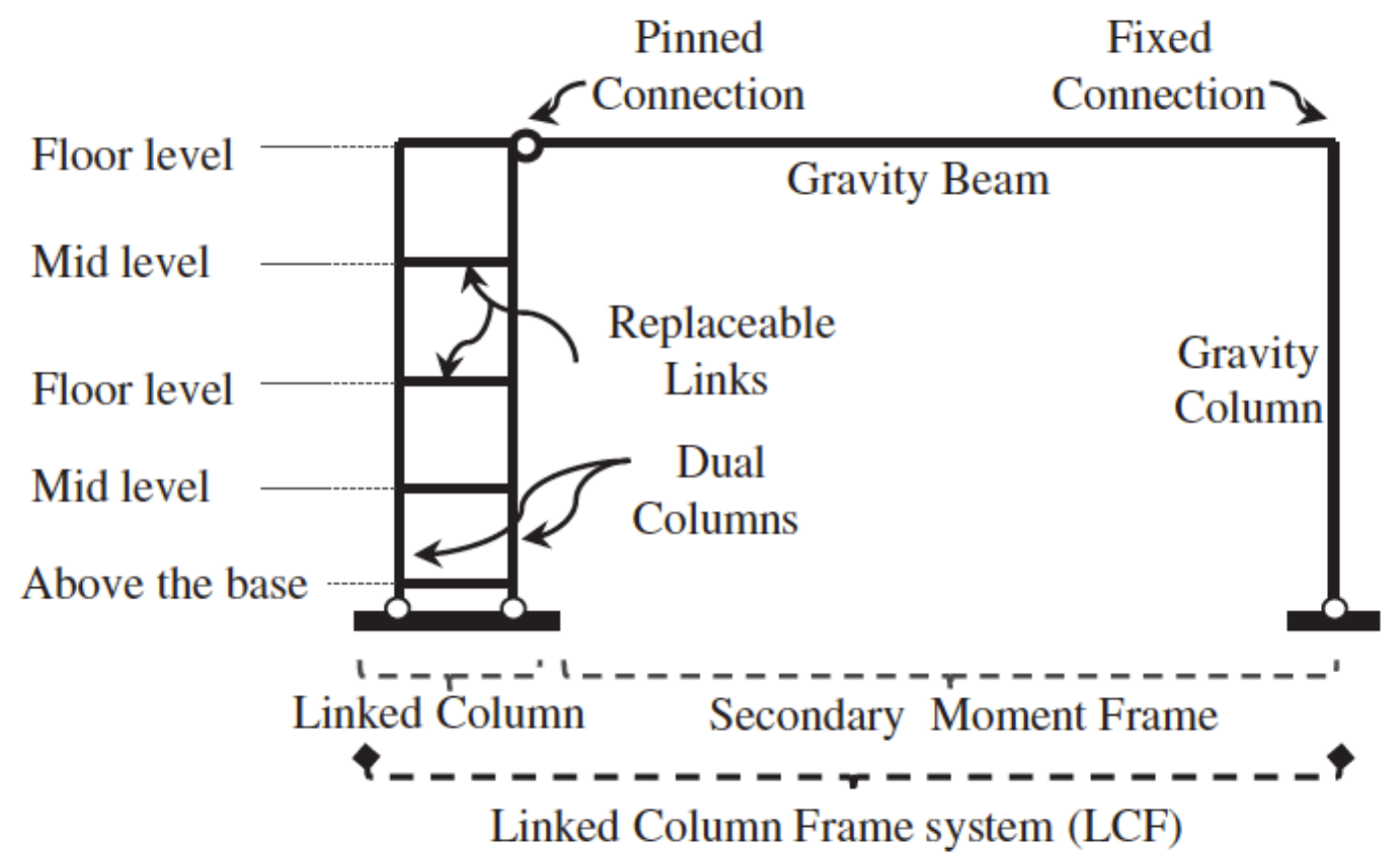

Figure 1.6 LCF system (Malakoutian et al. 2013) 


\subsubsection{Buckling Restrained Knee Braced Truss Moment Frame}

Wongpakdee et al. (2014) and Yang et al. (2014) proposed a new SFRS, as shown in Figure 1.7, called buckling restrained knee braced truss moment frame (BRKBTMF), which combines the advantages of open-web steel truss girders and buckling restrained knee braces (BRKBs). Significant advantages of open-web trusses include light weight, simple connections, and open passages for mechanical ductwork and pipes. In this system, the open-web trusses are designed to be elastic, while the BRKBs are strategically placed and designed to dissipate seismic energy. The combined features of the open-web trusses and BRKBs lead to a system with enhanced performance, safety, and economy.

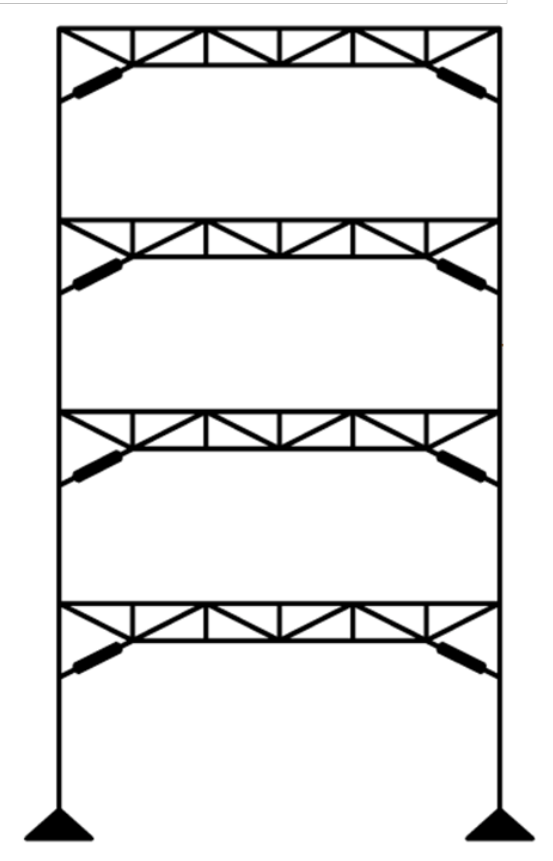

Figure 1.7 BRKBTMF system (Yang et al. 2014) 


\subsubsection{Buckling Restrained Knee Braced Frame}

Recently, Junda et al. (2018) presented an efficient structural steel system called bucklingrestrained knee-braced frame $(\mathrm{BRKBF})$ as shown in Figure 1.8. The advantages of a BRKBF include relatively simple connections, reparability after an earthquake, and fewer obstructions than conventional bracing systems. Various BRKBF configurations can be designed and detailed for different levels of strength, stiffness, and ductility. BRKBFs are designed so that all inelastic activities are confined to the BRKB. Hence, the structure can be repaired easily after a strong seismic shaking by replacing the BRKBs without affecting the functionality of the structure.

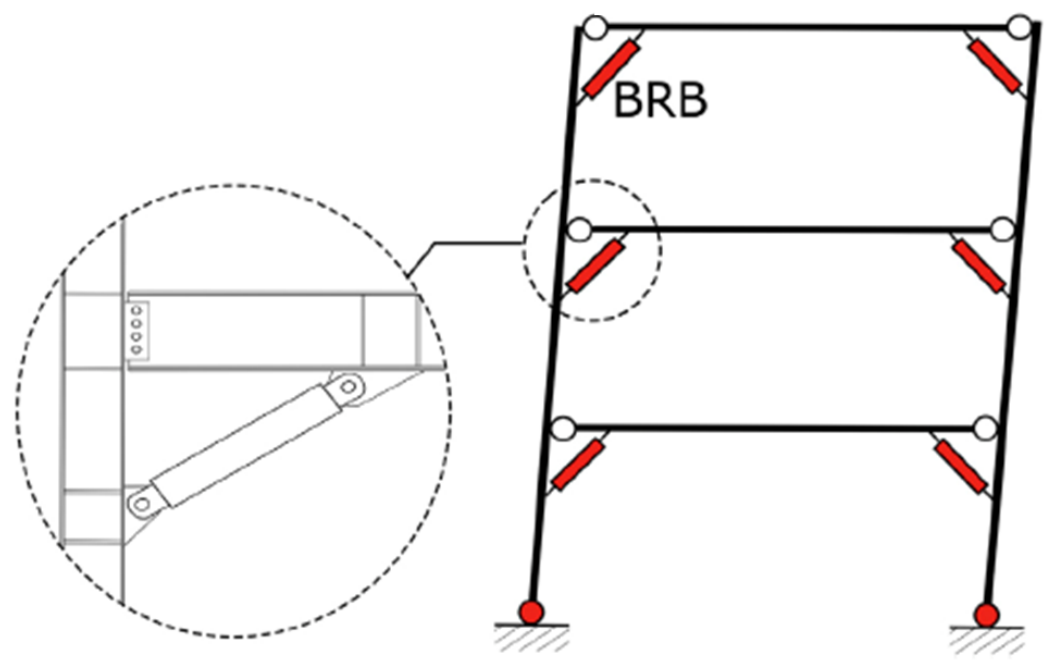

Figure 1.8 Buckling Restrained Knee Braced Frame System (Junda et al. 2018) 


\subsection{Dual Fused H-Frame System Description}

Most of the fused SFRSs mentioned in section 1.3 do not take construction efficiency into considerations. To address this issue, a novel resilient fused SFRS namely Dual-Fused H-Frame (DFHF) is proposed in this thesis. DFHF, as shown in Figure 1.9, combines H-Frames with two types of specially designed and replaceable structural fuses, Welded Wide Flange Fuses (WWFFs) (Yang et al. 2018a) and BRKBs, to create a dual energy dissipation mechanism. Each H-Frame consists of two columns pin connected to a beam. The combination of H-Frame and BRKBs defined as Damped H-Frame (Etebarian and Yang 2018) can be prefabricated to improve construction quality and reduce erection time. BRKBs provide stiffness to H-Frame. As H-Frame is displaced laterally, the damage free connection depicted in Figure 1.10(b) engages BRKBs axially to dissipate energy in tension or compression. Damped H-Frames are spliced on-site using simple bolt connection shown in in Figure 1.10(a) at the location where moment demand is relatively small. This simplify the design, construction, and cost of the connection. As shown in Figure 1.10(a), Damped H-Frames are connected via WWFFs at two different elevations: one at the BRKB and another below the column splice connection. WWFFs use the steel web plate to dissipate earthquake energy through shear yielding in the longitudinal direction, while the flanges are designed to remain elastic (Yang et al. 2018a). Figure 1.10(c) and Figure 1.10(d) present the close-up view of a WWFF. 


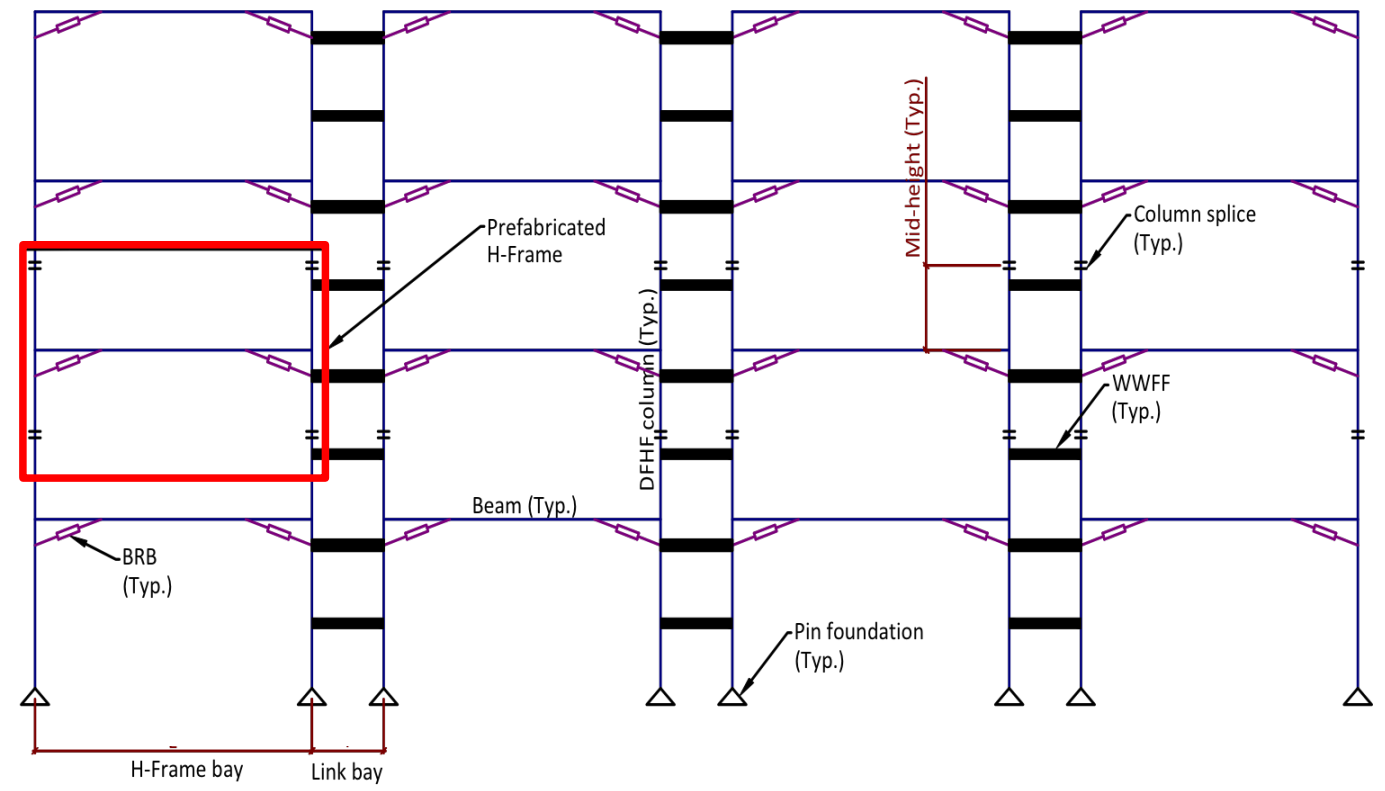

Figure 1.9 DFHF configuration

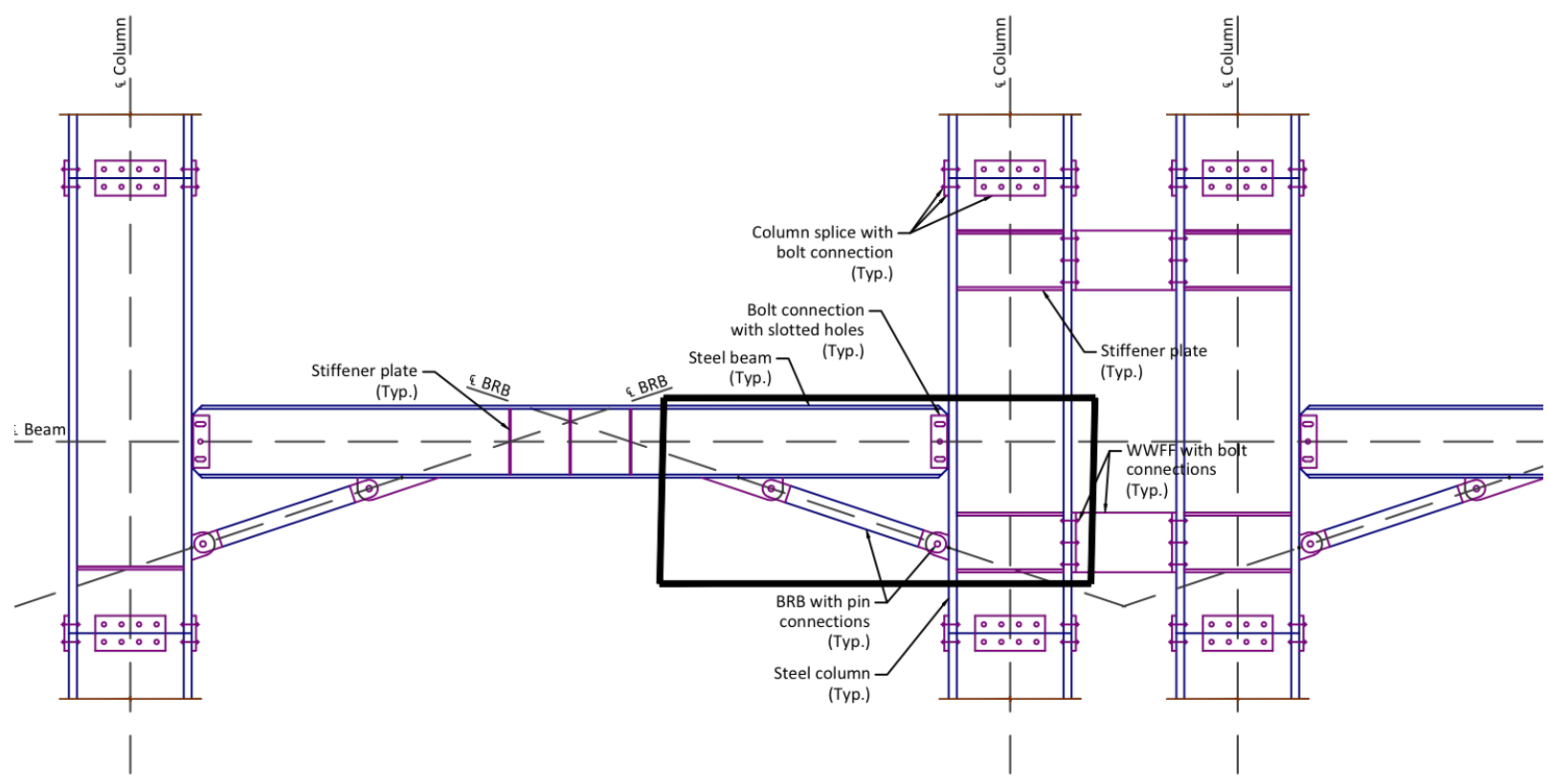

(a) Close-up view of H-Frame and structural fuses 


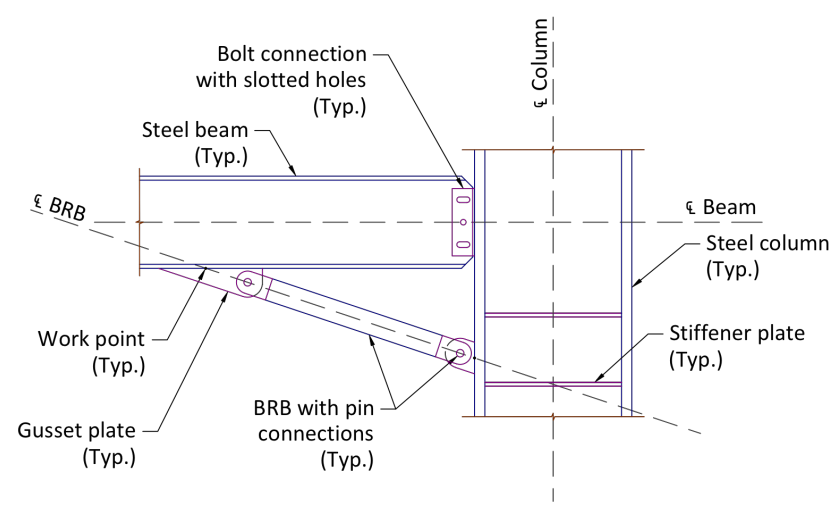

(b) BRKB connection

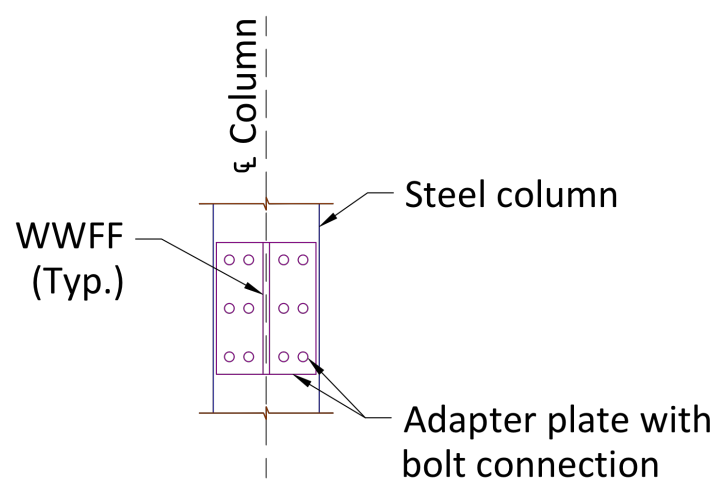

(c) WWFF connection

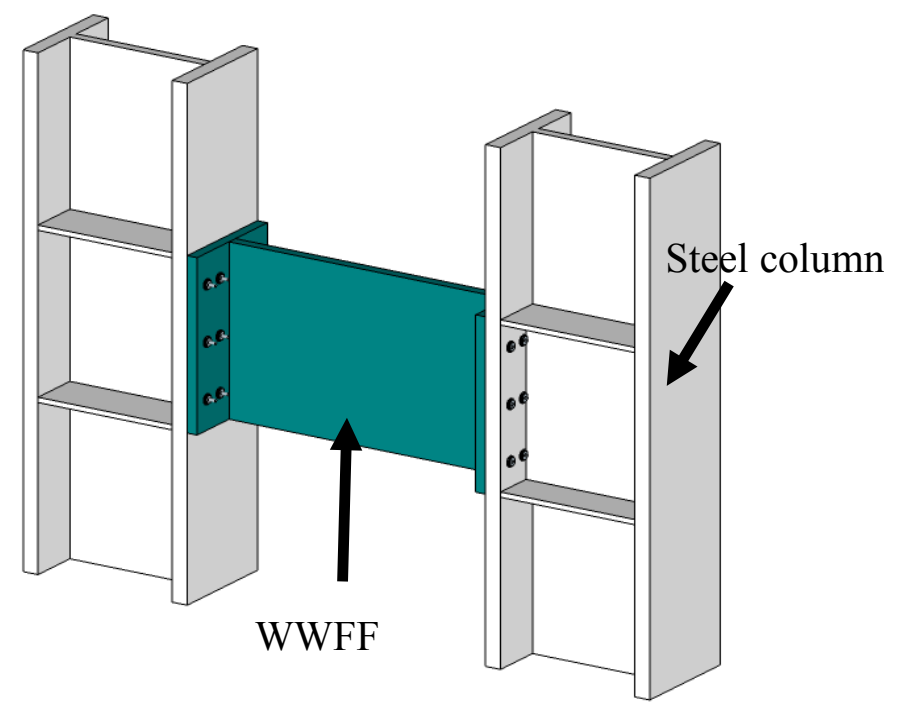

(d) Three-dimensional close-up view of WWFF

Figure 1.10 Detailing of DFHF 


\subsection{Energy Dissipation Mechanism of DFHF System}

As shown in Figure 1.9 and described previously, the proposed DFHF consists of prefabricated H-Frames and two types of structural fuses that work essentially in parallel to provide the desired seismic responses. WWFFs and BRKBs are designed to dissipate earthquake energy while protecting H-Frames from damages. WWFFs and BRKBs are decoupled from the gravity system. Hence, they can be quickly inspected, repaired, or replaced after a strong earthquake shaking. After the structural fuses are replaced, H-Frames can be re-centered to minimize residual deformation. This makes the proposed DFHF resilient and functional immediately or shortly after a strong earthquake shaking.

With the combination of WWFFs (primary structural fuse) and BRKBs (secondary structural fuse), the proposed DFHF has a tri-linear force-deformation relationship as shown in Figure 1.11. After a service level earthquake (SLE) shaking, the system's performance is targeted to be immediate occupancy (IO), where the structure is expected to remain elastic without repairs. After a design-based earthquake (DBE) shaking, the system's performance is targeted to be rapid return (RR), where WWFFs are designed to yield and dissipate earthquake energy, while BRKBs are designed to remain elastic. WWFFs are designed to be repaired or replaced quickly so that the structure can be functional immediately or shortly after a DBE shaking. After a maximum credible earthquake (MCE) shaking, the system's performance is targeted to be collapse prevention (CP), where both WWFFs and BRKBs are designed to yield to dissipate earthquake energy and to prevent the structure from collapse. It should be noted that nonstructural and floor damages are not considered here; however, proper design of nonstructural and floor systems would be necessary to fully achieve the stated target performances. 


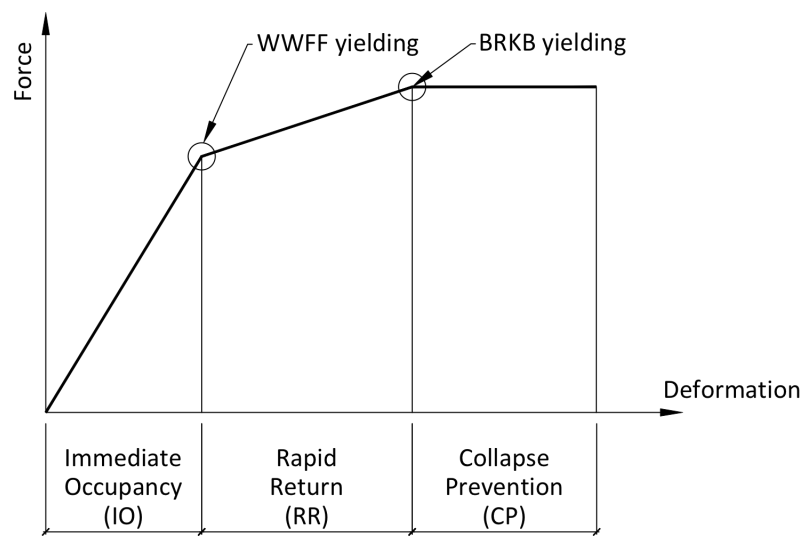

Figure 1.11 Performance objectives and force-deformation relationship of DFHF 


\subsection{Objectives and Research Scope}

The objective and scope of work for this thesis is as follows:

1) Propose an innovative resilient seismic force resisting system called Dual Fused H-Frame (DFHF) that not only recovers quickly following an earthquake, but also can be erected efficiently and effectively during the construction process.

2) Apply the Equivalent Energy Design Procedure (EEDP) to design prototype buildings using the proposed DFHF system.

3) Develop a simple macro model for Welded Wide Flange Fuse (WWFF) to enable its application in a system level. Hence, it can be used by researchers and engineers alike, to model WWFF in any desired system.

4) Create detailed finite element models of the prototype buildings utilizing the proposed macro model developed for WWFF.

5) Conduct extensive nonlinear time history analyses on the developed finite element models using the selected ground motions to assess the proposed DFHF seismic performance and quantify its capacity against collapse.

6) Carry out a parametric study to evaluate the effect of the geometric parameter of WWFF on the overall seismic response of the prototype building. 


\subsection{Thesis Organization}

Seismic design and performance evaluation of DFHF system is described in the following chapters:

- Chapter 2 presents the design procedure of DFHF system using EEDP design methodology. EEDP allows engineers to select multiple performance objectives under different earthquake shaking intensities. This can be achieved using simple hand calculations without iterations. Detailed step-by-step design guideline is provided for practicing engineers to design DFHF system.

- Chapter 3 describes two prototypes, 3- and 9-story office buildings, located in San Francisco, California (CA) and Seattle, Washington (WA), respectively. A suite of ground motions is selected and scaled for the sake of time history analyses. Design of all structural members are also presented in this chapter.

- Chapter 4 describes the numerical modeling for WWFFs, BRBs and DFHF system.

- Chapter 5 presents the results of nonlinear time history analyses, including the roof drift ratio, inter-story drift ratio and demand-capacity ratio of structural fuses.

- Chapter 6 assesses the collapse capacity of prototype buildings based on the procedure outlined in FEMA P-695 project.

- Chapter 7 studies the effect of the geometric parameter of WWFF on the overall seismic response of the prototype building.

- Chapter 8 presents a summary of research findings, conclusion and a list of topics for future research. 


\section{Chapter 2: Design Methodology for DFHF System}

\subsection{Conventional Design Approach}

The code-based conventional design approach is simple in concept and easy to implement. However, it may require multiple iterations if drift criteria are exceeded. In addition, the conventional design approach is restricted to a single performance objective, which is achieving collapse prevention after a structure is subjected to the maximum considered earthquake shaking. Since there are no intermediate performance objectives, a conventionally-designed structure could require costly repairs and downtime when subjected to earthquakes, even if the intensity of such events is below the design intensity.

\subsection{Equivalent Energy Design Procedure}

Performance-Based Earthquake Engineering (PBEE) was proposed as a method to consider performance objectives which, when used correctly, could lead to more resilient structures. Building displacements receive much more attention in PBEE methodologies because they are better correlated to damage of structural and nonstructural components. The Equivalent Energy Design Procedure (EEDP) (Yang et al. 2017) is one such methodology. EEDP allows engineers to select multiple performance objectives under different earthquake shaking intensities. This can be achieved using simple hand calculations without iterations. This practical and efficient design procedure has been applied to several innovative fused SFRSs (Yang et al. 2017; Yang et al. 2018b; Li et al. 2018; Etebarian and Yang 2018). The concept of EEDP is illustrated in Figure 2.1. In this figure, the vertical axis represents base shear, $\mathrm{F}$, which is calculated using pseudo acceleration, $\mathrm{S}_{\mathrm{a}}$, multiplied by structural mass, $m . \mathrm{F}_{\mathrm{SLE}}, \mathrm{F}_{\mathrm{DBE}}$, and $\mathrm{F}_{\mathrm{MCE}}$ are the corresponding elastic base shears 
under the SLE, DBE and MCE hazard intensities, respectively. The horizontal axis represents roof drift ratio, $\Delta$, which is roof displacement normalized by structural height, $H$. The dashed line represents the backbone of the equivalent nonlinear single degree-of-freedom (ENLSDOF) system. The solid line represents the backbone of the equivalent linear single degree-of-freedom (ELSDOF) system. EEDP relates the energy stored in the ELSDOF system (elastic energy, $E_{a}$ ) to the energy dissipated by the ENLSDOF system (elastic strain energy, $E_{s}$, and hysteretic energy, $E_{h}$ ) via energy modifications factors. The goal of EEDP is to calculate $F_{y}$ and $F_{p}$ which are the yielding and plastic base shears of the ENLSDOF system, respectively. $\Delta_{\mathrm{y}}$ and $\Delta_{\mathrm{p}}$ are the design roof drift ratios of the ENLSDOF system which correspond to the base shears of $F_{y}$ and $F_{p}$, respectively. $\Delta_{\mathrm{u}}$ is the ultimate roof drift ratio.

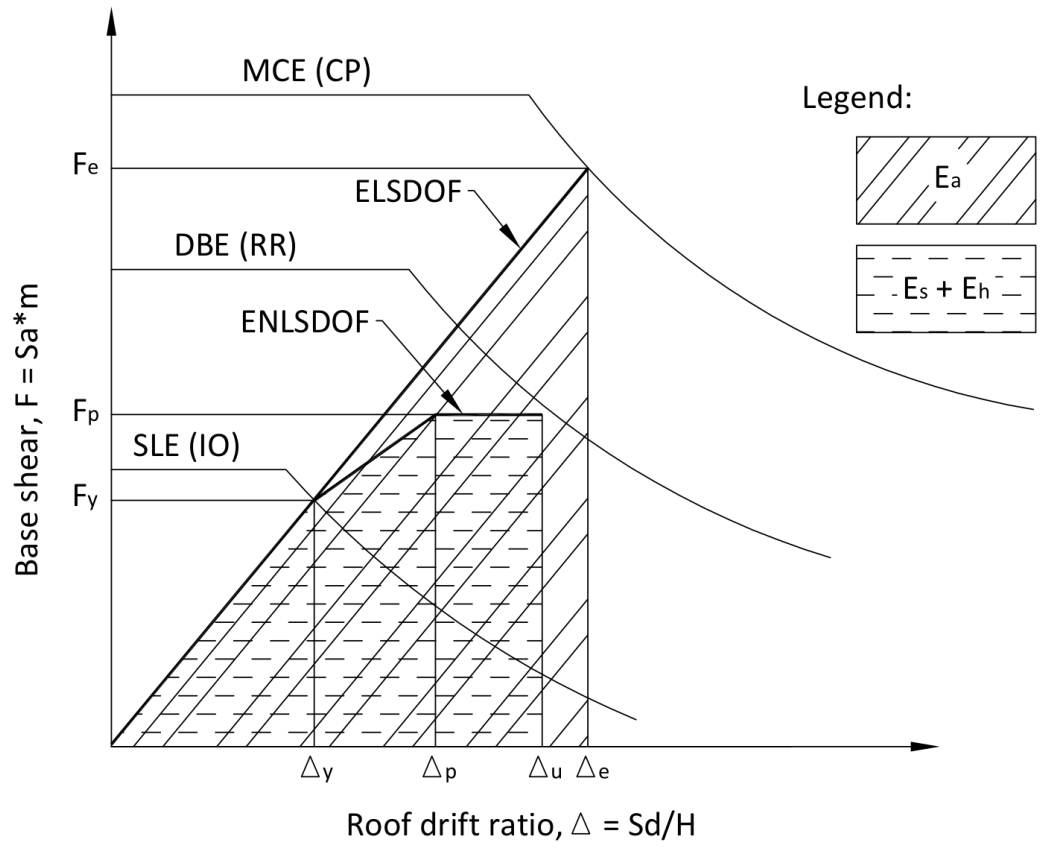

Figure 2.1 EEDP energy balanced concept 
In this research, EEDP methodology is implemented to design the DFHF system. The following paragraphs describe how to design the proposed DFHF step-by-step using EEDP.

\section{1) Select seismic hazard intensities}

The first step of EEDP is to select the three target hazard intensities (SLE, DBE and MCE). Different hazard intensities can be selected arbitrarily by stakeholders and engineers based on performance requirements.

\section{2) Determine $\Delta_{y}$ to calculate $F_{y}$ and $T$}

In this step, $\Delta_{\mathrm{y}}$, which is the roof drift ratio where WWFFs start to yield, is calculated using equation (2.1). This is based on the geometric relationship between the global and local deformations as shown in Figure 2.2.

$\Delta_{\mathrm{y}}=\delta_{\mathrm{y}, \mathrm{WWFF}} \frac{\mathrm{D} \prime}{\mathrm{L}}$

where $\mathrm{D}^{\prime}$ is the clear length of WWFFs, $\mathrm{L}$ is the distance between column centerlines, and $\delta_{\mathrm{y}, \mathrm{WWFF}}$ is the yielding ratio of WWFFs. Based on the experimental results presented in Yang et al. (2018a), $\delta_{\mathrm{y}, \mathrm{WWFF}}$ can be approximated as $0.23 \%$. 


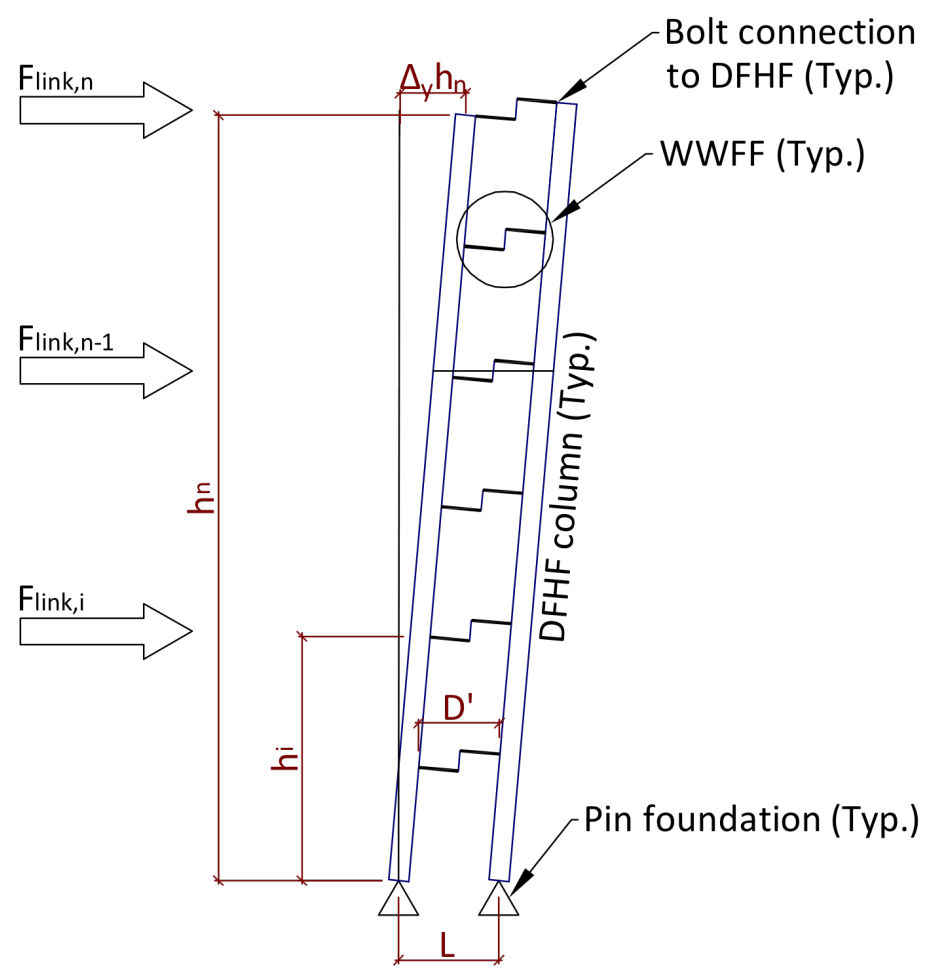

Figure 2.2 Primary system yielding mechanism

With $\Delta_{\mathrm{y}}$ calculated, $\mathrm{F}_{\mathrm{y}}$ is identified from the intersection of the SLE hazard curve and $\Delta_{\mathrm{y}}$ shown in Figure 2.1. With $\Delta_{\mathrm{y}}$ and $\mathrm{F}_{\mathrm{y}}$ identified, the structural period of the building, $\mathrm{T}$, can be calculated using equation (2.2).

$\mathrm{T}=2 \pi \sqrt{\frac{\Delta_{\mathrm{y}} \mathrm{H} / \mathrm{C}_{0}}{\mathrm{~F}_{\mathrm{y}} / \mathrm{m}}}$

where $\mathrm{C}_{0}$ is the coefficient to modify the displacement, $S_{d}$, of an ELSDOF system to the roof displacement of a multiple DOF system (ASCE 41 2006).

\section{3) Select $\Delta_{p}$ to calculate $F_{p}$}

At this step, designers should select a plastic roof drift ratio, $\Delta_{\mathrm{p}}$, which is the roof drift ratio where BRKBs start to yield. Since $\Delta_{\mathrm{y}}$ is calculated based on the building's geometry (equation (2.1)), $\Delta_{\mathrm{p}}$ is selected by design team to provide desirable ductility for the proposed DFHF. Once 
$\Delta_{\mathrm{p}}$ is selected, the plastic base shear, $\mathrm{F}_{\mathrm{p}}$, can be calculated using equation (2.3).

$\mathrm{F}_{\mathrm{p}}=\frac{2 \Delta \mathrm{E}_{\mathrm{E} 1}}{\gamma_{\mathrm{a}} \mathrm{H}\left(\Delta_{\mathrm{p}}-\Delta_{\mathrm{y}}\right)}-\mathrm{F}_{\mathrm{y}}$

where $\Delta \mathrm{E}_{\mathrm{E} 1}=\frac{m c_{0}}{2}\left[\left(S_{a}\right)_{D B E}+\left(S_{a}\right)_{S L E}\right]\left[\left(S_{d}\right)_{D B E}-\left(S_{d}\right)_{S L E}\right]$ is the incremental input energy from an earthquake when the shaking intensity increases from SLE to DBE, and $\gamma_{a}$ is the incremental energy modification factor from SLE to DBE. The detailed description of $\Delta \mathrm{E}_{\mathrm{E} 1}$ and values of $\gamma_{\mathrm{a}}$ can be found in Yang et al. (2017).

\section{4) Calculate $\Delta_{u}$}

At the MCE hazard intensity, DFHF shall withstand earthquake loading without collapse. This is achieved by designing WWFFs and BRKBs to maintain their yielding strengths until the structure reaches its ultimate roof drift ratio, $\Delta_{\mathrm{u}}$, which is calculated using equation (2.4).

$\Delta_{\mathrm{u}}=\frac{\Delta \mathrm{E}_{\mathrm{E} 2}}{\gamma_{\mathrm{b}} \mathrm{F}_{\mathrm{p}} \mathrm{H}}+\Delta_{\mathrm{p}}$

where $\Delta \mathrm{E}_{\mathrm{E} 2}=\frac{m c_{0}}{2}\left[\left(S_{a}\right)_{M C E}+\left(S_{a}\right)_{D B E}\right]\left[\left(S_{d}\right)_{M C E}-\left(S_{d}\right)_{D B E}\right]$ is the incremental input energy from an earthquake when the shaking intensity increases from $\mathrm{DBE}$ to $\mathrm{MCE}$, and $\gamma_{b}$ is the incremental energy modification factor from $\mathrm{DBE}$ to MCE. The detailed description of $\Delta \mathrm{E}_{\mathrm{E} 2}$ and values of $\gamma_{b}$ can be found in Yang et al. (2017).

\section{5) Distribute base shear between primary and secondary SFRSS}

The combination of WWFFs and BRKBs creates a trilinear force-deformation response of the proposed DFHF as shown in Figure 1.11. To design these structural fuses, this response needs to be distributed between WWFF (primary) and BRKB (secondary) systems as shown in Figure 2.3. Using the equilibrium relationships presented in Yang et al. (2017), the yielding strengths of the primary system, $\mathrm{F}_{\mathrm{pr}}$, and secondary system, $\mathrm{F}_{\mathrm{se}}$, are calculated by equation (2.5) and equation 
(2.6), respectively.

$\mathrm{F}_{\mathrm{pr}}=\mathrm{F}_{\mathrm{y}} \frac{\mu-\lambda}{\mu-1}$

$\mathrm{F}_{\mathrm{se}}=\mathrm{F}_{\mathrm{y}} \mu \frac{\lambda-1}{\mu-1}$

where $\lambda$ is defined as the ratio of $\mathrm{F}_{\mathrm{p}}$ over $\mathrm{F}_{\mathrm{y}}$, and $\mu$ is defined as the ratio of $\Delta_{\mathrm{p}}$ over $\Delta_{\mathrm{y}}$.

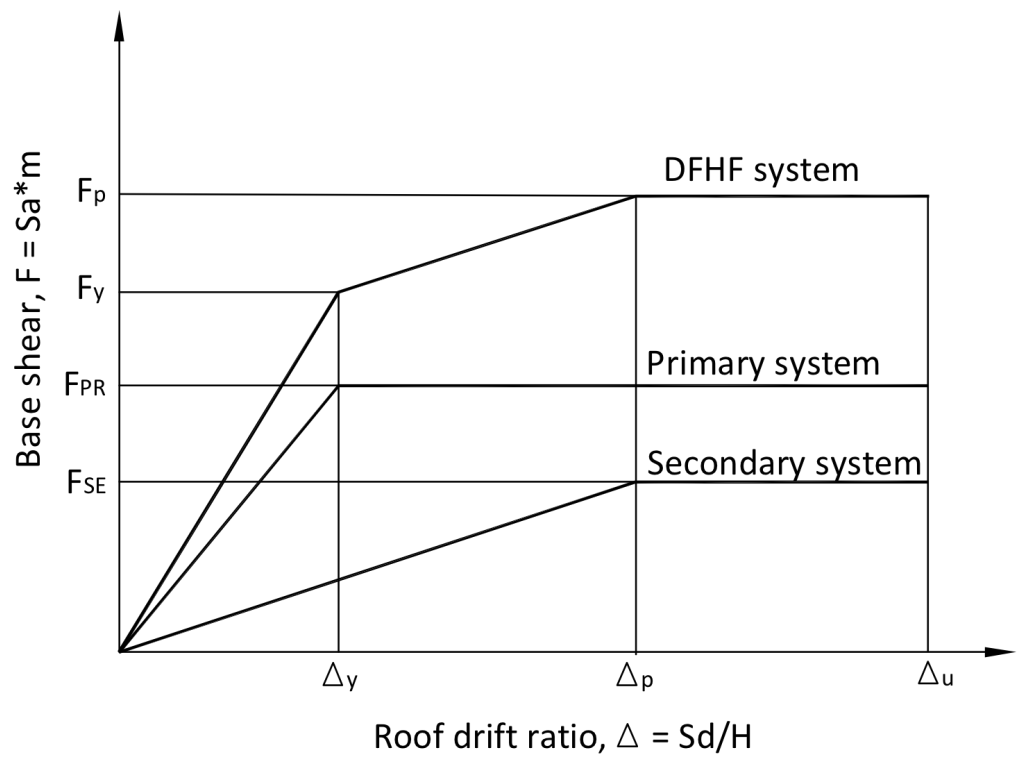

Figure 2.3 Distribution of design base shear to primary and secondary system

\section{6) Distribute base shear over building height}

Once the yielding strengths of the primary and secondary systems are established, the calculated design base shears in equation (2.5) and equation (2.6) are distributed vertically over the height of the primary and secondary systems using the distribution proposed by Chao et al. (2007) shown in equation (2.7).

$\beta_{\mathrm{i}}=\frac{\mathrm{v}_{\mathrm{i}}}{\mathrm{V}_{\mathrm{n}}}=\left(\frac{\sum_{\mathrm{j}=\mathrm{i}}^{\mathrm{n}} \mathrm{w}_{\mathrm{j}} \mathrm{h}_{\mathrm{j}}}{\mathrm{w}_{\mathrm{n}} \mathrm{h}_{\mathrm{n}}}\right)^{0.75 \mathrm{~T}^{-0.2}}$

Equation (2.7) represents the normalized story shear distribution with respect to the story shear in the top story, $V_{n}$, where $w_{n}$ and $w_{j}$ are the seismic weights at the roof (level $n$ ) and level $j$, 
respectively, and $h_{n}$ and $h_{j}$ are the heights from the ground to the roof (level $n$ ) and level $j$, respectively. Using the given normalized story shear distribution, the vertical distribution of the design lateral forces for primary and secondary systems are obtained using equation (2.8).

$\mathrm{F}_{\mathrm{i}}=\lambda_{\mathrm{i}} \mathrm{V}_{\mathrm{y}}$

where $\lambda_{i}=\left(\beta_{i}-\beta_{i+1}\right)\left(\frac{w_{n} h_{n}}{\sum_{j=i}^{n} w_{j} h_{j}}\right)^{0.75 T^{-0.2}}$.

\section{7) Design structural fuses}

The design lateral forces obtained from step 6 are then used to design the primary and secondary structural fuses. Design details are given in steps 7-1 and 7-2. Note that the columns are pinned at the base to minimize damages and repairs.

\section{7-1) Primary structural fuse - WWFF}

Using the yielding mechanism shown in Figure 2.2, the external work shown in equation (2.9), shall be equal to the internal work shown in equation (2.10).

$\mathrm{W}_{\text {ext,pr }}=\sum_{\mathrm{i}}^{\mathrm{n}}\left(\mathrm{F}_{\mathrm{i}} \mathrm{h}_{\mathrm{i}}\right) \Delta_{\mathrm{y}}$

$\mathrm{W}_{\mathrm{int}, \mathrm{pr}}=\sum_{\mathrm{i}}^{\mathrm{n}}\left(\beta_{\mathrm{i}}\right) V_{\mathrm{n}} \delta_{\mathrm{y}, \mathrm{WWFF}} \mathrm{D}^{\prime}$

Having equation (2.9) equal to equation (2.10) and substituting $\delta_{\mathrm{y}, \mathrm{WWFF}}$ from equation (2.1) in equation (2.10), the total yielding strength for WWFFs at the roof, $V_{n}$, can be calculated as shown in equation (2.11).

$$
\mathrm{V}_{\mathrm{n}}=\frac{\sum_{\mathrm{i}}^{\mathrm{n}} \mathrm{F}_{\mathrm{i}} \mathrm{h}_{\mathrm{i}}}{\sum_{\mathrm{i}}^{\mathrm{n}} \beta_{\mathrm{i}} \times \mathrm{L}}
$$

Using the $\beta$ factor calculated from equation (2.7), the total yielding strength at the other floors can be calculated using equation (2.12).

$\mathrm{V}_{\mathrm{i}}=\beta_{\mathrm{i}} \mathrm{V}_{\mathrm{n}}$ 
It should be noted that $V_{i}$ is the total yielding strength shared by multiple WWFFs at each floor. To calculate the yielding strength for each WWFF, $V_{i}$ should be divided by the total number of of WWFF used at each floor.

\section{7-2) Secondary structural fuse - BRKB}

Figure 2.4 shows the yielding mechanism of the secondary structural fuse. Figures $2.5(\mathrm{a})$ and 2.5(b) show the undeformed and deformed configurations of BRKBs. Using the energy balanced concept, the external work shown in equation (2.13) shall be equal to the internal work shown in equation (2.14).

$\mathrm{W}_{\text {ext,se }}=\sum_{\mathrm{i}}^{\mathrm{n}}\left(\mathrm{F}_{\mathrm{i}} \mathrm{h}_{\mathrm{i}}\right) \Delta_{\mathrm{p}}$

$\mathrm{W}_{\mathrm{int}, \mathrm{se}}=\sum_{\mathrm{i}}^{\mathrm{n}} 2\left(\beta_{\mathrm{i}} \mathrm{N}_{\mathrm{BRKB}, \mathrm{n}}\right) \delta_{\mathrm{y}, \mathrm{BRKB}}$

where $\mathrm{N}_{\mathrm{BRKB}, \mathrm{n}}$ is the total yielding strength of BRKBs at the top story (level $\mathrm{n}$ ), and $\delta_{\mathrm{y}, \mathrm{BRKB}}$ is the yielding axial deformation of BRKBs as shown in equation (2.15).

$\delta_{\mathrm{y}, \mathrm{BRKB}}=\frac{\mathrm{D}_{\mathrm{x}} \mathrm{D}_{\mathrm{y}}}{l_{b}}\left(\Delta_{\mathrm{p}}\right)=l_{b} \sin \alpha \cos \alpha\left(\Delta_{\mathrm{p}}\right)$

where $l_{b}$ is the length of BRKBs, $\alpha$ is the BRKB vertical inclination angle, $\mathrm{D}_{\mathrm{x}}$ and $\mathrm{D}_{\mathrm{x}}$ are the horizontal and vertical length of BRKBs, respectively. 


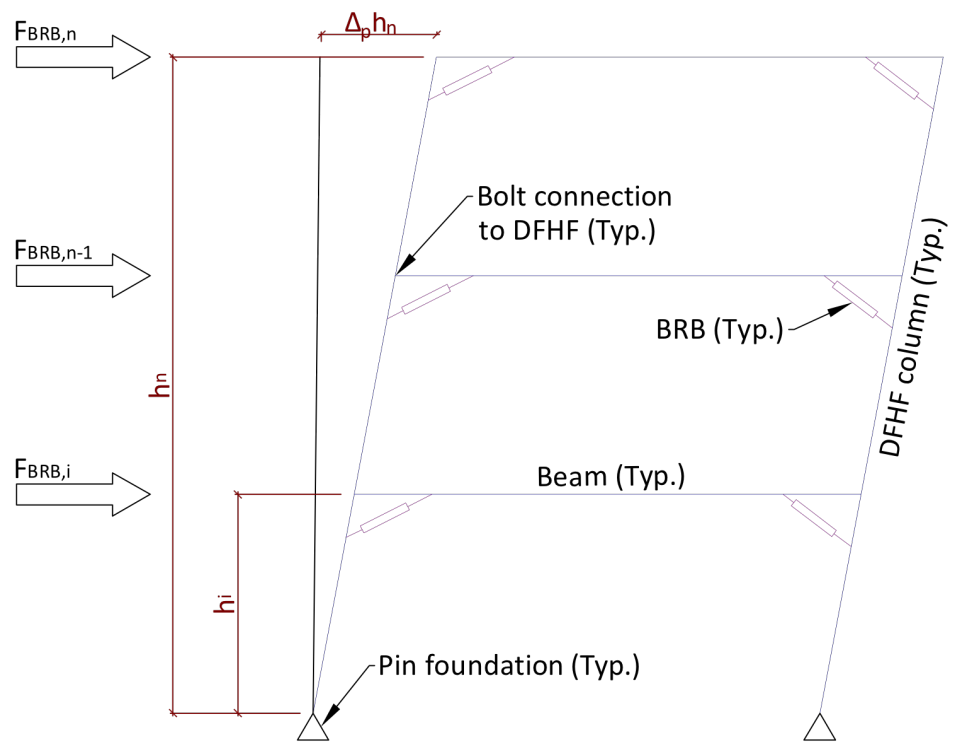

Figure 2.4 Secondary system yielding mechanism

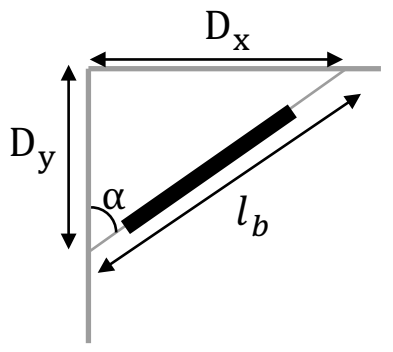

(a)

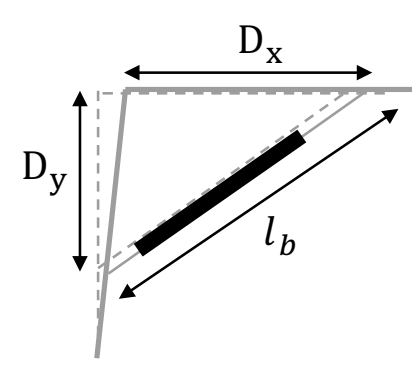

(b)

Figure 2.5 (a) undeformed and (b) deformed geometry of BRKBs

By rearranging equation (2.15) and substituting $\delta_{\mathrm{y}, \mathrm{BRKB}}=\varepsilon_{\mathrm{y}} l_{b}$, where $\varepsilon_{\mathrm{y}}$ is the BRKB yielding strain, $\alpha$ can be determined as shown in equation (2.16). Thus, when $\varepsilon_{\mathrm{y}}$ is defined by the BRB properties and when $\Delta_{\mathrm{p}}$ is selected by the engineer, the selection of $\alpha$ is restricted as shown in equation (2.16). Choosing other values for $\alpha$ will force the BRKBs to yield at different roof drifts other than $\Delta_{\mathrm{p}}$ which is not desired. 
$\alpha=0.5 \sin ^{-1} \frac{2 \varepsilon_{\mathrm{y}}}{\Delta_{\mathrm{p}}}$

Once $\alpha$ is determined, $\delta_{\mathrm{y}, \mathrm{BRKB}}$ can be calculated from equation (2.15). Having equation (2.13) equal to equation (2.14) and substituting $\delta_{\mathrm{y}, \mathrm{BRKB}}$ from equation (2.15) in equation (2.14), $\mathrm{N}_{\mathrm{BRKB}, \mathrm{n}}$ can be calculated as shown in equation (2.17).

$\mathrm{N}_{\mathrm{BRKB}, \mathrm{n}}=\frac{\sum_{\mathrm{i}}^{\mathrm{n}} \mathrm{F}_{\mathrm{i}} \mathrm{h}_{\mathrm{i}}}{2 \sum_{\mathrm{i}}^{\mathrm{n}} \beta_{\mathrm{i}} \times \frac{\mathrm{D}_{\mathrm{x}} \mathrm{D}_{\mathrm{y}}}{l_{b}}}$

Using the $\beta$ factor calculated from equation (2.7), the total yielding strength of BRKBs in other floors can be calculated using equation (2.18).

$N_{B R K B, i}=\beta_{i} N_{B R K B, n}$

It should be noted that $N_{B R K B, i}$ is the total yielding strength shared by multiple bays of BRKBs at each floor. To calculate the yielding strength for each BRKB, $N_{B R K B, i}$ should be divided by the number of bays of BRKBs.

\section{8) Design of non-yielding members}

After WWFFs and BRKBs are designed, H-Frames are capacity designed to remain elastic under the expected gravity loads and maximum probable forces created by the structural fuses. To determine the maximum probable force from WWFFs, the overstrength value presented by Yang et al. (2018a) is adopted in this thesis. For the maximum probable force from BRKBs, strain hardening, material overstrength, compression overstrength, and resistant factor as summarized in AISC 341 (AISC 2010) are employed. 


\section{Chapter 3: Prototype Buildings}

Two DFHF prototype office buildings of varying heights (3- and 9-story) are designed using the design procedure presented in chapter 2 for locations in San Francisco, CA, and Seattle, WA, respectively. This chapter summarizes the prototype buildings used in this study, including the seismic hazards, used ground motions and structural member sizes.

\subsection{Seismicity of Building Site}

San Francisco, CA, and Seattle, WA are both located in the "Pacific ring of fire", which is a belt of seismically active zones surrounding the Pacific Ocean. The site is dominated by potential ground motions generated from the Hayward fault, which is a strike-slip fault. The prototypes are assumed to be located on type C soil according to ASCE/SEI 7-10 (ASCE 2010). The MCE and DBE hazard intensities are selected as $2 \%$ and $10 \%$ probability of exceedance in 50 years, respectively (ASCE 2010). The SLE hazard intensity is selected as $1 / 5$ of the MCE intensity. Figures 3.1(a) and 3.1(b) show the three design hazard intensities for the locations in San Francisco, CA, and Seattle, WA, respectively. 


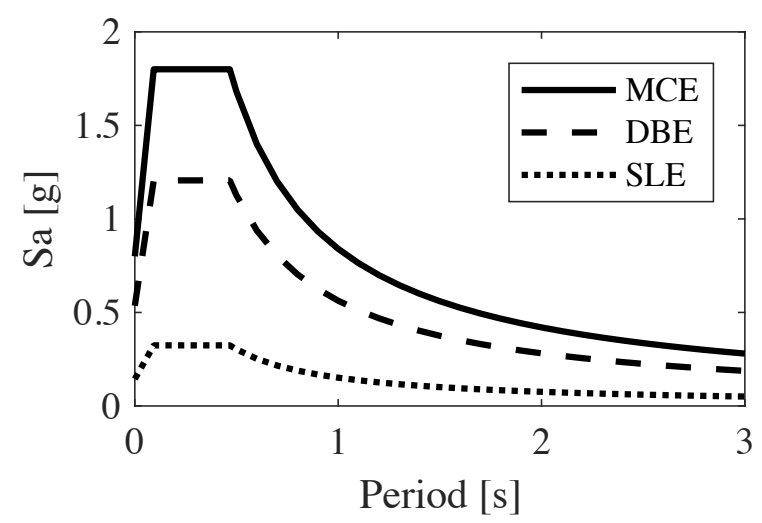

(a)

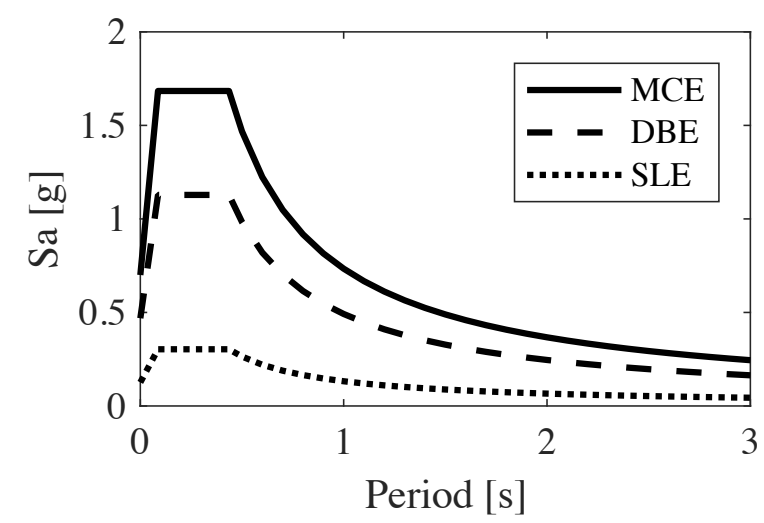

(b)

Figure 3.1. Design spectra for a) San Francisco, CA and b) Seattle, WA

\subsection{Ground Motion Selection}

A suite of the 22 far-field ground motion records identified by the FEMA P695 project (FEMA 2009) is used in this study. Table 3.1 presents the summary of the used ground motions. As presented in Figure 3.2, the records are amplitude scaled such that the median spectrum matches the target spectra of SLE, DBE and MCE hazard intensities within the period range of $0.2 \mathrm{~T}$ and $1.5 \mathrm{~T}$, where $\mathrm{T}$ is the fundamental period of the building. The shorter periods account for higher modes, and the longer periods account for period elongation due to fuse yielding. Tables A.1 and A. 2 present all the adopted scale factors for the 3 hazard intensities for both prototype buildings. 


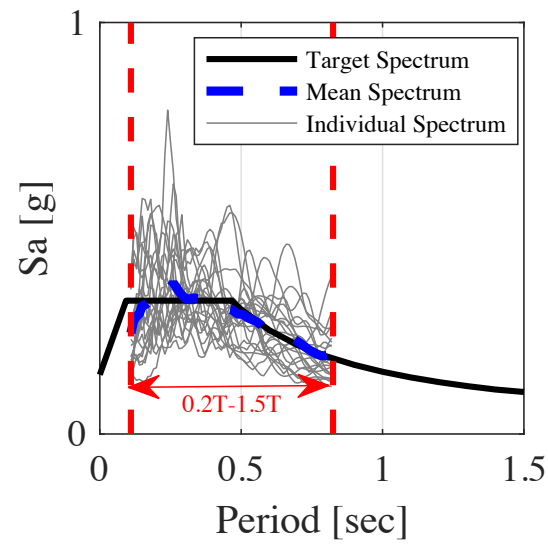

(a) SLE

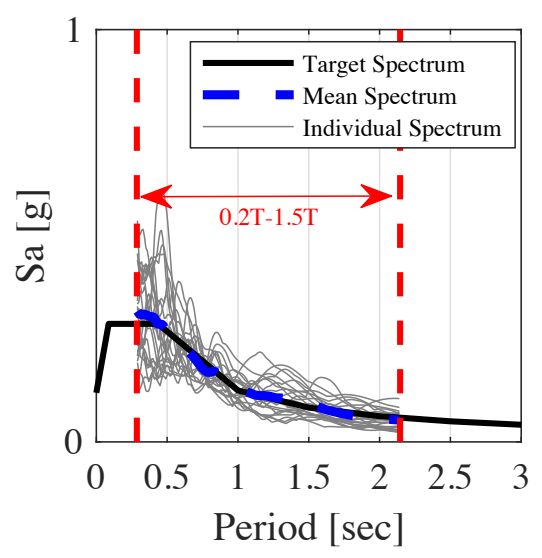

(d) SLE

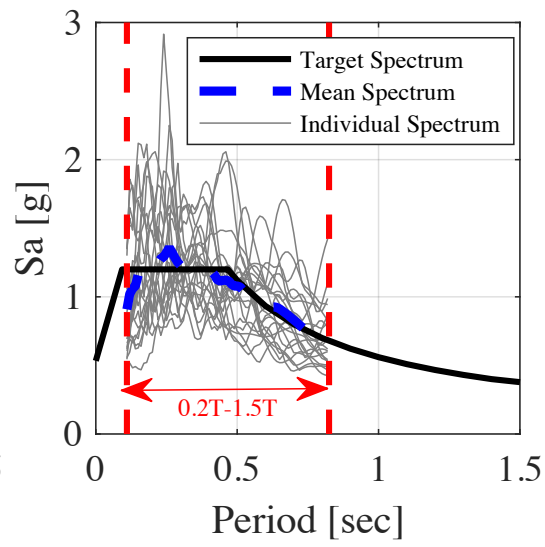

(b) $\mathrm{DBE}$

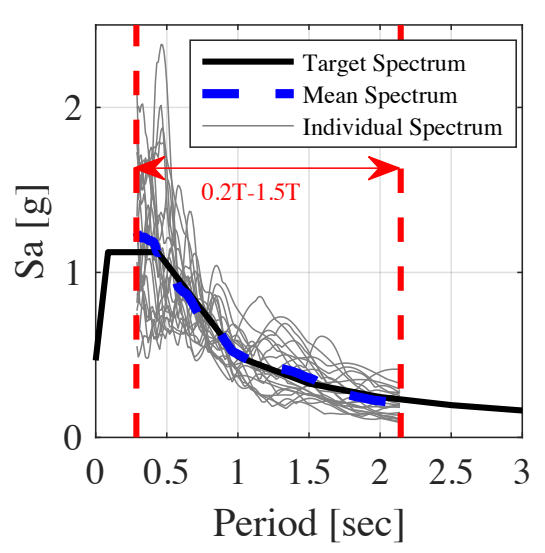

(e) DBE

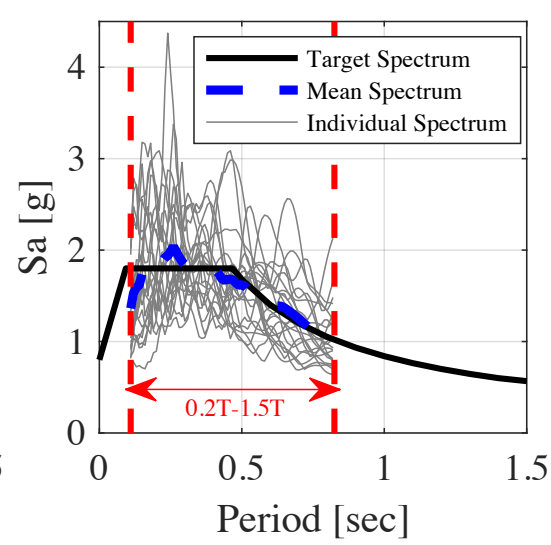

(c) $\mathrm{MCE}$

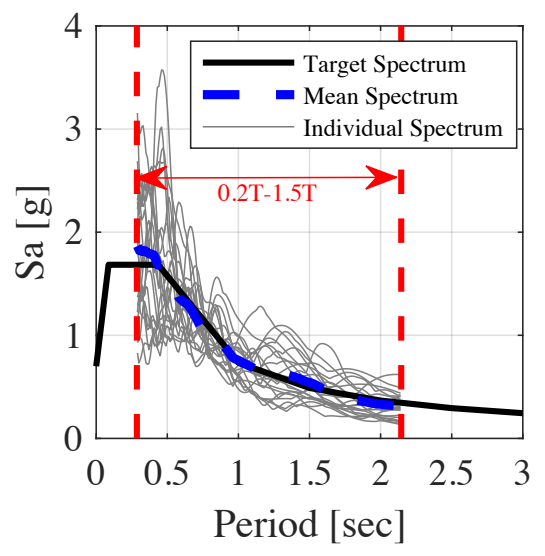

(f) MCE

Figure 3.2 Response spectra of scaled ground motion records for 3-story (a-b-c) and 9-story (d-e-f) prototype buildings 
Table 3.1 Record set information summary

\begin{tabular}{|c|c|c|c|c|c|c|}
\hline ID No. & Record Seq. No. & EQ name & Year & $\mathbf{M}_{\mathbf{w}}$ & PGA & $\mathrm{V}_{\mathrm{s}} 30[\mathrm{~m} / \mathrm{s}]$ \\
\hline 1 & 953 & Northridge & 1994 & 6.7 & 0.34 & 356 \\
\hline 2 & 960 & Northridge & 1994 & 6.7 & 0.4 & 309 \\
\hline 3 & 1602 & Duzce, Turkey & 1999 & 7.1 & 0.52 & 326 \\
\hline 4 & 1787 & Hector Mine & 1999 & 7.1 & 0.37 & 85 \\
\hline 5 & 169 & Imperial Valley & 1979 & 6.5 & 0.46 & 275 \\
\hline 6 & 174 & Imperial Valley & 1979 & 6.5 & 0.39 & 196 \\
\hline 7 & 1111 & Kobe, Japan & 1995 & 6.9 & 0.53 & 609 \\
\hline 8 & 1116 & Kobe, Japan & 1995 & 6.9 & 0.26 & 256 \\
\hline 9 & 1158 & Kocaeli, Turkey & 1999 & 7.5 & 0.25 & 276 \\
\hline 10 & 1148 & Kocaeli, Turkey & 1999 & 7.5 & 0.3 & 523 \\
\hline 11 & 900 & Landers & 1992 & 7.3 & 0.24 & 354 \\
\hline 12 & 848 & Landers & 1992 & 7.3 & 0.48 & 271 \\
\hline 13 & 752 & Loma Prieta & 1989 & 6.9 & 0.58 & 289 \\
\hline 14 & 767 & Loma Prieta & 1989 & 6.9 & 0.49 & 350 \\
\hline 15 & 1633 & Manjil, Iran & 1990 & 7.4 & 0.4 & 724 \\
\hline 16 & 721 & Superstition Hills & 1987 & 6.5 & 0.31 & 192 \\
\hline 17 & 725 & Superstition Hills & 1987 & 6.5 & 0.53 & 208 \\
\hline 18 & 829 & Cape Mendocino & 1992 & 7 & 0.45 & 312 \\
\hline 19 & 144 & Chi-Chi. Taiwan & 1999 & 7.6 & 0.18 & 259 \\
\hline 20 & 1485 & Chi-Chi. Taiwan & 1999 & 7.6 & 0.49 & 705 \\
\hline 21 & 68 & San Fernando & 1971 & 6.6 & 0.44 & 316 \\
\hline 22 & 125 & Friuli, Italy & 1976 & 6.5 & 0.5 & 425 \\
\hline
\end{tabular}




\subsection{Description of Prototype Building}

The overall building dimensions, story heights, story masses, and gravity loads are adopted from the 3- and 9-story SAC buildings (Gupta \& Krawinkler 2000). To maintain the overall plan dimensions of the SAC buildings, the original bay width is decreased to accommodate WWFF link bays. The 3-story building has 4 bays of H-Frames with 3 link bays, while the 9-story building has 5 bays of H-Frames with 4 link bays. Figure 3.3 shows the elevation and plan of the prototype buildings. Due to double axis symmetry, the seismic responses in the orthogonal directions are expected to be identical. Hence, only the analyses of one direction is presented in this thesis. To avoid the design of the corner column in the 9-story building, a one foot offset from each side is provided (Figure $(\mathrm{d}))$.

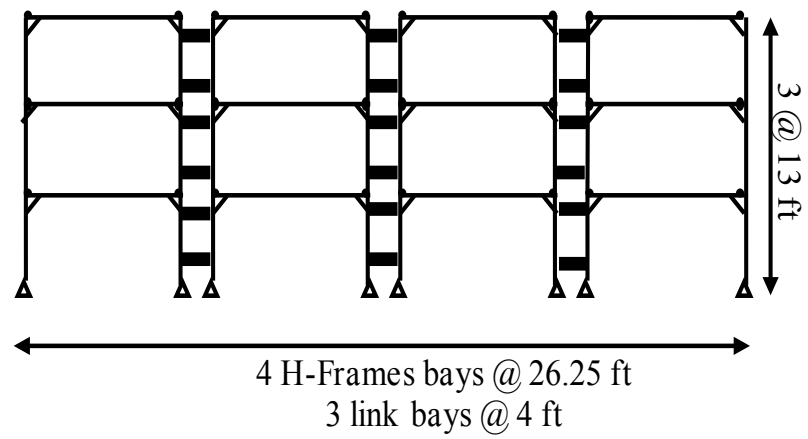

(a) 


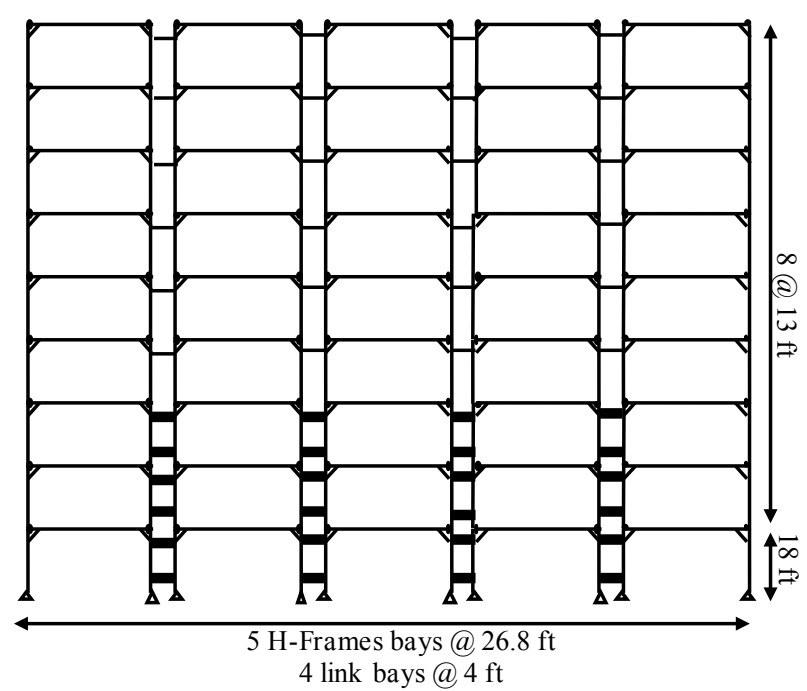

(b)

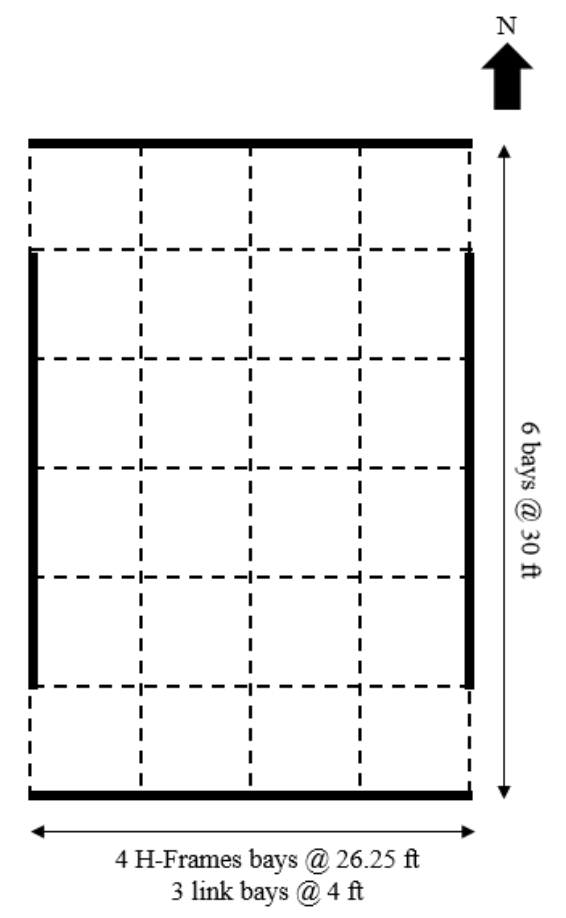

(c) 


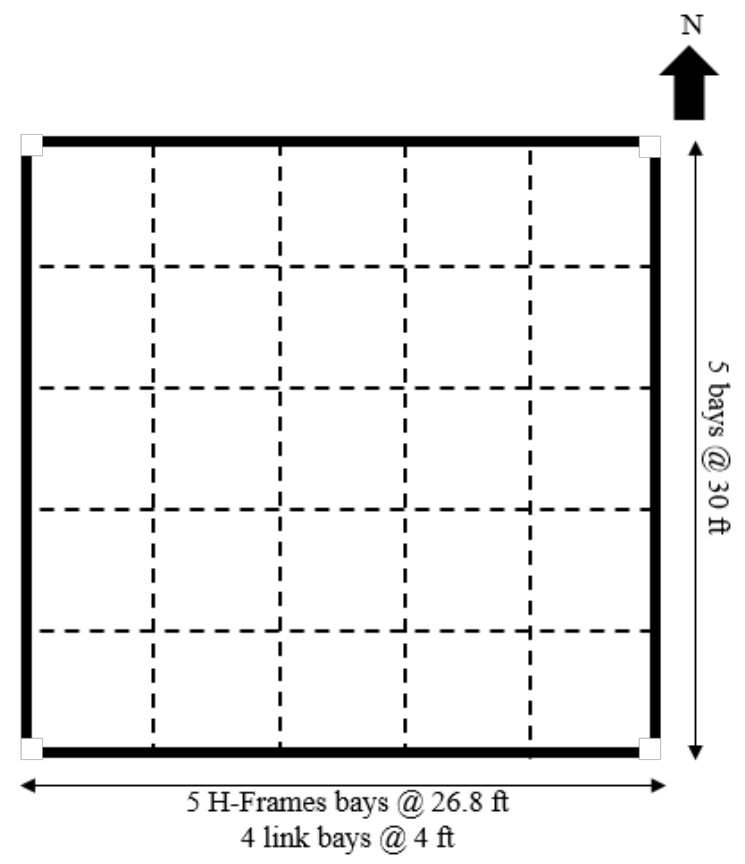

(d)

Figure 3.3 Elevation and plan of prototype buildings

\subsection{Design Demonstration}

Table 3.2 presents the EEDP design parameters for the two prototype buildings. The values for $\Delta_{\mathrm{y}}$ are calculated based on the building geometries using equation (2.1). Since $\Delta_{\mathrm{p}}$ is related to the BRKB's vertical inclination angle ( $\alpha$ ) (equation (2.16)), engineers can choose either $\Delta_{\mathrm{p}}$ or $\alpha$ during the design process. In this study, $\Delta_{\mathrm{p}}$ is selected and then $\alpha$ is calculated to be $80^{\circ}$ and $75^{\circ}$ for the 3- and 9-story buildings, respectively. $\mathrm{C}_{0}$ is selected based on the recommendations from ASCE 41 (2006). $\gamma_{a}$ and $\gamma_{b}$ are the incremental energy modification factors obtained from Yang et al. (2017).

Using the EEDP presented in chapter 2 and input parameters from Table 3.2, Tables 3.3 and 3.4 are obtained to present the design of the structural fuses and H-Frames, respectively. Noted 
that WWFFs are placed throughout the height of the 3-story building (Figure (a)). To be efficient, the 9-story building only employs WWFFs at the first three floors. Pin connected rigid links are utilized to connect the Damped H-Frames at the top six floors (Figure (b)).

It should be noted that axial load demands in the columns of the DFHF are large and care will be necessary in designing the foundation's system. However, this is a concern with many steel braced frame and steel shear walls systems and must be weighed relative to performance goals and life cycle costs.

Table 3.2 Summary of EEDP design parameters

\begin{tabular}{|c|c|c|c|c|c|c|}
\hline Building & $\Delta_{\mathrm{y}}[\%]$ & $\Delta_{\mathrm{p}}[\%]$ & $\Delta_{\mathrm{u}}[\%]$ & $\mathrm{C}_{0}[-]$ & $\gamma_{a}[-]$ & $\gamma_{b}[-]$ \\
\hline 3-story & 0.15 & 0.9 & 1.8 & 1.3 & 1.25 & 1.15 \\
\hline 9-story & 0.15 & 0.45 & 1.2 & 1.5 & 1.51 & 2.18 \\
\hline
\end{tabular}

Table 3.3 Summary of structural fuses

\begin{tabular}{c|c|c|c|c|c|c|c|c|c|c}
\hline \multicolumn{1}{|c|}{ WWFF yielding force [kips] } \\
\hline Building & Floor1 & Floor2 & Floor3 & Floor4 & Floor5 & Floor6 & Floor7 & Floor8 & Floor9 \\
\hline 3-story & 740 & 633 & 412 & & & & & & \\
\hline 9-story & 666 & 653 & 629 & & & & & & \\
\hline \multicolumn{7}{|c|}{ BRKB yielding force [kips] } \\
\hline Building & Floor1 & Floor2 & Floor3 & Floor4 & Floor5 & Floor6 & Floor7 & Floor8 & Floor9 \\
\hline 3-story & 250 & 214 & 139 & & & & & & \\
\hline 9-story & 381 & 373 & 360 & 341 & 315 & 282 & 241 & 190 & 123 \\
\hline
\end{tabular}


Table 3.4 Summary of H-Frames

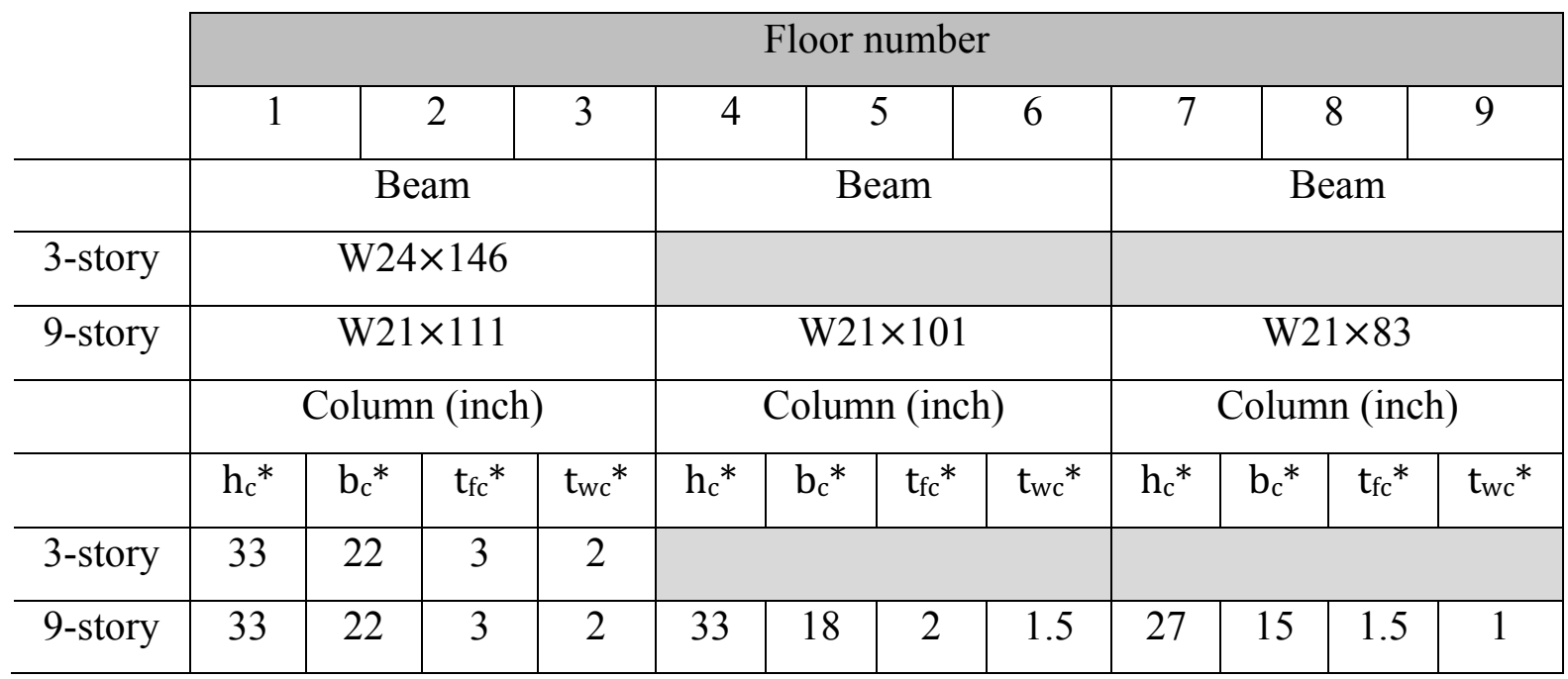

$* h_{c}$ is the column height, $b_{c}$ is the column width, $t_{f c}$ is the flange thickness, and $t_{w c}$ is the web thickness. 


\section{Chapter 4: Analytical Modeling}

This chapter presents the analytical modeling method used in this thesis. The experimental tests of WWFF and BRB used in this study are introduced and calibrated with numerical models. This chapter also describes the advanced element removal technique to simulate the WWFF and BRB factures and force redistribution in the building. Finally, the finite element modeling of the EEDP designed prototype buildings is also described.

\subsection{Experimental Test of WWFF}

Welded Wide Flange Fuse (WWFF) was originally proposed by (Yang et al. 2018a). The web of WWFF is designed to yield thorough shear loading in longitudinal direction, while the flanges are designed to remain elastic. The use of welded wide flange sections makes the WWFF very stiff and efficient in dissipating the earthquake energy, where WWFF can be used as a cost effective and efficient metallic damper. WWFF was experimentally tested with cyclic loading at the Structural Engineering Laboratory at the University of British Columbia, Vancouver, Canada (Yang et al. 2018a). The test setup, as shown is Figure 4.1(a), was designed to shear the WWFF in pure shear in the longitudinal direction without in-plan rotation and out-of-plan deformation. The AISC 341-16 (AISC 2016) loading protocol for beam-to-column connections with minor modification was applied to the test and shown in Figure 4.1(b). Table 4.1 and Figure 4.1(c) show the geometry of the 8 tested specimens and the notation used for the WWFF, respectively. Aspect ratio $(A)$ is defined as the ratio of the web height $(a)$ to the clear length of the web $\left(D^{\prime}\right)$, where the slenderness ratio $(S)$ is the ratio of $D^{\prime}$ to the web thickness $\left(t_{w}\right)$. It should be noted that all 
specimens were made from A36 steel plates. Several key parameters such as the yielding force $\left(V_{y}\right)$, yielding drift $\left(\gamma_{y}\right)$, ultimate force $\left(V_{u}\right)$, ultimate drift ratio $\left(\gamma_{u}\right)$ were obtained from the experimental results and presented in Table 4.2

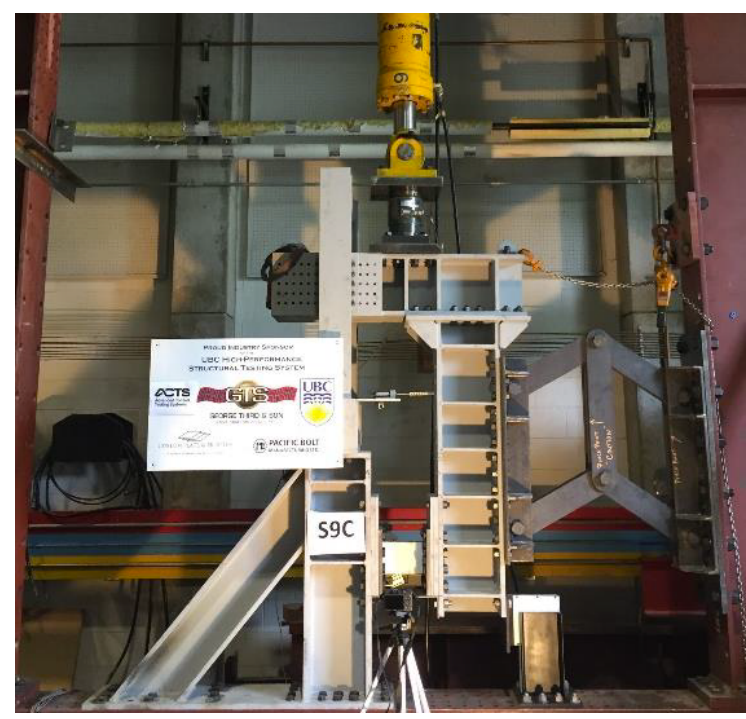

(a) (Yang et al. 2018a).

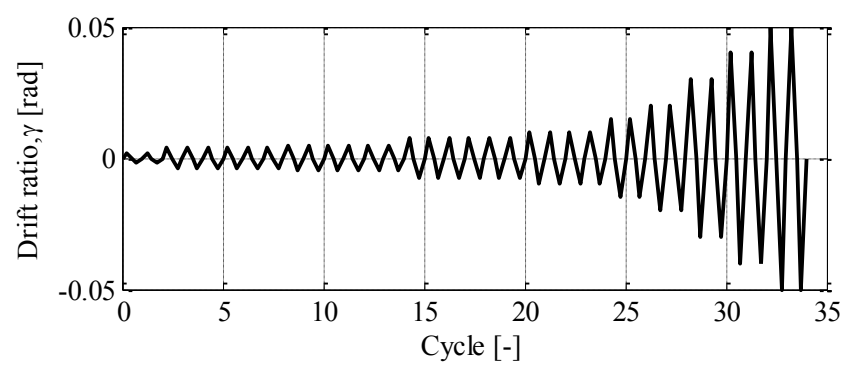

(b)

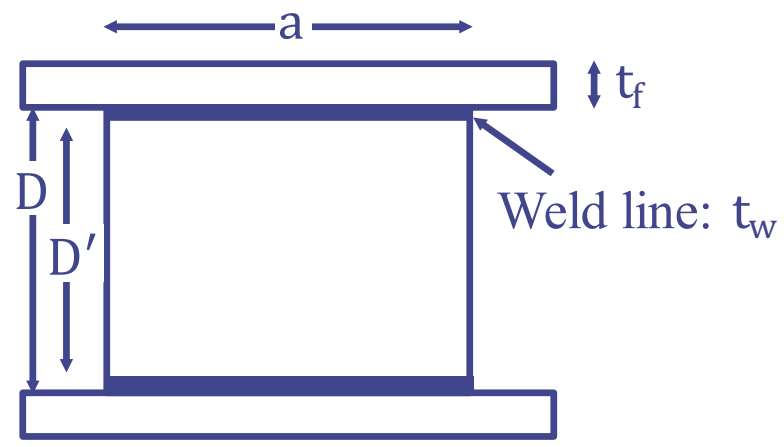

(c)

Figure 4.1 (a) Experimental setup, (b) loading protocol, and (c) notation for WWFF 
Table 4.1 Summary of test specimens

\begin{tabular}{|c|c|c|c|c|c|c|}
\hline \multirow{3}{*}{ Specimen } & $\begin{array}{l}\text { Web } \\
\text { Thk }\end{array}$ & $\begin{array}{c}\text { Web } \\
\text { height }\end{array}$ & $\begin{array}{l}\text { Web } \\
\text { length }\end{array}$ & $\begin{array}{c}\text { Web } \\
\text { net length }\end{array}$ & $S$ & $\boldsymbol{A}$ \\
\hline & $t_{w}$ & $a$ & $D$ & $D^{\prime}=D-2 t_{w}$ & \multirow{2}{*}{$\frac{D^{\prime}}{t_{w}}$} & \multirow{2}{*}{$\frac{a}{D^{\prime}}$} \\
\hline & {$[\mathrm{mm}]$} & {$[\mathrm{mm}]$} & {$[\mathbf{m m}]$} & [mm] & & \\
\hline A0.75S 22 & 4.8 & 78.6 & 114.3 & 104.8 & 22.0 & 0.75 \\
\hline $\mathrm{A} 1.5 \mathrm{~S} 22$ & 4.8 & 157.2 & 114.3 & 104.8 & 22.0 & 1.50 \\
\hline A2S22 & 4.8 & 209.6 & 114.3 & 104.8 & 22.0 & 2.00 \\
\hline A0.75S32 & 4.8 & 114.3 & 161.9 & 152.4 & 32.0 & 0.75 \\
\hline $\mathrm{A} 1.5 \mathrm{~S} 32$ & 4.8 & 228.6 & 161.9 & 152.4 & 32.0 & 1.50 \\
\hline $\mathrm{A} 2 \mathrm{~S} 32$ & 4.8 & 304.8 & 161.9 & 152.4 & 32.0 & 2.00 \\
\hline A0.75S43 & 4.8 & 152.4 & 212.7 & 203.2 & 42.7 & 0.75 \\
\hline A $1.5 \mathrm{~S} 43$ & 4.8 & 304.8 & 212.7 & 203.2 & 42.7 & 1.50 \\
\hline
\end{tabular}

Table 4.2 Summary of test results

\begin{tabular}{|c|c|c|c|c|c|c|c|c|}
\hline \multirow{3}{*}{ Specimen } & $\begin{array}{l}\text { Web } \\
\text { Thk }\end{array}$ & $\begin{array}{c}\text { Web } \\
\text { height }\end{array}$ & $\begin{array}{l}\text { Web } \\
\text { length }\end{array}$ & $\begin{array}{c}\text { Web } \\
\text { net length }\end{array}$ & $S$ & $\boldsymbol{A}$ & $\begin{array}{c}\text { Flange } \\
\text { Thk }\end{array}$ & \multirow{3}{*}{$\begin{array}{c}\text { Flange } \\
\text { type }\end{array}$} \\
\hline & $t_{w}$ & $a$ & $D$ & $D^{\prime}=D-2 t_{w}$ & \multirow{2}{*}{$\frac{D^{\prime}}{t_{w}}$} & \multirow{2}{*}{$\frac{a}{D^{\prime}}$} & $t_{f}$ & \\
\hline & {$[\mathrm{mm}]$} & {$[\mathrm{mm}]$} & {$[\mathrm{mm}]$} & {$[\mathrm{mm}]$} & & & {$[\mathbf{m m}]$} & \\
\hline $\mathrm{A} 0.75 \mathrm{~S} 22$ & 4.8 & 78.6 & 114.3 & 104.8 & 22.0 & 0.75 & 19 & B \\
\hline A0.75S22-1.3 & 6.4 & 104.8 & 152.4 & 139.7 & 22.0 & 0.75 & 19 & B \\
\hline A0.75S22-2 & 9.5 & 157.2 & 228.6 & 209.6 & 22.0 & 0.75 & 25 & A \\
\hline $\mathrm{A} 1.5 \mathrm{~S} 22$ & 4.8 & 157.2 & 114.3 & 104.8 & 22.0 & 1.50 & 19 & B \\
\hline A2S22 & 4.8 & 209.6 & 114.3 & 104.8 & 22.0 & 2.00 & 19 & $\mathrm{~A}$ \\
\hline A0.75S 32 & 4.8 & 114.3 & 161.9 & 152.4 & 32.0 & 0.75 & 19 & B \\
\hline $\mathrm{A} 1.5 \mathrm{~S} 32$ & 4.8 & 228.6 & 161.9 & 152.4 & 32.0 & 1.50 & 19 & A \\
\hline A2S32 & 4.8 & 304.8 & 161.9 & 152.4 & 32.0 & 2.00 & 25 & $\mathrm{~A}$ \\
\hline A0.75S43 & 4.8 & 152.4 & 212.7 & 203.2 & 42.7 & 0.75 & 19 & B \\
\hline A $1.5 \mathrm{~S} 43$ & 4.8 & 304.8 & 212.7 & 203.2 & 42.7 & 1.50 & 25 & $\mathrm{~A}$ \\
\hline
\end{tabular}




\subsection{Numerical Modeling of WWFF}

In this thesis, a simple macro model, as shown in Figure 4.2(a), is developed to accurately simulate the key characteristics of WWFF hysteretic response in OpenSees platform (PEER 2000). This macro model contains two nodes which are connected to each other using a twonodelink element. To properly capture the force-deformation response, a suitable material model should be selected for the numerical simulation. As it was shown in Yang et al. (2018a), WWFFs exhibit a pinched response at the transition between cycles, thus traditional elastic-plastic or other simple hysteresis models, such as Stee102, which cannot simulate pinching, are not appropriate. Therefore, the Pinching4 material model (Mitra and Lowes 2007), as shown in Figure 4.2(b), is employed to simulate the hysteresis behavior of WWFF. The material model is assigned to the element's second degree-of-freedom, as shown in Figure 4.2(a), to properly simulate the WWFF force-deformation relationship. The Pinching4 model has 22 parameters including the backbone points (16 parameters) and 6 other parameters defining the unload-reload path, stiffness and strength loss under cyclic loading. These parameters (rDispP, rForceP, uForceP, rDispN, rForceN and uForceN) are based upon ratios of deformation (Disp) or force (Force) to maximum (P) or minimum (N) historic demands at various points in the unloading (u) reloading (r) curve. 


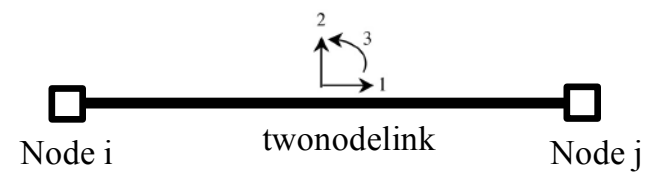

(a)

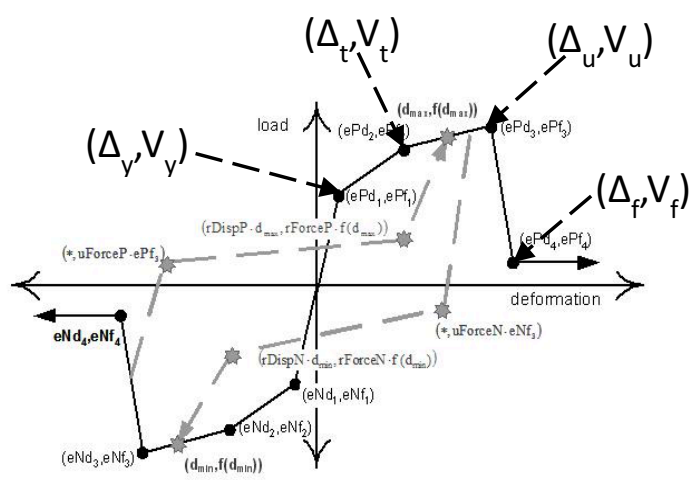

(b) (Mitra and Lowes 2007)

Figure 4.2 (a) WWFF macro model and (b) Pinching4 material model

The initial step in this modeling approach is to determine the force-displacement backbone relationship. The Pinching 4 backbone curve is characterized by a total of 8 points, 4 positive and 4 negative. It was shown that WWFF has a symmetric behavior in positive and negative deformations (Yang et al. 2018a). Thus, only 4 points, Yield $\left(\Delta_{y}, V_{y}\right)$, transition $\left(\Delta_{t}, V_{t}\right)$, ultimate $\left(\Delta_{\mathrm{u}}, \mathrm{V}_{\mathrm{u}}\right)$ and fracture $\left(\Delta_{\mathrm{f}}, \mathrm{V}_{\mathrm{f}}\right)$, are required to be calculated to determine the backbone curve. In the following paragraphs these 4 points are explained in details.

\section{Yield point $\left(\Delta_{y}, V_{y}\right)$ :}

The first point on the backbone is where WWFF starts to yield and becomes nonlinear. To quantify the yield drift of WWFF, a simple equation is derived based on the first principal and shown in equation (4.1).

$\mathrm{G}=\frac{\tau_{\mathrm{xy}}}{\gamma_{\mathrm{xy}}}=\frac{\frac{\left(0.6 \mathrm{at}_{\mathrm{w}} \sigma_{\mathrm{y}}\right)}{\left(\mathrm{at}_{\mathrm{w}}\right)}}{\frac{\Delta_{\mathrm{y}}}{\mathrm{D} \prime}}=\frac{\left(0.6 \mathrm{at}_{\mathrm{w}} \sigma_{\mathrm{y}}\right) \mathrm{D} \prime}{\mathrm{at}_{\mathrm{w}} \Delta_{\mathrm{y}}} \rightarrow \frac{\Delta_{\mathrm{y}}}{\mathrm{D} \prime}=\frac{0.6 \sigma_{\mathrm{y}}}{\mathrm{G}}$ 
where $\mathrm{G}$ is shear modulus or modulus of rigidity; $\tau_{\mathrm{xy}}$ is shear stress ; $\gamma_{\mathrm{xy}}$ is shear strain; $\sigma_{\mathrm{y}}$ is the yield stress; $\Delta_{\mathrm{y}}$ is the yield displacement.

As it is illustrated in equation (4.1), the yield drift ratio is dependent to the steel properties and independent to the fuse geometry. This independency enables the engineers to calculate the yield drift ratio prior to any design and sizing. Based on the derived equation, for the typical steel properties $\left(\sigma_{\mathrm{y}}=41 \mathrm{ksi} \mathrm{G}=10900 \mathrm{ksi}\right)$, the WWFF's yielding drift equals to $0.23 \%$ regardless its geometry. The experimental results conducted by Yang et al. (2018a) also showed that the yielding drift for WWFF is about $0.23 \%$.

WWFF yield force is calculated using equation (4.2), which incorporates both shear and flexural deformations (Yang et al. 2018a). As it was stated earlier, WWFF is aimed to yield through shear in the longitudinal direction. However, due to the fixed connection between the flanges and the web, this fuse dissipates the earthquake energy by a combination of flexure and shear yielding of the web. Therefore, the commonly used shear force equation $\left(\mathrm{V}_{\mathrm{p}}=0.6 \mathrm{at}{ }_{\mathrm{w}} \sigma_{\mathrm{y}}\right)$ which considers pure shear only, is not accurate.

$V_{\mathrm{y}}=\sqrt{\frac{4 \mathrm{t}_{\mathrm{w}}{ }^{2} \mathrm{a}^{4}}{9 \mathrm{D}^{\prime 2}+12 \mathrm{a}^{2}}} \sigma_{\mathrm{y}}$

\section{Transition $\left(\Delta_{i} V\right)$, ultimate $\left(\Delta_{u}, V_{u}\right)$ and fracture $\left(\Delta_{f} V\right)$ points:}

To derive equations for the other 3 backbone points, WWFF hysteretic experimental results are employed. Three backbone points are selected from each of the 8 specimens' hysteresis responses, based upon capturing the overall shape of backbone curve. These points and 3 pairs of 
equations which are derived based on fitting a linear line into the data points are shown in Figure 4.3. For ease of presentation, where these trends can be used simply by the engineers, proposed equations are normalized using the yield drift and the yield force. It should be noted that Figures 4.3(e) and 4.3(f) have only 6 points (instead of 8). This is because the experimental test was stopped for the 2 of the specimens with $S$ equals to 43 ; thus, they are not used for generating the equations for the fracture point. As it is illustrated in Figure 4.3, the backbone points are less sensitive to $A$. That is why the proposed equations are only in terms of $S$. It should be noted that the proposed equations are only effective for WWFF with $S$ between 20-45.

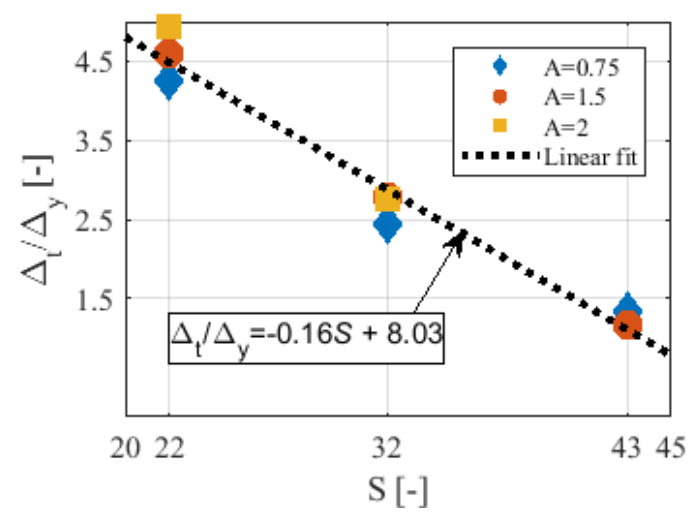

(a)

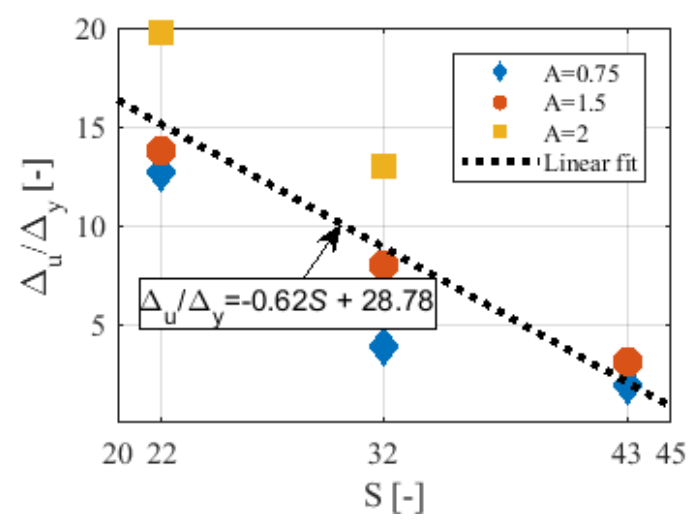

(c)

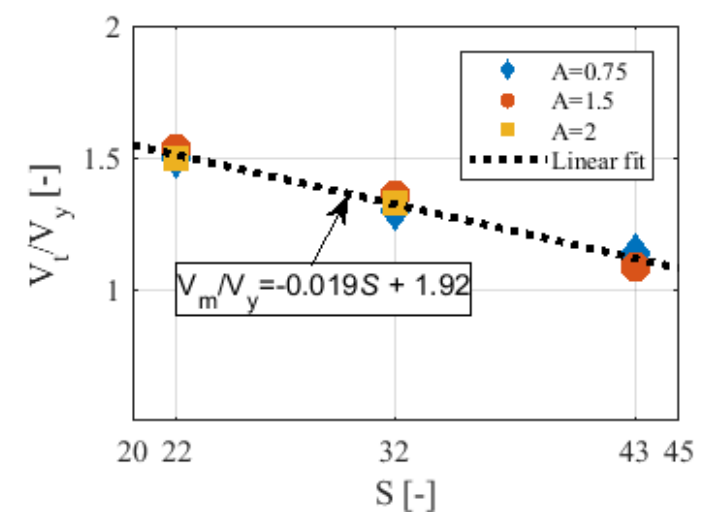

(b)

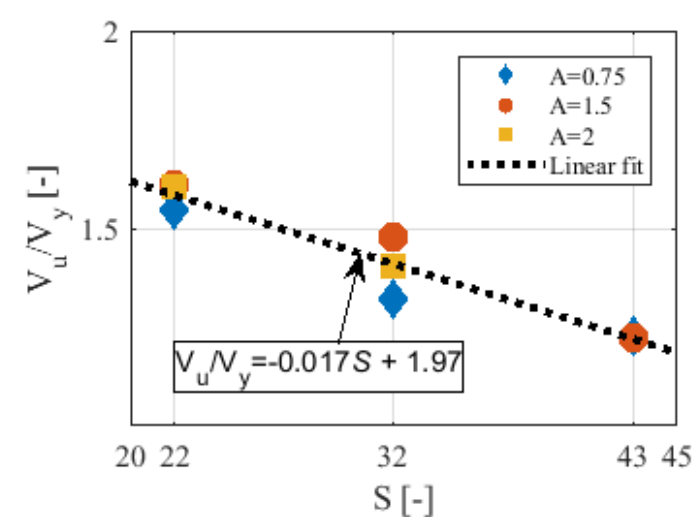

(d) 


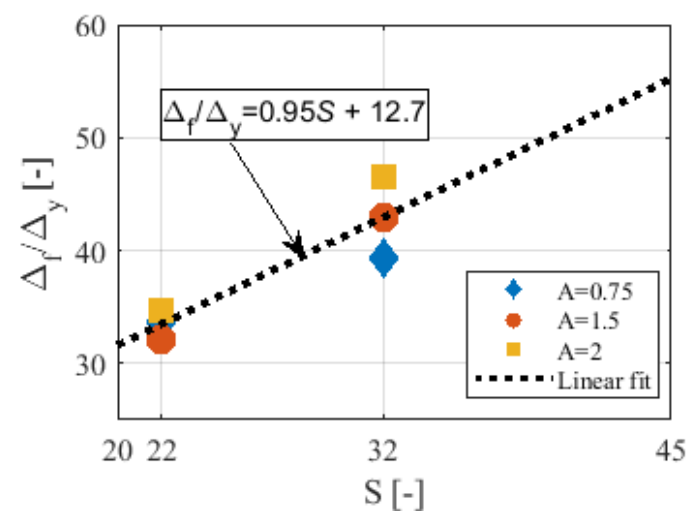

(e)

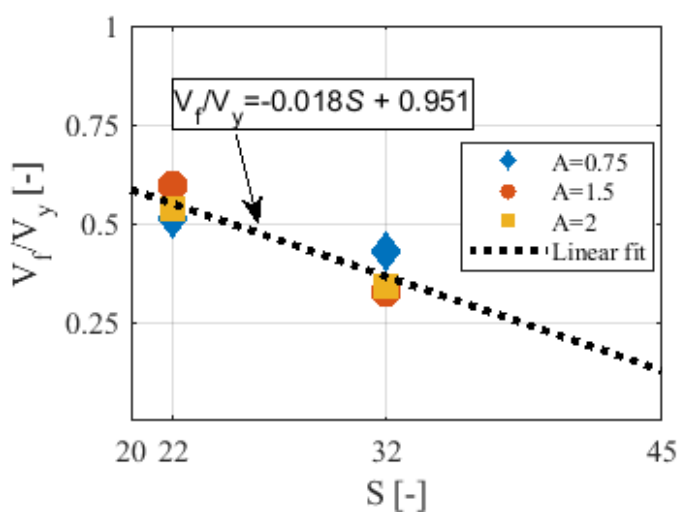

(f)

Figure 4.3 Transition point (a) displacement and (b) force; ultimate point (c) displacement and (d) force; fracture point (e) displacement and (f) force

\section{Parameter calibration:}

After determining the 4 backbone points, a calibration procedure is executed for one of the tested specimens, $A 1.5 S 32$, to determine the 6 aforementioned pinching parameters. The proposed macro model is created in OpenSees and same loading protocol of the experimental program, as presented in the Figure 4.1(b), is used for the numerical simulation. The pinching parameters, as listed in Table 4.3, are iterated to fit the pre-peak load-deformation responses. Figure 4.4 presents the comparison of the force-deformation relationship of the WWFF from the experimental result and OpenSees numerical simulation for A1.5S32 specimen. The result indicates that the proposed macro model in OpenSees can simulate very well the force-deformation response of the WWFF. 
Table 4.3 Calibrated pinching parameters

\begin{tabular}{|c|c|c|c|c|c|}
\hline rDispP & rForceP & uForceP & rDispN & rForceN & uForceN \\
\hline-0.35 & 0.85 & 0.3 & -0.5 & 0.9 & -0.4 \\
\hline
\end{tabular}

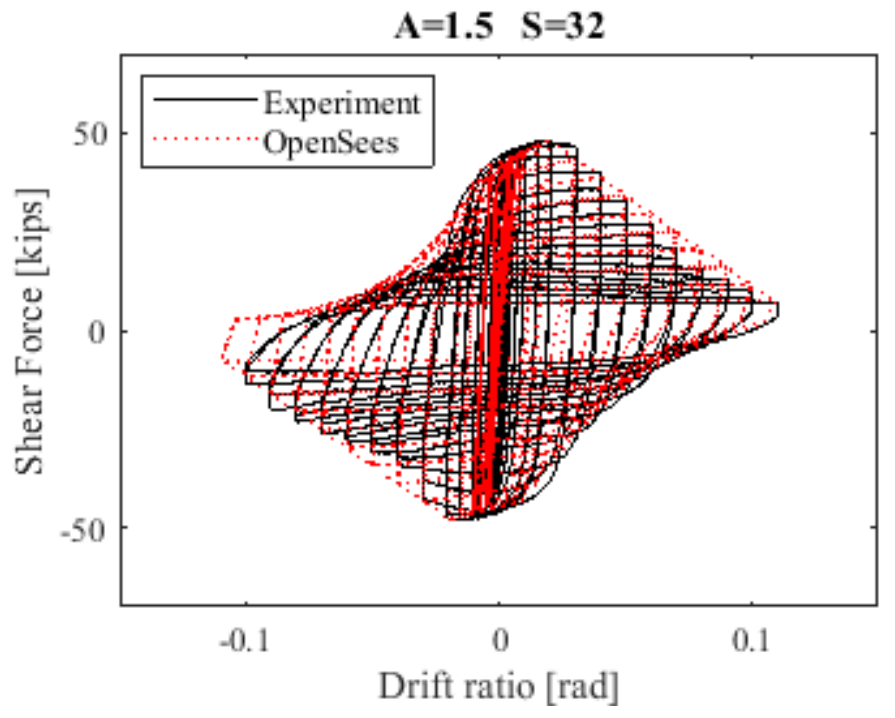

Figure 4.4 Comparison of WWFF force-deformation in OpenSees simulations and experiment results for

$\mathrm{A} 1.5 \mathrm{~S} 32$

To further validate the proposed macro model, hysteretic behavior of the other 7 specimens are also simulated. The backbone points are calculated using the proposed equations, shown in Figure 4.3, and pinching parameters are employed from Table 4.3. Figure 4.5 illustrates the comparison of the force-deformation relationship of the WWFF from the experimental results and OpenSees numerical simulation for the other 7 specimens. This comparison establishes the accuracy and reliability of the developed macro model including the proposed equations and the pinching parameters. 

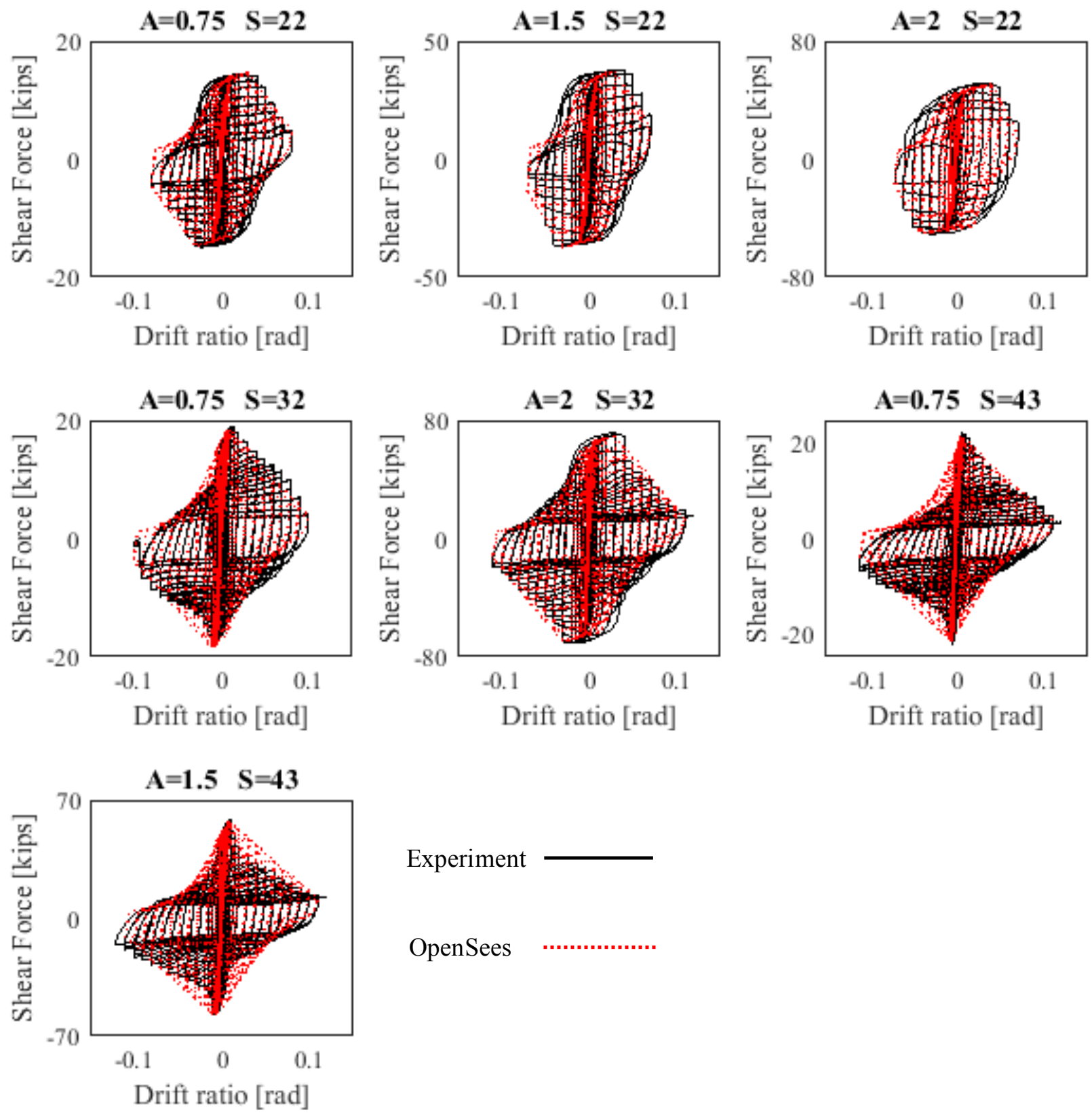

Experiment

OpenSees

Figure 4.5 Comparison of the WWFF force-deformation relationship from the experimental results and OpenSees numerical simulations for 7 test specimens 


\subsection{Validation of WWFF Numerical Model}

The proposed macro model is developed based on a limited number of specimens tested with only 3 different variations of $S$ and $A$. Thus, the model should be further validated with a wider range of $S$ and $A$ to generally validate its application. In this study, the proposed model is validated with an ABAQUS finite element model, developed by Yang et al. (2018a), for a broader range of $S$ and $A$. For each finite element model with specific $S$ and $A$, the points on the backbone curve are calculated using the proposed equations and same calibrated pinching parameters are employed. Figure 4.4 shows the comparison of the force-deformation relationship of the WWFF from finite element models in ABAQUS and OpenSees. The result indicates that the proposed macro model in OpenSees can simulate the force-deformation response of the WWFF very well.
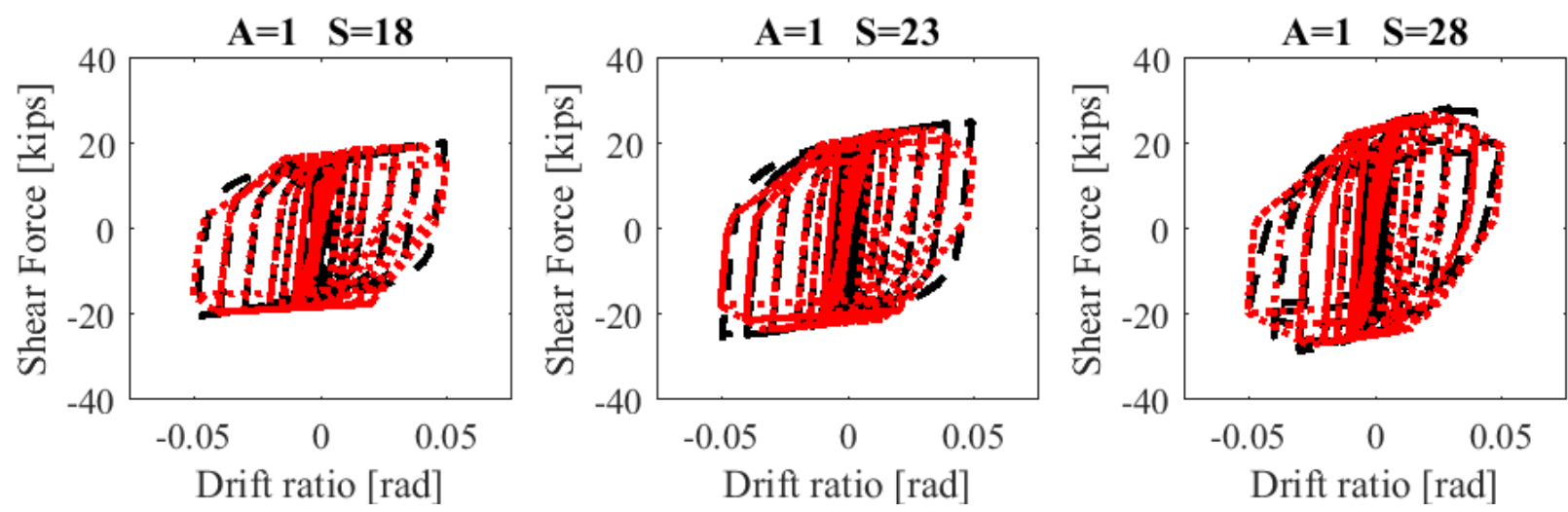

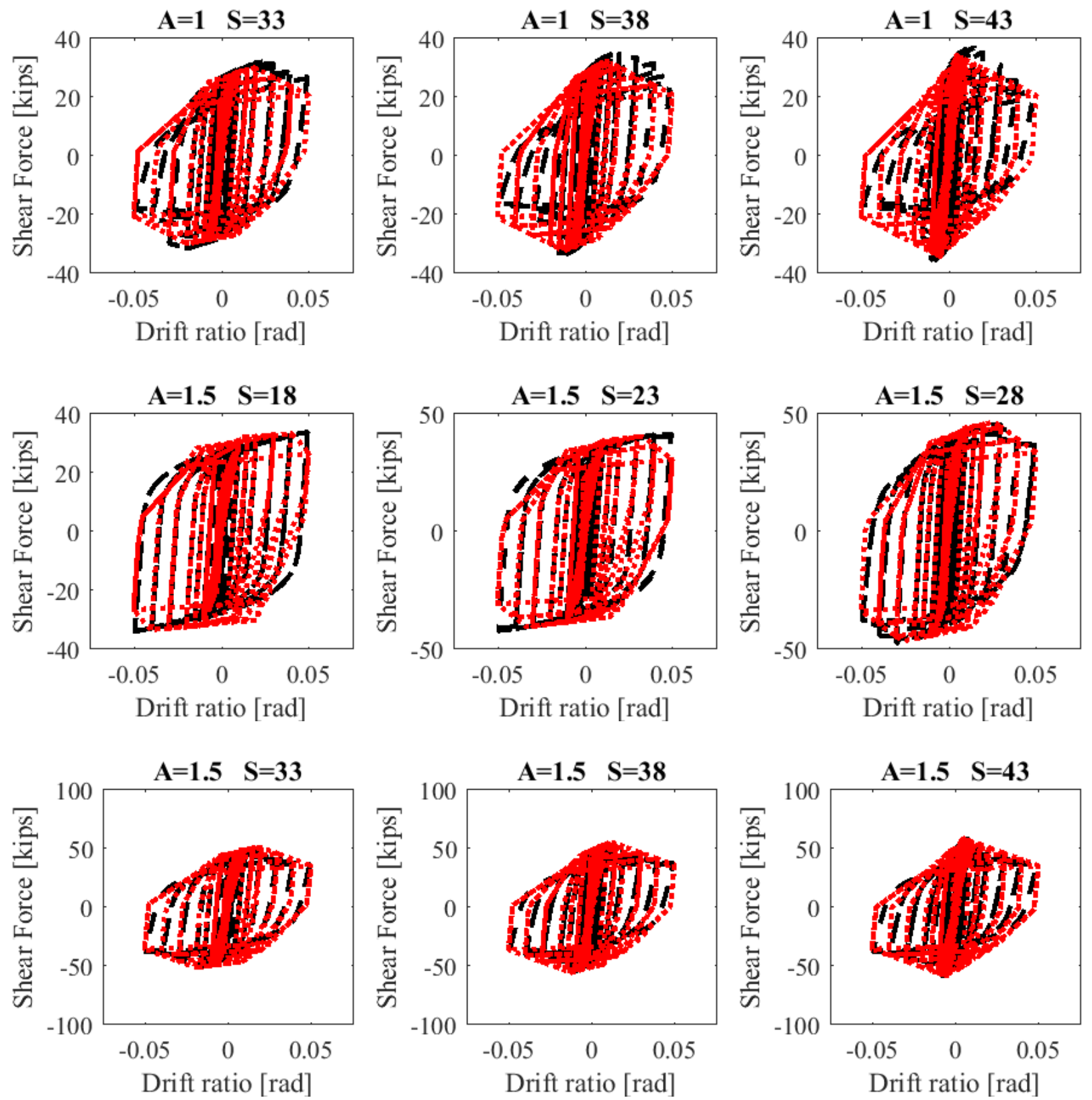

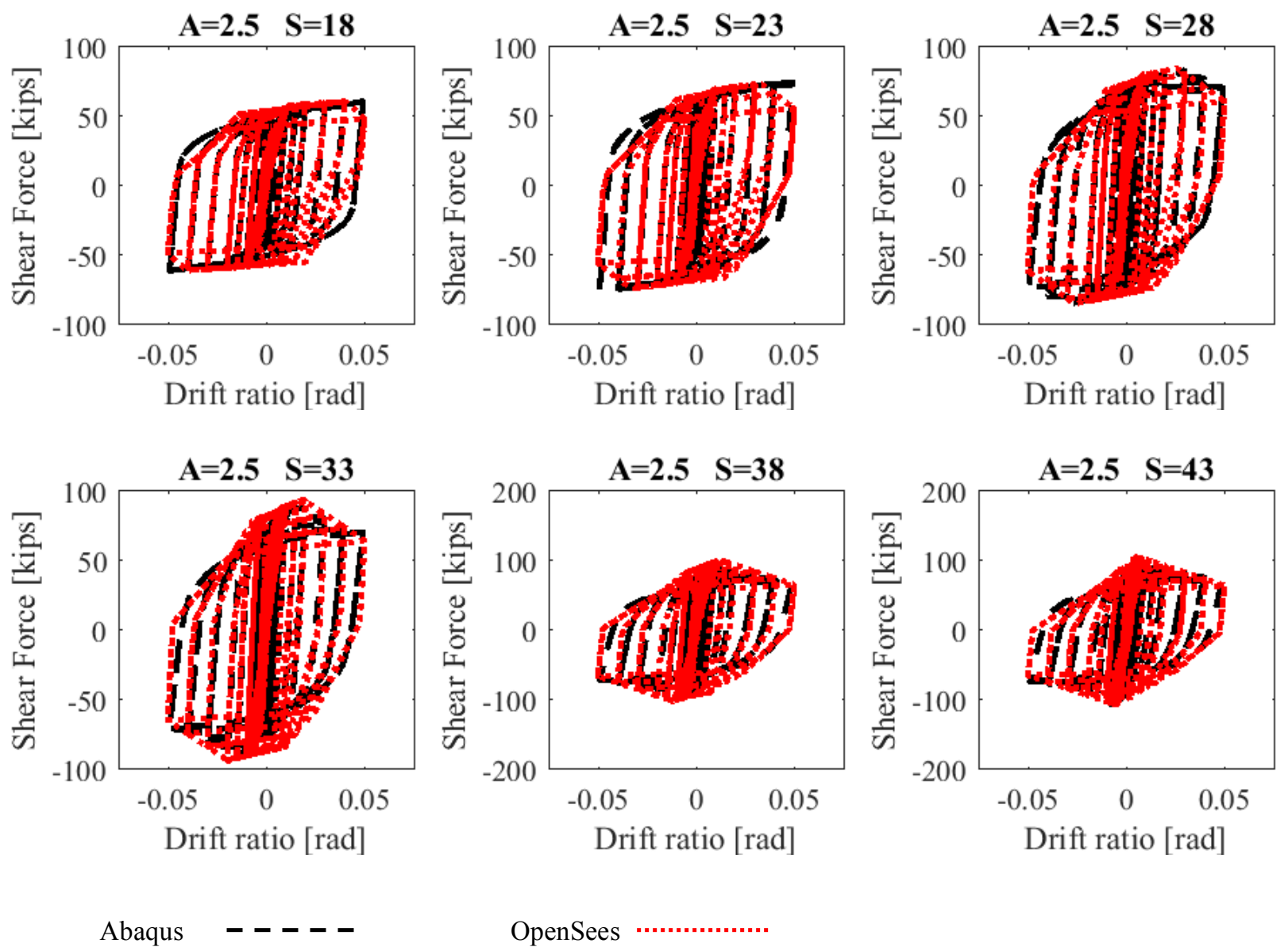

OpenSees

Figure 4.6 Comparison of the WWFF force-deformation relationship from the ABAQUS and OpenSees numerical simulations 


\subsection{Experimental Test of BRB}

Buckling restrained braces (BRBs) were studied extensively by researchers around the world. The first research started by Yoshino and Karino (1971). Thereafter, Clark (1999) conducted three large-scale unbonded brace tests at University of California, Berkeley. The first two specimens had a rectangular yielding cross section and the third specimen had a cruciform cross section. Clark (1999) used the SAC loading protocols, a simulated earthquake displacement record and constantamplitude low-cycle fatigue tests to examine the force-deformation response of the BRBs. The tests showed that the BRBs had stable force-deformation hysteresis. Merritt at al. (2003) tested a large arrays of subassemblage tests for BRB and reported the relationship between the tensile strength adjustment factor and the brace axial deformation from these tests. Black et al. (2004) conducted several numerical simulations and experiments to study the stability against global buckling of BRB, buckling of the inner core and plastic torsional buckling of the inner core. Tremblay and Robert (2001) tested two types of BRBs, one with long core steel plates and the other one with short core steel plates. The experimental tests showed the BRBs with short steel core had much larger ductility demands than the one with long steel core. In this thesis, the experimental results from Black et al. (2004) is used to calibrate the numerical model. 


\subsection{Numerical Modeling of BRB}

The BRB material is modeled using Giuffré-Menegotto-Pinto material (Filippou et al. 1983). This model was obtainable in an explicit algebraic equation for stress in the function of strain. Due to its simplicity and accuracy, it is one of the most popular models for isotropic material. This model can precisely simulate the Bauschinger effect, which is common for most steel material. In this thesis, the BRB material force-deformation relationship is calibrated in OpenSees (PEER 2010) against the experimental data obtained by Black et al. (2004) and shown in Figure 4.7. The results illustrate that the calibrated model is capable of modeling the kinematic and isotropic hardening of the BRB. The modeling parameters are also tabulated in Table 4.4.

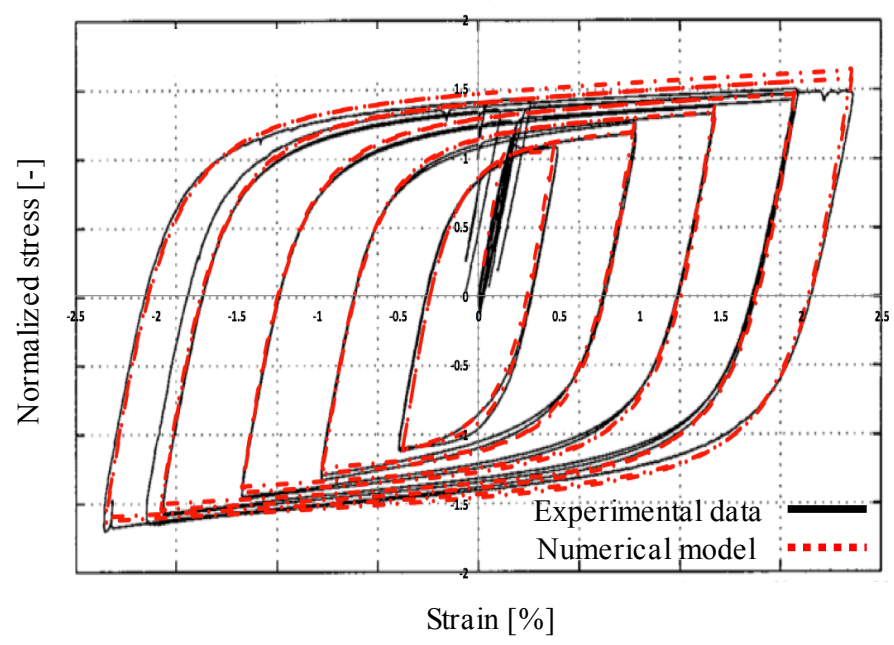

Figure 4.7 Force-deformation relationship comparison for BRB between experimental result and OpenSees numerical simulation

Table 4.4 BRB material parameters in OpenSees

\begin{tabular}{|c|c|c|c|c|c|c|c|c|c|c|}
\hline Fy & E & b & R0 & cR1 & cR2 & a1 & a2 & a3 & a4 & sig0 \\
\hline 41.4 & 31000 & 0.008 & 20 & 0.905 & 0.1 & 0.05 & 0.95 & 0.05 & 0.95 & 0 \\
\hline
\end{tabular}




\subsection{Element Removal Modeling Technique}

When the strain exceeded the strain limit of WWFF and BRB, WWFF and BRB are expected to fracture. This would result to a sudden loss of force in WWFF and BRB. To properly model such behavior, a robust modeling technique was proposed by Yang et al. 2015 and is implemented in in this study. Figure 4.6 shows the general procedure of the element removal technique. At the beginning of the analysis, a strain capacity is selected. In this study, the fracture limits for the WWFF and BRB are 10\% (Yang et al. 2018a) and 2\% (López and Sabelli 2004), respectively. At each stage of the analysis, WWFF and BRB strain is compared with the strain capacity. If the WWFF and BRB strain is less than the capacity, element removal would not be triggered and the analysis would be carried on as usual. Once WWFF and BRB strain exceeded the limit, the element removal would be activated and those WWFF or BRB elements would be removed. Similarly, the associated nodes and recorders would be also removed to avoid software errors. The stiffness matrix would be updated before the next analysis. This modeling technique allowed the model to accurately simulate the force redistribution, hence captured the progressive collapse sequence of the structure.

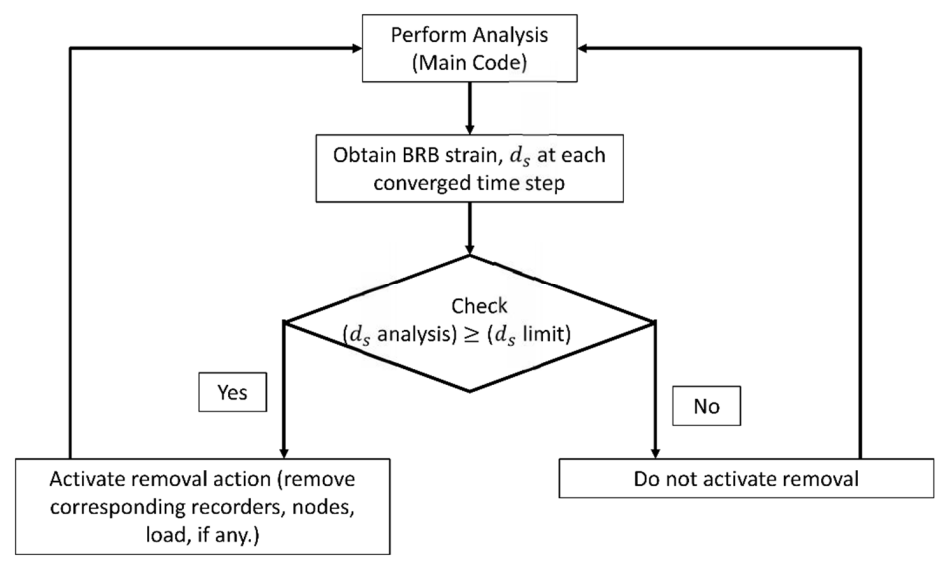

Figure 4.8 Element removal procedure (Yang et al. 2015) 


\subsection{Modeling of Prototype buildings}

Two-dimensional finite element model is constructed for each prototype building using OpenSees (PEER 2010) to evaluate the seismic performances of the DFHFs designed using EEDP. The H-Frames, i.e. columns and beams, are capacity designed to remain elastic. Hence, they are modeled using elastic beam-column elements and are checked during post-processing to ensure that they do not yield. The beams are pin connected to the columns, and the columns are pinned at the base. These connections reduce damages and allow for the rotation necessary to yield the structural fuses. Noted that rigid end offsets are used at all beam-to-column and WWFF-to-column intersections to account for the width of the columns. The BRKBs are modeled using calibrated nonlinear truss elements with Giuffré-Menegotto-Pinto material (Filippou et al. 1983) presented in section 4.5. The WWFFs are modeled using calibrated nonlinear two-node-link elements with Pinching4 material developed by Mitra and Lowes (2007) presented in section 4.2. In this study, slenderness ratio (S) of 30 is adopted for WWFFs. The element removal algorithm is implemented as described in section 4.6. Masses are assigned as lump masses at the nodes based on the tributary area. Similarly, gravity loads are uniformly distributed within the floors and assigned to the nodes based on their tributary area. P- $\Delta$ effects are modeled using the P- $\Delta$ transformation in OpenSees (PEER 2010). 2.5\% Rayleigh stiffness and mass proportional damping is calculated based on the first and third modes of each prototype building. The first three modal periods are $0.55 \mathrm{sec}, 0.11 \mathrm{sec}$, $0.10 \mathrm{sec}$ and $1.43 \mathrm{sec}, 0.24 \mathrm{sec}, 0.08 \mathrm{sec}$ for the 3 - and 9-story prototype buildings, respectively. Figures 4.9 (a) and (b) show the finite element models developed in OpenSees platform. 


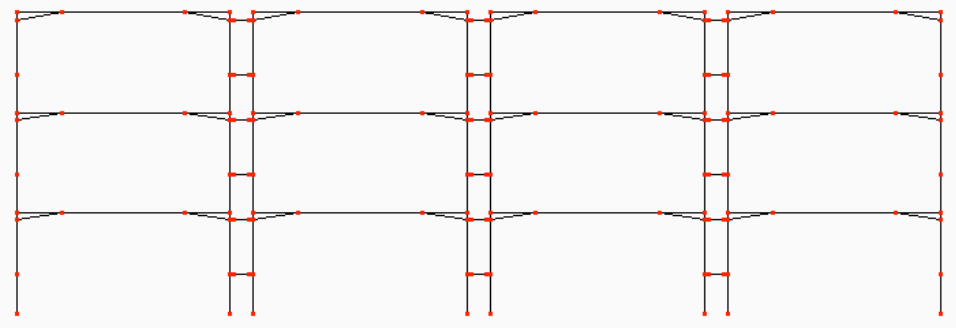

(a) 3-story

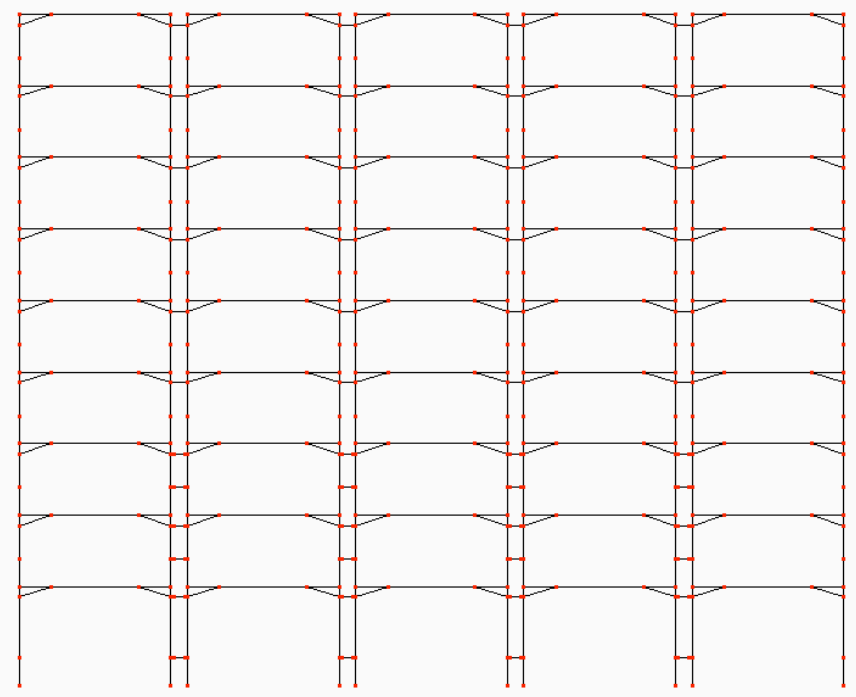

(b) 9-story

Figure 4.9 Two-dimensional finite element models in OpenSees platform 


\section{Chapter 5: Results of Nonlinear Time History}

\section{Analysis}

The numerical models as presented in section 4.7 are subjected to a range of earthquake shaking intensities, presented in section 3.2, to assess the seismic performances of the DFHFs in both prototype buildings.

\subsection{Roof Drift Ratio}

Figure 5.1 presents the maximum roof drift ratio (RDR) of the DFHF for each prototype building when the DFHF is subjected to all the scaled ground motions presented in Figure 3.2. The results show that at $50 \%$ probability of exceedance, RDRs are $0.2 \%, 1.0 \%$ and $1.6 \%$ for the 3 story building and $0.17 \%, 0.50 \%$ and $1.07 \%$ for the 9 -story building. These values are very close to the target RDRs set during the EEDP process (Table 3.2). In other words, the proposed DFHF can be effectively designed using EEDP to achieve the target RDRs.

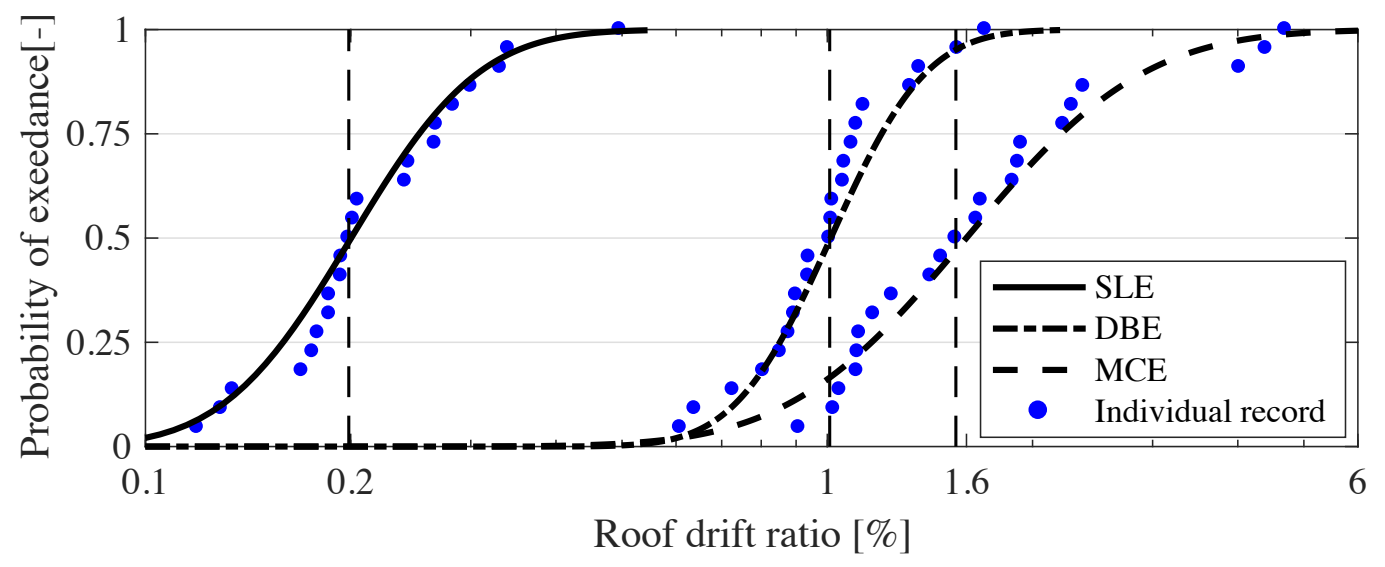




\section{(a) 3-story}

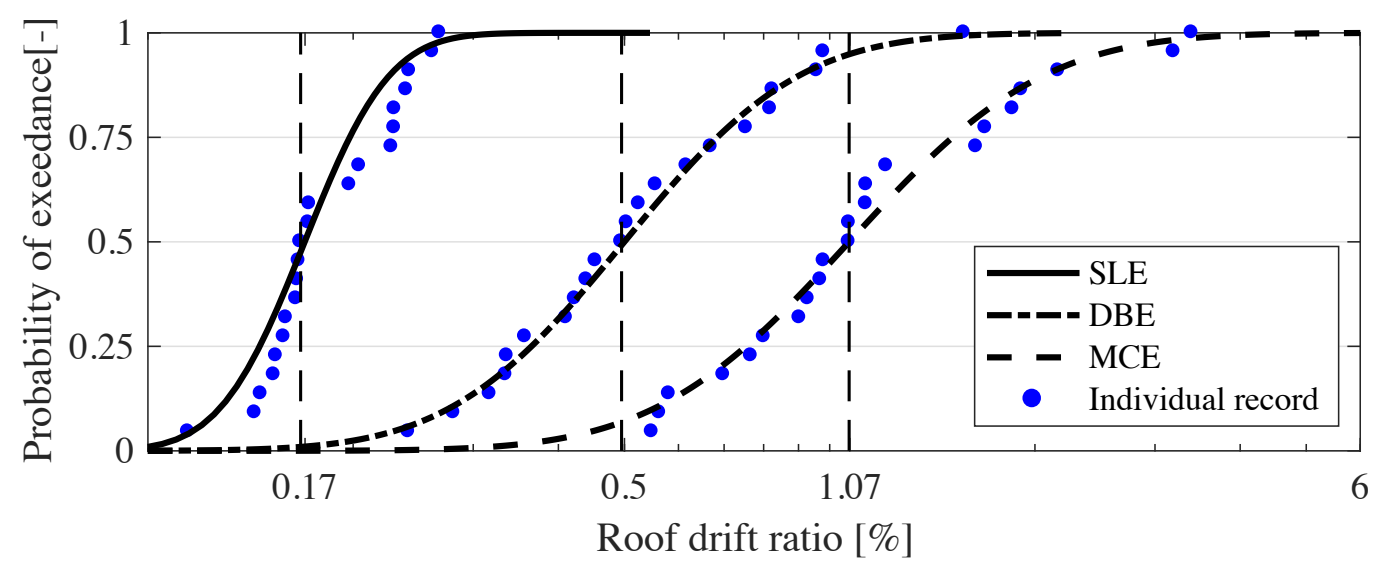

(b) 9-story

Figure 5.1 Roof drift ratio probability of exceedance

\subsection{Inter-story Drift Ratio}

Figure 5.2 presents the median of maximum inter-story drift ratio (ISDR) of the DFHF for each prototype building. Results show that for the 3 -story building the displacement is uniformly distributed throughout the height of the building and ISDRs are equal to the median RDR presented in Figure 5.1 (a). However, for the 9-story building, the ISDR is not truly uniform throughout the height of the building, which is because of the higher mode and multi-degree-of-freedom effects (Figure 5.2 (b)). It should be noted that although ISDRs for the 9-story building do not match perfectly with RDRs, it is still acceptable and satisfies the code requirements. 


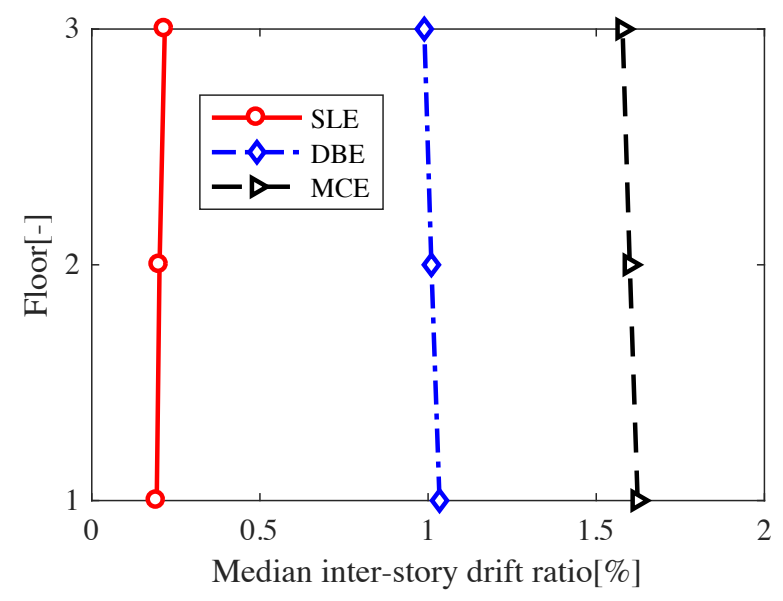

(a) 3-story

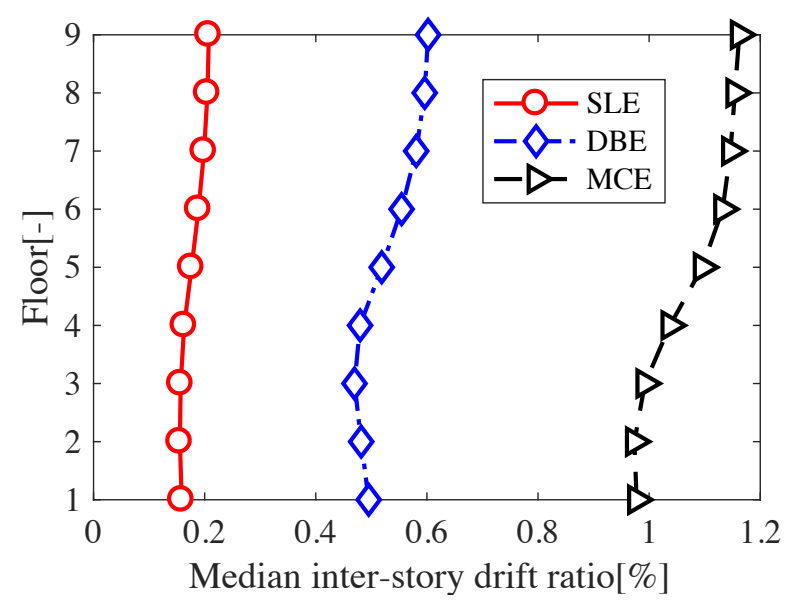

(b) 9-story

Figure 5.2 Inter-story Drift Ratio

\subsection{Demand-Capacity Ratio of Structural Fuses}

Figure 5.3 presents the median of the maximum demand-capacity ratio (DCR) for the WWFFs and BRKBs at each floor when the prototype buildings are subjected to the scaled ground motions as presented in Figure 3.2. The results show that when the ground motions are scaled to the SLE shaking intensity, both the WWFF and BRKB demands are under the yielding capacities. This 
means that the DFHFs are damage-free and hence, have achieved the IO performance objective. When the ground motions are scaled to the DBE shaking intensity, the WWFFs are yielded while the BRKBs are protected. This means that emergency responders can enter the buildings to repair or replace the WWFFs without affecting the occupants. This allows the DFHFs to achieve the RR performance objective. When the DFHFs are subjected to the MCE shaking intensity, both the WWFFs and BRKBs are yielded but not fractured to achieve the CP performance objective.

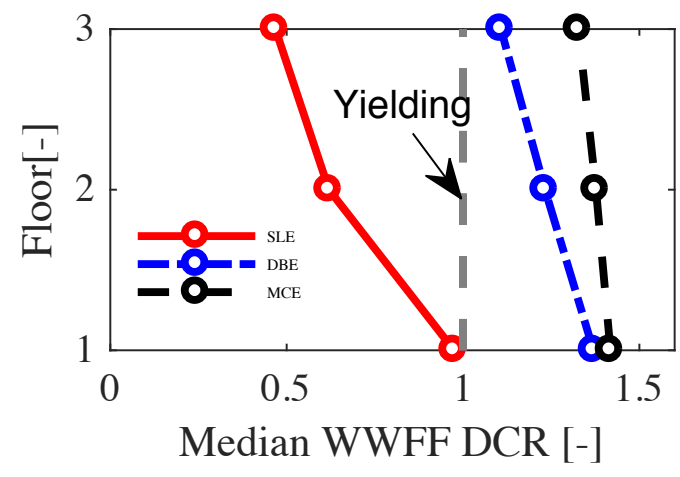

(a) 3-story

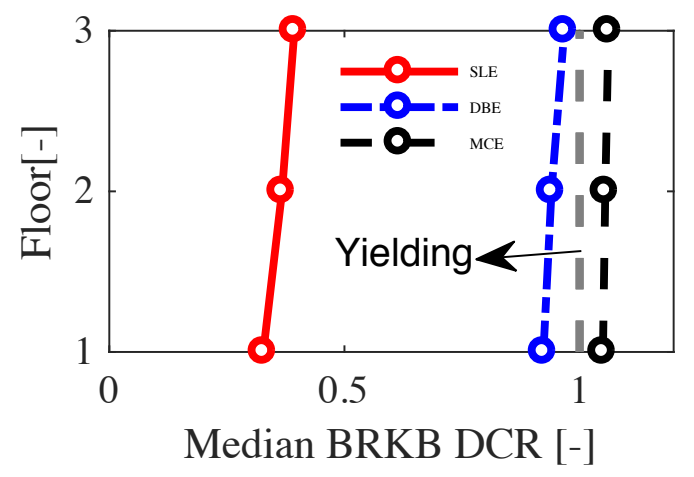

(c) 3-story

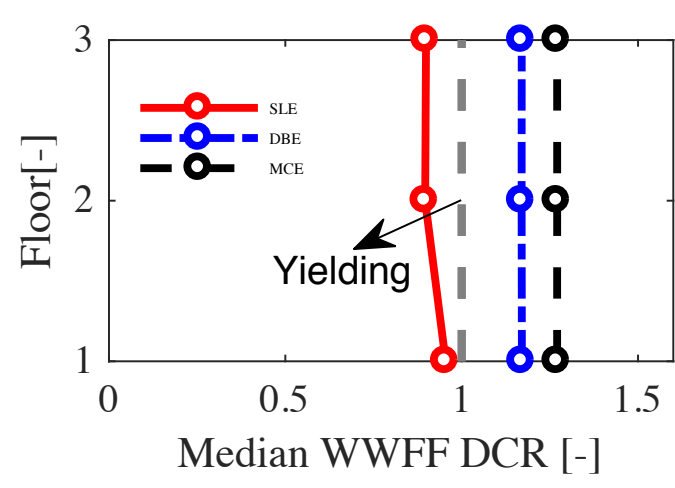

(b) 9-story

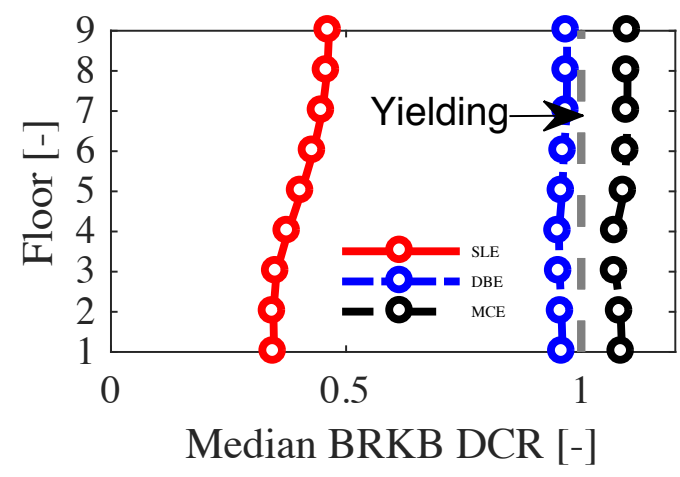

(d) 9-story

Figure 5.3 Demand-capacity ratio of (a,b) WWFFs and (c,d) BRKBs 


\section{Chapter 6: Collapse Assessment}

To evaluate the seismic performance of the proposed DFHF against collapse, the prototype buildings are analyzed using the procedure recommended in FEMA P695 (FEMA, 2009). Accordingly, the prototype models are subjected to extensive incremental dynamic analyses (IDA) (Vamvatsikos and Cornell 2002) using the aforementioned 22 far-field ground motion records. To properly model force redistribution when the WWFFs and BRKBs fracture, the element removal technique as described in section 4.6 has been implemented during the IDA. In this paper, the fracture limits for the WWFFs and BRKBs are 10\% (Yang et al. 2018a) and 2\% (López and Sabelli 2004), respectively. After a fractured WWFF or BRKB is removed, the building's stiffness and geometry are both updated. Figure 6.1 shows the IDA results for the prototype models. The vertical axis represents the shaking intensity of the ground motions defined using the spectral acceleration at the fundamental period of the prototype model. The horizontal axis represents the corresponding peak inter-story drift ratios (ISDRs). Collapse is defined when the maximum ISDR reaches $10 \%$. Fragility curves are also constructed from the IDA results and shown in Figure 6.2. The horizontal axis represents the spectral acceleration at the fundamental period of the prototype building, and the vertical axis represents the corresponding probability of collapse. The collapse margin ratio (CMR), which is defined as the ratio of the spectral acceleration at $50 \%$ collapse probability, $S_{\mathrm{CT}}$, to the spectral acceleration of the design base level at the fundamental period of the structure, $S_{\mathrm{MT}}$, is calculated to be 1.82 and 3.93 for the 3-and 9-story buildings, respectively. 


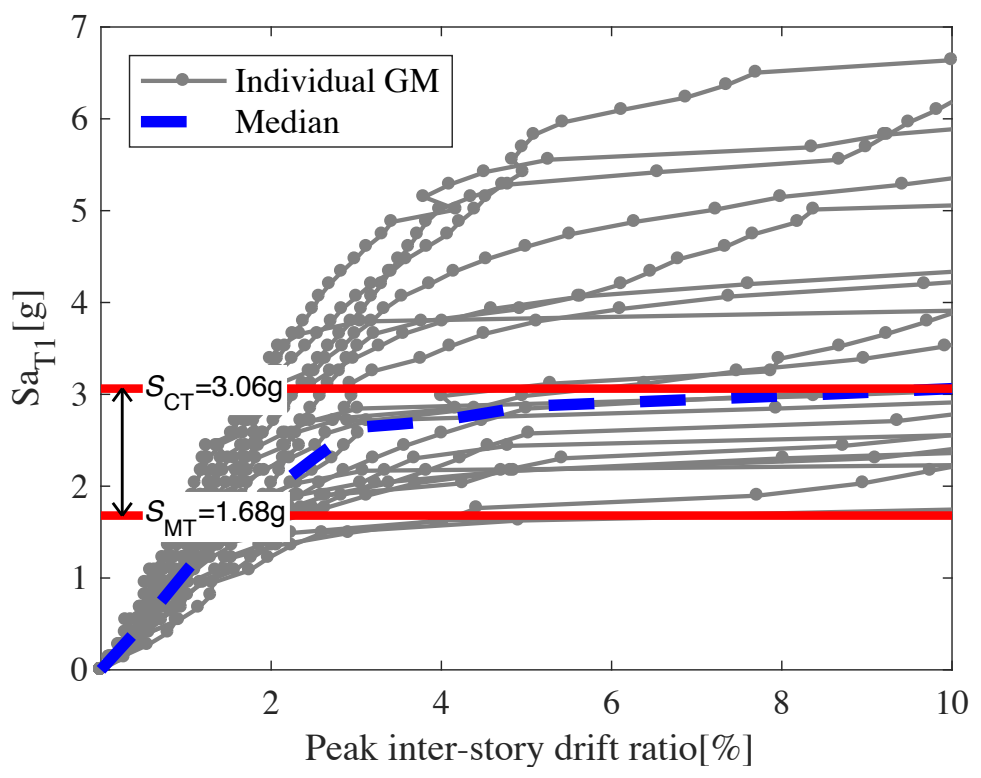

(a) 3-story

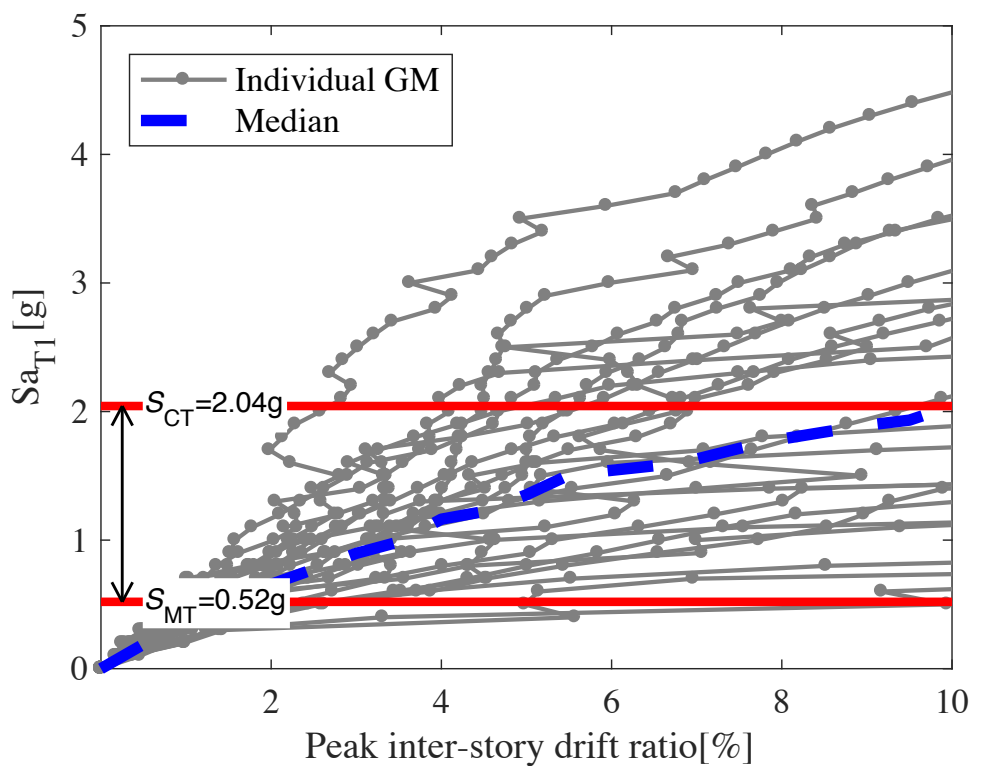

(b) 9-story

Figure 6.1 Incremental dynamic analysis curves 


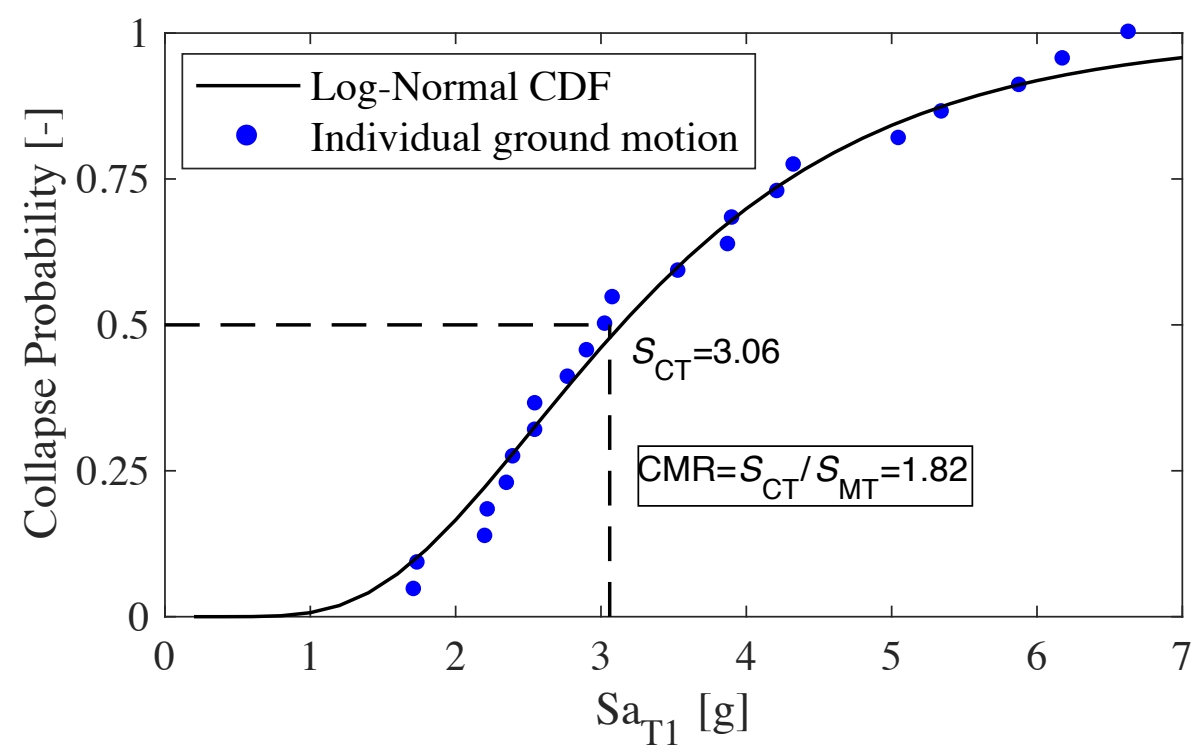

(a) 3-story

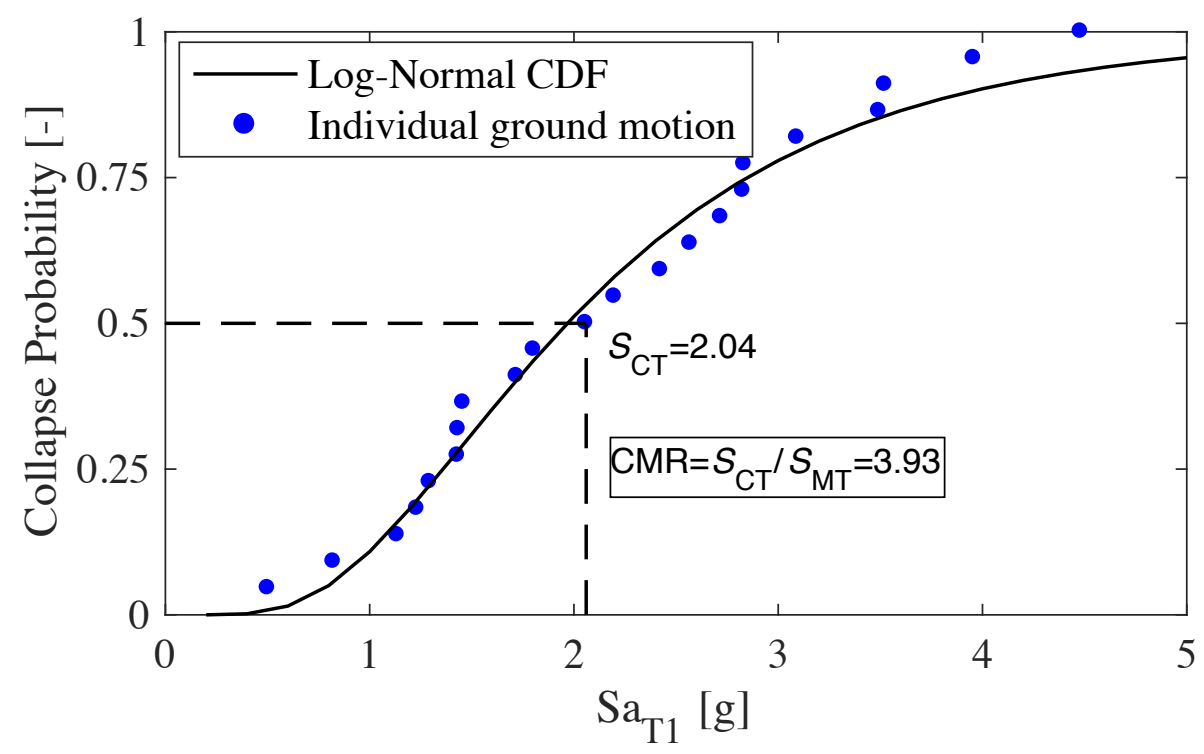

(b) 9-story

Figure 6.2 Collapse fragility curve 
Once CMRs are determined, adjusted CMRs (ACMRs) should be computed to account for the difference in spectral shape of the applied ground motion records. ACMR is obtained by multiplying CMR with the spectral shape factor (SSF) provided in Table 7-1 of FEMA P695 (2009). SSFs of the 3- and 9-story prototype buildings are 1.28 and 1.18, respectively. Therefore, ACMRs are found to be 2.32 and 4.63 for the 3- and 9-story prototype buildings, respectively. For adequate structural safety against collapse, the calculated ACMR should be greater than the acceptable $\mathrm{ACMR}$, i.e. $\mathrm{ACMR}_{10 \%}$. $\mathrm{ACMR}_{10 \%}$ is determined by evaluating the total system collapse uncertainty due to various sources of uncertainties including record-to-record variability in ground motions, quality ratings of design requirement, test data and numerical model. In this thesis, the system total composite uncertainty $\left(\beta_{\text {TоT }}\right)$ is computed as $\beta_{\text {TOT }}=$

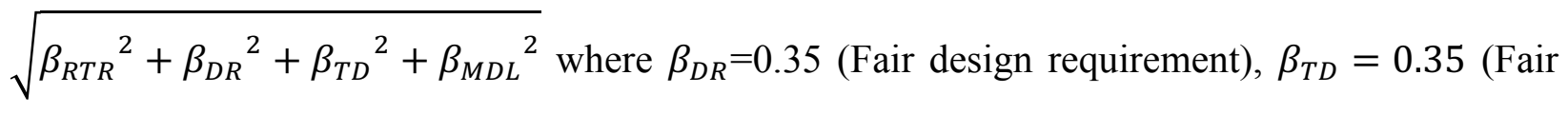
test data), $\beta_{M D L}=0.35$ (Fair modeling), and $\beta_{R T R}=0.4$ for systems with $\mu \geq 3.0$. Thus, according to the Table 7-3 of FEMA P695 (2009), the acceptable collapse margin, ACMR $10 \%$, is found to be 2.1 which is less than the calculated ACMRs for both the 3- and 9-story prototype buildings. In other words, the proposed DFHF designed by EEDP has adequate seismic resistance against collapse. 


\section{Chapter 7: Parametric Study of WWFF Geometric}

\section{Parameter}

This chapter describes the effect of geometric parameter of WWFF on the overall seismic performance of the prototype building. As it was shown in the proposed equations in Figure 4.3, S is the only WWFF's geometric parameter which defines the fuse's pinching behavior. To study the effect of the fuse's pinching behavior on the seismic performance of the system, the 3-story prototype building as described in chapter 3 is further investigated by trying different $\mathrm{S}$ values for WWFF.

\subsection{Description of Parametric Study}

As it is illustrated in equations presented in Figure 4.3, first point (yielding point $\left(\Delta_{\mathrm{y}}, \mathrm{V}_{\mathrm{y}}\right)$ ), on the backbone curve is independent to the $S$ value. However, all other 3 points on the backbone (Transition $\left(\Delta_{\mathrm{t}}, \mathrm{V}_{\mathrm{t}}\right)$, ultimate $\left(\Delta_{\mathrm{u}}, \mathrm{V}_{\mathrm{u}}\right)$ and fracture $\left(\Delta_{\mathrm{f}}, \mathrm{V}_{\mathrm{f}}\right)$ points $)$ are calculated according to $\mathrm{S}$ value. To study the effect of WWFF's backbone curve on the overall seismic response of the building, seismic performance of five finite element models with identical design, same as the 3-story prototype building described in chapter 3, but with 5 different WWFF's S variations $(20,25,30$, 35 and 40) is assessed using extensive IDA (Vamvatsikos and Cornell, 2002). In this analyses, an increment of $0.1 \mathrm{~g}$ is employed using the 22 far-field ground motions as suggested by FEMA P695 (2009). This created a total of more than 11000 NTHA in OpenSees platform. 


\subsection{Results of Parametric Study}

\subsubsection{Inter-story drift}

Figure 7.1 (a, b, c, d and e) present the results of the IDA response for the five prototype models. In each curve, the vertical axis represents the shaking intensity of the ground motions defined using the spectral acceleration at the fundamental period of the prototype model and the horizontal axis represents the corresponding peak ISDs. In addition, IDA curves are all plotted as fragility curves and shown in Figure 7.1 (f) where the horizontal axis represents the spectral acceleration at the fundamental period of the prototype building and the vertical axis represents the corresponding probability of collapse. Collapse is defined when the slope of the IDA curve approaches zero. Collapse margin ratio (CMR), which is defined as the ratio of the spectral acceleration at $50 \%$ collapse probability, $\hat{S}_{\mathrm{CT}}$, to the spectral acceleration of the design base level at the fundamental period of the structure, $S \mathrm{a}_{\mathrm{T} 1}$, is shown on each IDA curve. As it is illustrated in Figure 7.1, as the $\mathrm{S}$ increases $\hat{S}_{\mathrm{CT}}$ and CMR values decreases. This means that the building is more likely to collapse when larger S value is applied. Thus, engineers should pay a meticulous attention while selecting the S value for the WWFFs during the design process. 


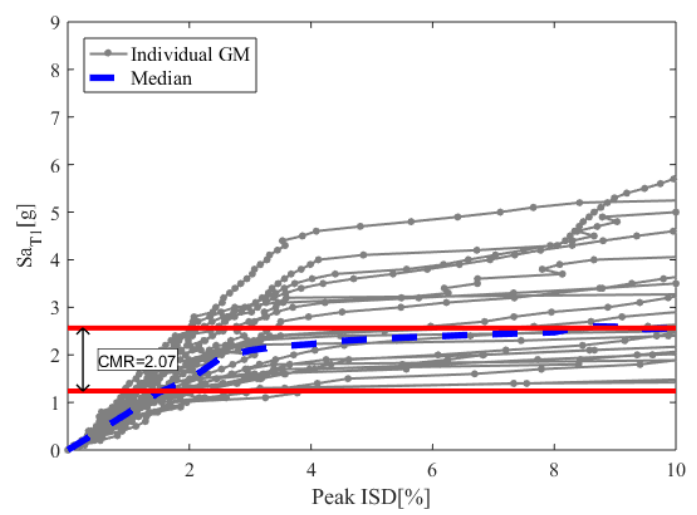

(a) $\mathrm{S}=20$

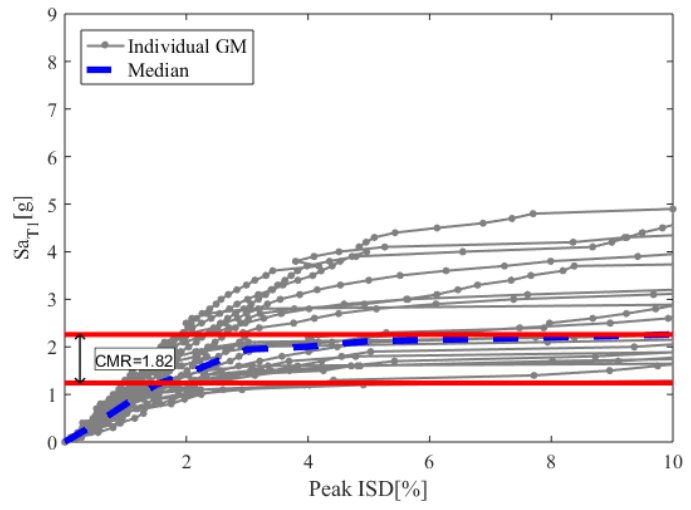

(c) $\mathrm{S}=30$

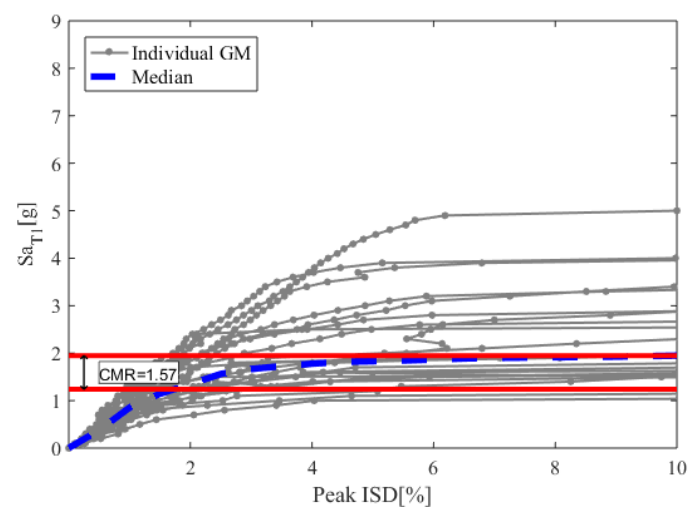

(e) $\mathrm{S}=40$

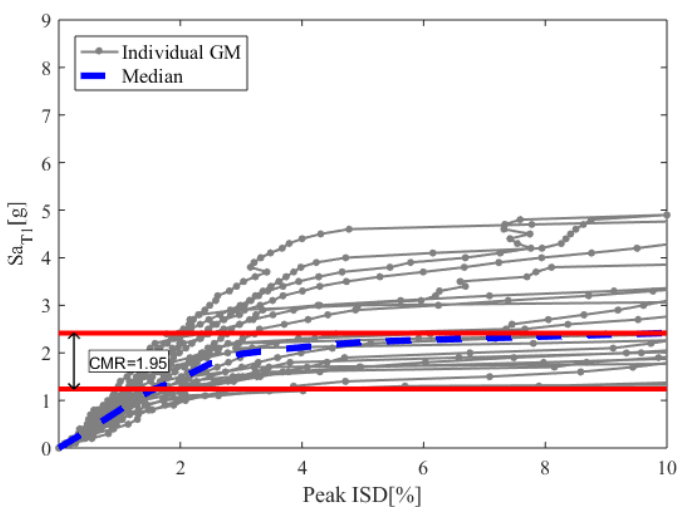

(b) $\mathrm{S}=25$

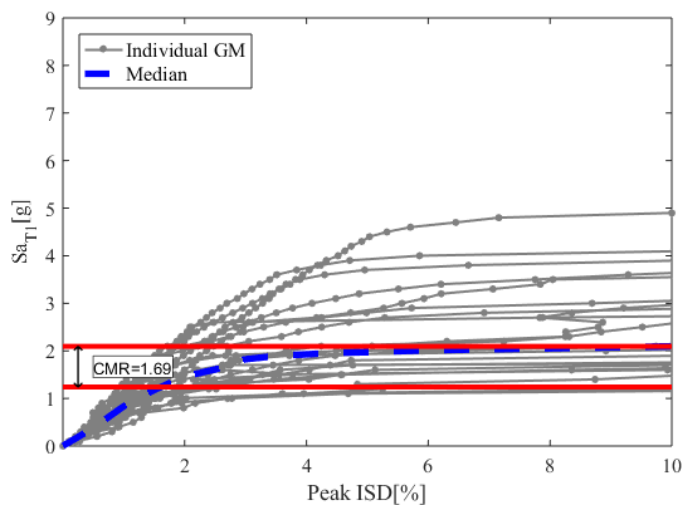

(d) $\mathrm{S}=35$

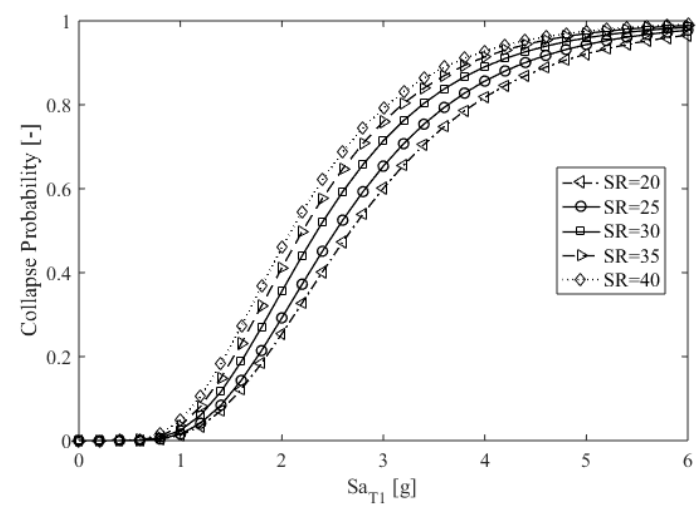

(f)

Figure 7.1 Incremental dynamic analyses result for (a) $S=20$, (b) $S=25$, (c) $S=30$, (d) $S=35$, (e) $S=40$ and (f) fragility curve 
In order to choose an appropriate $\mathrm{S}$ for WWFF, the acceptable CMR value should be identified. To do so, CMR values are modified by a spectral shape factor (SSF), provided in the Table 7-1 of FEMA P695 (2009), to adjusted CMR (ACMR) to account for the difference in spectral shape of the applied ground motion records. The ACMR values are then normalized by the acceptable ACMR values and shown in Figure 7.2. Acceptable ACMR values which are provided in Table 73 of FEMA P695 (2009) are a function of the system's total composite uncertainty $\left(\beta_{T O T}\right)$, which is determined based on the certainties of design, test data, modeling and record-to-record variability as described in chapter 6 . Each of these parameters can be categorized in one of these 4 groups: superior, good, fair and poor. Since these categories are subjective and are based upon engineering decisions, all 4 possible categorizes are shown in Figure 7.2. As it is illustrated in Figure 7.2, for the superior category, all $\mathrm{S}$ values $(20,25,30,35$ and 40$)$ are acceptable and satisfy the FEMA requirements. However, to have an acceptable collapse margin for good, fair and poor categories, $S$ should be below 35, 30 and 20, respectively. Noted that these findings are limited to the prototype building used in this study. Further research should be conducted to find the exact WWFF's acceptable slenderness ratios for different SFRS so it can generally be applied for all systems. The results presented here are just to aware researchers and engineers that fuse's slenderness ratio (S) and the selected total system's uncertainty play a significant role in the system's collapse capacity. Thus, fuse's slenderness ratio (S) and total system's uncertainty should be selected carefully to have a reliable and reasonable system's collapse capacity. 


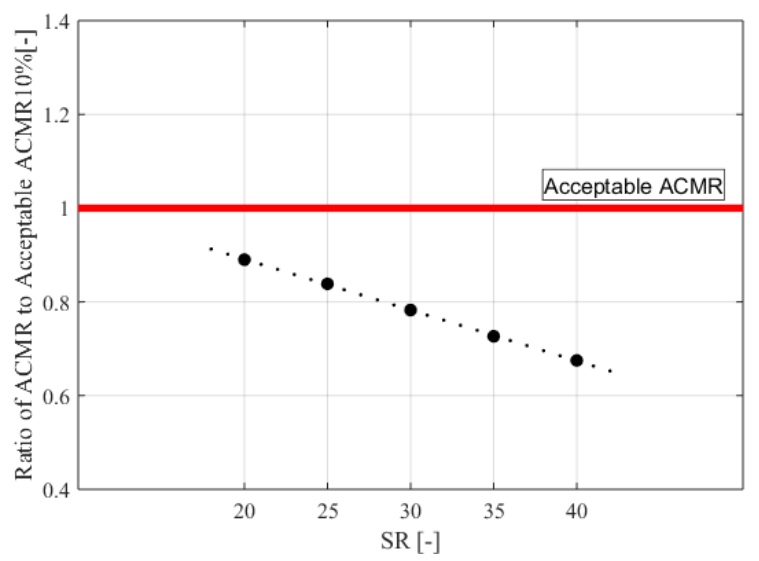

(a)

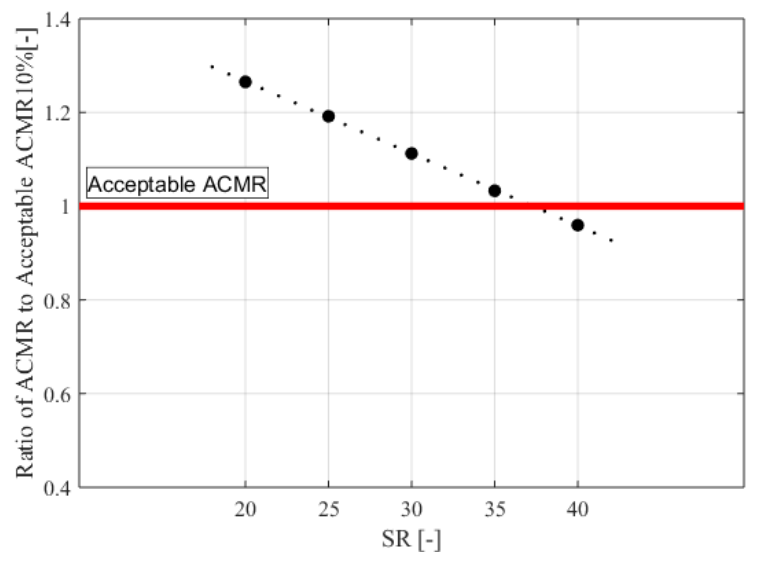

(c)

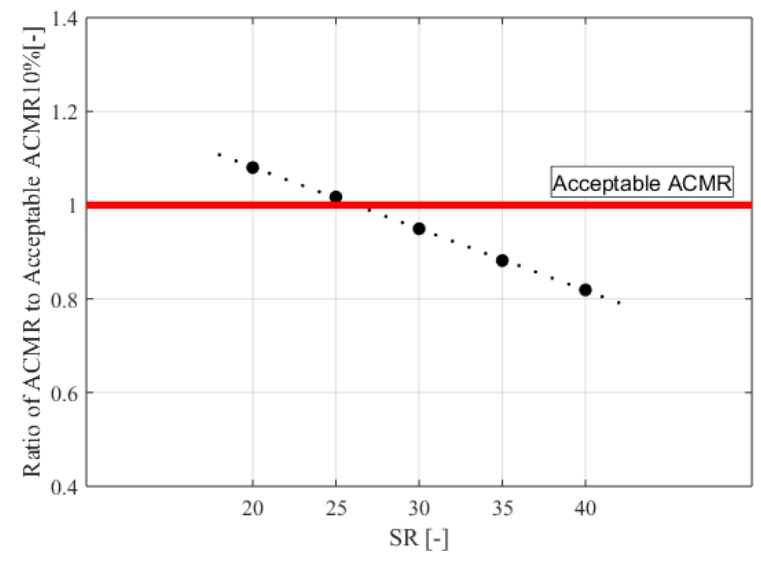

(b)

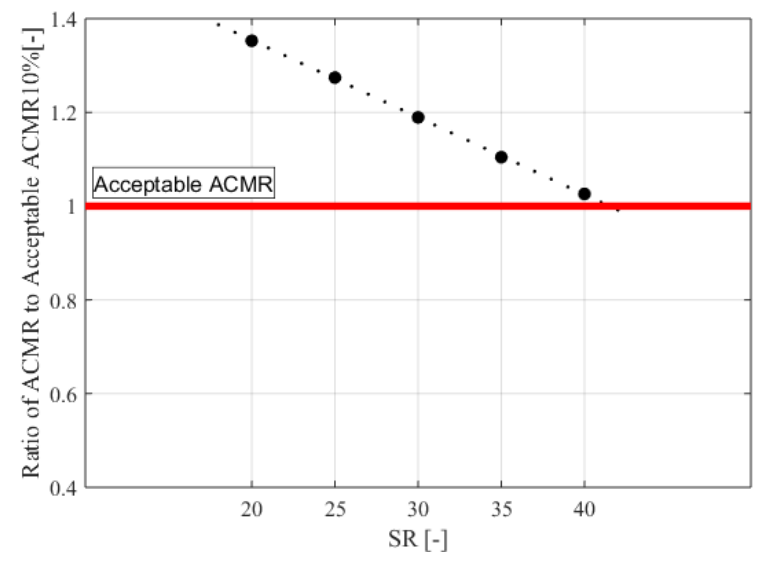

(d)

Figure 7.2 Acceptable collapse margin ratios for different categories: (a) poor, (b) fair, (c) good and (d) superior 


\subsubsection{Floor acceleration and base shear}

Results of the parametric study are also presented for the median peak floor acceleration and base shear in Figure7.3 (a) and Figure7.3 (b), respectively. As it is illustrated in Figure7.3 (a) as spectral acceleration increases the peak floor acceleration is identical for all different $S$ cases. In other words, the floor acceleration is independent to the $S$ value of the WWFF. On the other hand, as it is shown in Figure7.3 (b), the maximum base shear is lower for the prototype with slender (larger S values) WWFF. This is because the over strength factor, as presented in Figure 4.3(d), for slender WWFF is smaller than the stocky WWFF (smaller $S$ values). In other words, the force transferred from WWFF to the columns and subsequently to the base is higher for stocky WWFF.

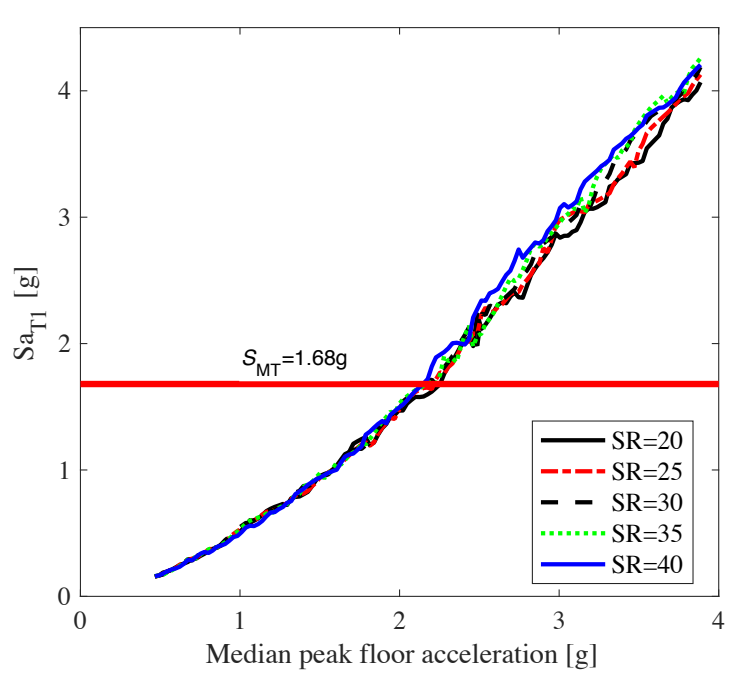

(a)

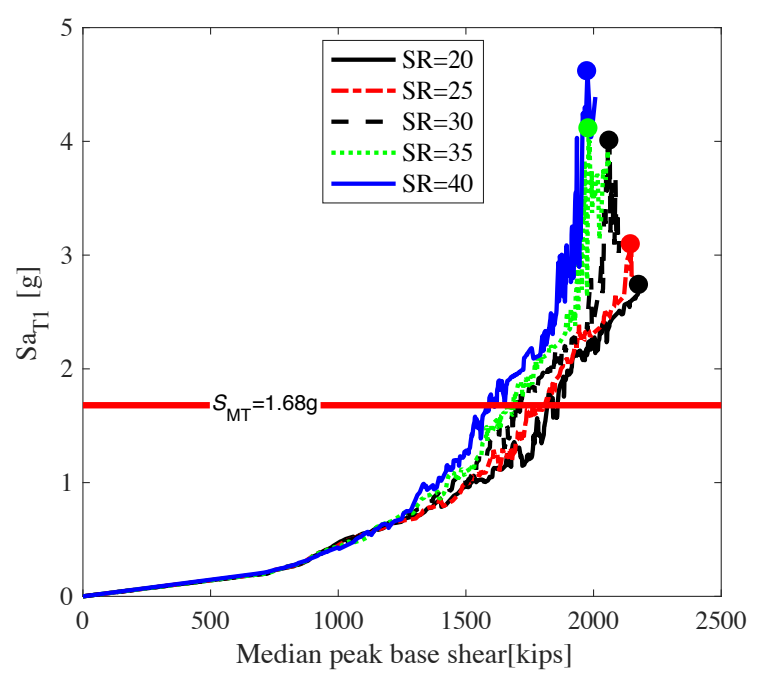

(b)

Figure 7.3 Median peak floor (a) acceleration and (b) base shear 


\section{Chapter 8: Summary, Conclusion and}

\section{Recommendation}

\subsection{Summary and Conclusion}

A novel resilient seismic force resisting system (SFRS) called Dual-Fused H-Frame (DFHF) is proposed in this thesis. DFHF combines prefabricated H-Frames with two types of specially designed and replaceable structural fuses, Welded Wide Flange Fuses (WWFFs) and Buckling Restrained Knee Braces (BRKBs), to create a dual energy dissipation mechanism. WWFFs serve as the primary structural fuses that are designated to yield and dissipate energy when the seismic hazard exceeds the SLE shaking intensity. BRKBs are the secondary structural fuses that are designed to yield when the hazard exceeds the DBE shaking intensity. Both WWFFs and BRKBs are decoupled from the gravity system such that they can be easily inspected, repaired or replaced if needed after a strong earthquake.

To promote the implementation of this fused SFRS, equivalent energy design procedure (EEDP) is employed to facilitate the design. EEDP directly takes structural strength and ductility into consideration, and allows engineers to select multiple performance objectives under different hazard intensities. In this thesis, two prototype office buildings of varying heights (3- and 9-story) are designed using EEDP for the locations in San Francisco, CA, and Seattle, WA, respectively. Calibrated nonlinear finite element models are constructed to verify the energy dissipation mechanism and examine the seismic performance of the DFHF prototypes. The numerical models are subjected to a suite of far-field ground motions scaled to the target hazard intensities. The results of the nonlinear time history analyses (NTHA) show that the proposed DFHF can achieve 
the selected performance objectives through developing the designed energy dissipation mechanisms. Moreover, the EEDP designed DFHF prototypes show an acceptable seismic safety margin against collapse. Noted that implementing slender WWFFs in DFHF system will result in a decrease in the system's collapse capacity. Hence, stocky WWFFs are recommended for increasing the total collapse capacity of the system. All in all, it is concluded that the proposed DFHF can be used as an alternative SFRS, and can be effectively designed by EEDP for high seismic regions around the world. 


\subsection{Recommendation for Future Studies}

The presented thesis provides a comprehensive examination of the DFHF under seismic load for two prototype buildings with varying heights, dimensions and seismic hazards. However, it should be noted that the conclusions provided in this study are limited to the building's geometry and the ground motions used in this study.

1) Further research should be conducted to ensure the applicability of the DFHF with different building geometry and different ground motions.

2) WWFF hysteretic behavior used in this study was from the cyclic experimental program conducted by Yang et al. (2018a), which did not consider the axial constraints in the boundary condition. Conducting the WWFF cyclic experiment with axial constraint will provide more accurate hysteretic response for WWFF and can be used as an alternative hysteretic behavior in this thesis.

3) Cost and time study should be conducted in accordance with a project engineer in order to substantiate the efficiency and applicability of the proposed Dual-Fused HFrame system.

4) Parametric study conducted in chapter 7 presents a range of acceptable slenderness ratios for WWFFs against collapse which is very dependent to structural frame system used in the study (DFHF). Further research on WWFF's slenderness ratio should be conducted while WWFFs are implemented in different structural frame systems rather than DFHF to have a more applicable results. 


\section{References}

American Institute of Steel Construction(AISC). (2010). Specification for Structural Steel Buildings. ANSI/AISC 360-10, Chicago, Illinoi.

American Society of Civil Engineering(ASCE). (2010). Minimum Design Loads for Buildings and Other Structures (7-10). Standards ASCE/SEI 7-10, Reston, VA.

American Society of Civil Engineers (ASCE). (2006). Seismic Evaluation and Retrofit of Existing Buildings. ASCE/SEI 41-06, Reston, Virginia.

Balut, N., \& Gioncu, V. (2003). Suggestion for an improved “dog-bone” solution. In 4th International Conference STESSA, Naples, Italy.

Black, C. J., Makris, N., \& Aiken, I. D. (2004). Component Testing, Seismic Evaluation and Characterization of Buckling-Restrained Braces. Journal of Structural Engineering, 130(6), 880-894. https://doi.org/10.1061/(ASCE)0733-9445(2004)130:6(880)

Chao, S., Goel, S. C., \& Lee, S. (2007). A Seismic Design Lateral Force Distribution Based on Inelastic State of Structures. Earthquake Spectra, 23(3), 547-569. https://doi.org/10.1193/1.2753549

Clark, P. W. (1999). Design procedures for buildings incorporating hysteretic damping devices. In International Post-SMiRT Conference Seminar on Seismic Isolation, Korea.

Dusicka, P., \& Iwai, R. (2007). Development of Linked Column Frame System for Seismic Lateral Loads. Structural Engineering Research Frontiers, 1-13. https://doi.org/10.1061/40944(249)63

Etebarian, H., \& Yang, T. Y. (2018). Development and Assessment of Innovative Modular Damped H-Frame system. In Proceedings of the 11th National Conference in Earthquake Engineering, Earthquake Engineering Research Institute, Los Angeles, CA (p. 11). 
FEMA-355C. (2000). State of the Art Report on Systems Performance of Steel Moment Frames

Subject to Earthquake Ground Shaking. Federal Emergency Management Agency, Washington:, D.C.

FEMA P-695. (2009). Quantification of building seismic performance factors. FEMA P-695, Washington, DC., 421.

Filippou, F. C., Popov, E. P., Bertero, V. V., Tech. Rep. EERC-83/19, Berkeley, C., \& 500. (1983). Effects of Bond Deterioration on Hysteretic Behavior of Reinforced Concrete Joints. Tech. Rep. EERC-83/19, Berkeley, California.

Gray, M. G., Christopoulos, C., \& Packer, J. A. (2013). Cast Steel Yielding Brace System for Concentrically Braced Frame: Concept Development and Experimental Validations. Journal of Structural Engineering, 140(4), 4013095. https://doi.org/10.1061/(ASCE)ST.1943-541X.0000910.

Gupta, A., \& Krawinkler, H. (2000). BEHAVIOR OF DUCTILE SMRFS AT VARIOUS SEISMIC HAZARD LEVELS, 126(1), 98-107.

Junda, E., Leelataviwat, S., \& Doung, P. (2018). Cyclic testing and performance evaluation of buckling-restrained knee-braced frames. Journal of Constructional Steel Research, 148, 154-164. https://doi.org/10.1016/j.jcsr.2018.05.012

Li, T., Yang, T. Y., Tong, G., Tung, D. P., \& Li, Y. (2018). Performance-based seismic design and evaluation of fused steel diagrid frame. Earthquake Spectra.

López, W. A., \& Sabelli, R. (2004). Seismic design of buckling-restrained braced frames. Steel Tips.

Malakoutian, M., Berman, J. W., \& Dusicka, P. (2012). Seismic response evaluation of the linked column frame system. EARTHQUAKE ENGINEERING \& STRUCTURAL 
DYNAMICS. https://doi.org/10.1002/eqe

Mansour, N., Christopoulos, C., \& Tremblay, R. (2011). Experimental Validation of Replaceable Shear Links for Eccentrically Braced Steel Frames. Journal of Structural Engineering, 137(10), 1141-1152. https://doi.org/10.1061/(ASCE)ST.1943-541X.0000350

Merritt, S., Uang, C. M., \& Benzoni, G. (2003). Subassemblage testing of corebrace bucklingrestrained braces. Final Report to CoreBrace, LLC, Department of Structural Engineering, University of California, San Diego.

Mitra, N., \& Lowes., L. N. (2007). Evaluation, calibration, and verification of a reinforced concrete beam-column joint model. Journal of Structural Engineering.

National Research Council of Canada (NRCC). (2015). National Building Code of Canada 2015. National Research Council of Canada, Ottawa, Ontario, Canada.

Nikoukalam, M. T., \& Dolatshahi, K. M. (2015). Development of structural shear fuse in moment resisting frames. Journal of Constructional Steel Research, 114, 349-361. https://doi.org/10.1016/j.jcsr.2015.08.008

Nikoukalam, M. T., Mirghaderi, S. R., \& Dolatshahi, K. M. (2015). Analytical study of momentresisting frames retrofitted with shear slotted bolted connection. Journal of Structural Engineering, 141(11), p.04015019.

Popov, E. P., \& Engelhardt, M. D. (1988). Seismic eccentrically braced frames. Journal of Constructional Steel Research, 10, pp.321-354.

Shen, Y., Christopoulos, C., Asce, M., Mansour, N., \& Tremblay, R. (2011). Seismic design and performance of steel moment resisting frames with nonlinear replaceable links. J. Struct. Eng., 137(10), 1107-1117. https://doi.org/10.1061/(ASCE)ST.1943-541X.0000359.

Tremblay, R., \& Robert, N. (2001). Seismic performance of low-and medium-rise chevron 
braced steel frames. Canadian Journal of Civil Engineering, 28(4), pp.699-714.

Vamvatsikos, D., \& Allin Cornell, C. (2002). Incremental dynamic analysis. Earthquake

Engineering and Structural Dynamics, 31(3), 491-514. https://doi.org/10.1002/eqe.141

Vayas, I., \& Thanopoulos, P. (2005). Innovative Dissipative ( INERD ) Pin Connections for Seismic Resistant Braced Frames. International Journal of Steel Structures, 5.

Wongpakdee, N., Leelataviwat, S., Goel, S. C., \& Liao, W. C. (2014). Performance-based design and collapse evaluation of buckling restrained knee braced truss moment frames.

Engineering Structures, 60, 23-31. https://doi.org/10.1016/j.engstruct.2013.12.014

Yang, T. Y., Atkinson, J., Tobber, L., \& Tung, D. P. (2018). Seismic Design of Outrigger Systems Using Equivalent Energy Design Procedure. Earthquake Spectra.

Yang, T. Y., Banjuradja, W., \& Tobber, L. (n.d.). Experimental Test of Welded Wide Flange Fuses.

Yang, T. Y., Li, Y., \& Goel, S. C. (2015). Seismic Performance Evaluation of Long-Span Conventional Moment Frames and Buckling-Restrained Knee-Braced Truss Moment Frames. Journal of Structural Engineer- Ing, 4015081(14). https://doi.org/10.1061/(ASCE)ST

Yang, T. Y., Li, Y., \& Leelataviwat, S. (2013). Performance-Based Design and Optimization of Buckling Restrained Knee Braced Truss Moment Frame. Journal of Performance of Constructed Facilities, 28(2010), 1-11. https://doi.org/10.1061/(ASCE)CF.19435509.0000558 .

Yang, T. Y., Tung, D. P., \& Li, Y. (2017). Equivalent energy-based design procedure for innovative earthquake resilient structures. Earthquake Spectra.

Yoshino, T., \& Karino, Y. (1971). Experimental study on shear wall with braces. InSummaries of 
Technical Paper S of Annua L Meeting: Part 2, (pp. 403-404). 


\section{Appendices}

\section{A.1 3-story Building Ground Motions Scale Factor}

Table A.1 3-story building scale factors

\begin{tabular}{|c|c|c|c|}
\hline Record Name & SLE & DBE & MCE \\
\hline RSN1111 & 0.24 & 0.89 & 1.33 \\
\hline RSN1116 & 0.49 & 1.82 & 2.73 \\
\hline RSN1148 & 1.24 & 4.60 & 6.90 \\
\hline RSN1158 & 0.41 & 1.54 & 2.30 \\
\hline RSN1244 & 0.45 & 1.65 & 2.48 \\
\hline RSN125 & 0.48 & 1.76 & 2.64 \\
\hline RSN1485 & 0.30 & 1.10 & 1.65 \\
\hline RSN1602 & 0.20 & 0.74 & 1.11 \\
\hline RSN1633 & 0.29 & 1.08 & 1.62 \\
\hline RSN169 & 0.43 & 1.59 & 2.38 \\
\hline RSN174 & 0.39 & 1.43 & 2.15 \\
\hline RSN1787 & 0.64 & 2.36 & 3.54 \\
\hline RSN3745 & 0.72 & 2.66 & 3.99 \\
\hline RSN68 & 0.68 & 2.51 & 3.76 \\
\hline RSN721 & 0.42 & 1.56 & 2.33 \\
\hline RSN725 & 0.39 & 1.44 & 2.16 \\
\hline RSN752 & 0.24 & 0.87 & 1.31 \\
\hline RSN767 & 0.28 & 1.03 & 1.55 \\
\hline RSN848 & 0.41 & 1.52 & 2.29 \\
\hline RSN900 & 0.58 & 2.16 & 3.24 \\
\hline RSN953 & 0.27 & 0.99 & 1.49 \\
\hline RSN960 & 0.30 & 1.13 & 1.69 \\
\hline
\end{tabular}




\section{A.2 9-story Building Ground Motions Scale Factor}

Table A.2 9-story building scale factors

\begin{tabular}{|c|c|c|c|}
\hline Record Name & SLE & $\mathrm{DBE}$ & MCE \\
\hline RSN1111 & 0.26 & 1.04 & 1.57 \\
\hline RSN1116 & 0.40 & 1.56 & 2.30 \\
\hline RSN1148 & 0.98 & 3.85 & 6.17 \\
\hline RSN1158 & 0.32 & 1.27 & 1.96 \\
\hline RSN1244 & 0.31 & 1.21 & 2.04 \\
\hline RSN125 & 0.53 & 2.08 & 3.07 \\
\hline RSN1485 & 0.34 & 1.35 & 1.93 \\
\hline RSN1602 & 0.20 & 0.77 & 1.14 \\
\hline RSN1633 & 0.33 & 1.28 & 2.06 \\
\hline RSN169 & 0.33 & 1.29 & 1.92 \\
\hline RSN174 & 0.34 & 1.34 & 2.24 \\
\hline RSN1787 & 0.48 & 1.90 & 2.79 \\
\hline RSN3745 & 0.70 & 2.74 & 3.76 \\
\hline RSN68 & 0.58 & 2.29 & 3.52 \\
\hline RSN721 & 0.35 & 1.38 & 2.05 \\
\hline RSN725 & 0.36 & 1.41 & 2.11 \\
\hline RSN752 & 0.22 & 0.88 & 1.25 \\
\hline RSN767 & 0.38 & 1.50 & 2.28 \\
\hline RSN848 & 0.48 & 1.89 & 2.75 \\
\hline RSN900 & 0.35 & 1.39 & 2.00 \\
\hline RSN953 & 0.20 & 0.79 & 1.12 \\
\hline RSN960 & 0.27 & 1.08 & 1.62 \\
\hline
\end{tabular}

